\title{
Human Health Biotechnologies to 2015
}

\author{
Anthony Arundel \\ David Sawaya \\ Ioana Valeanu
}

This article provides an overview of the current use of biotechnology to produce human health products and short-term estimates of the number and types of these products that are likely to reach the market by 2015. Relevant health products include biopharmaceuticals, experimental therapies (e.g. cell/tissue engineering and gene therapy), small molecule therapeutics, diagnostics, bioinformatics (including DNA sequencing and pharmacogenetics), functional food and nutraceuticals, and medical devices. The analysis of current use is based on regulatory approval data and the current literature and includes a comparison of the additional therapeutic value of biopharmaceuticals compared to small molecule pharmaceuticals. The short-term estimates of the number and types of products that are likely to reach the market by 2015 are based, where possible, on an analysis of quantitative data on clinical trials. For several other products, including functional foods and nutraceuticals, it is not possible to make short-term estimates due to a lack of reliable data.

While the biopharmaceutical share of all pharmaceuticals reaching the market is expected to remain very close to historical levels, biotechnology is expected to be used in the discovery, development, manufacturing, and/or prescribing of nearly all new drugs by 2015. In addition, the use of biotech based diagnostics (especially genetic testing), bioinformatics, and pharmacogenetics is likely to increase. In some cases, these technologies will be used to improve the safety and efficacy of clinical trials, to personalise prescribing practises, and to reduce adverse drug reactions. 
Table of Contents

Abbreviations . . . . . . . . . . . . . . . . . . . . . . . . . . . . . . . . . . 118

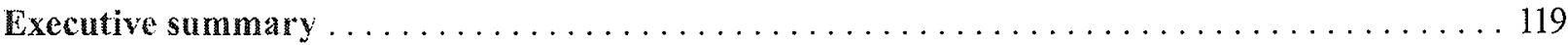

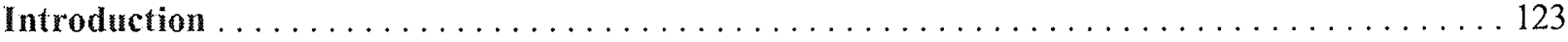

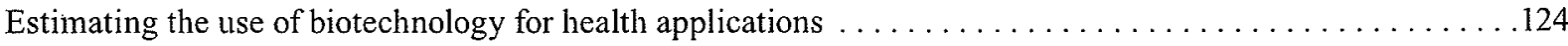

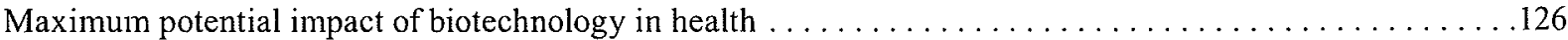

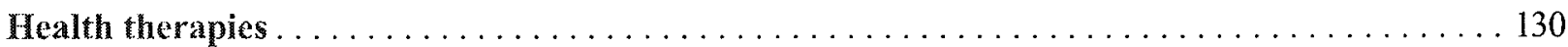

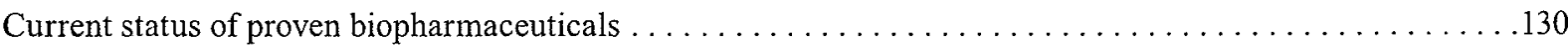

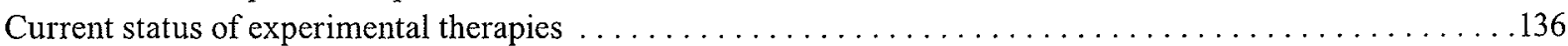

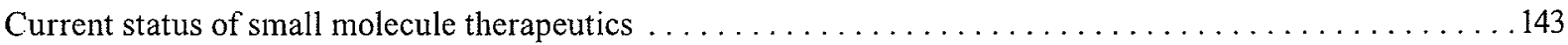

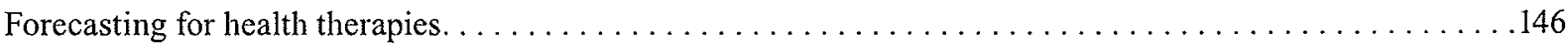

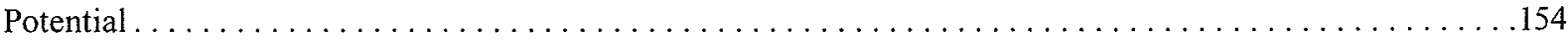

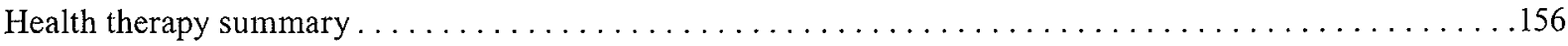

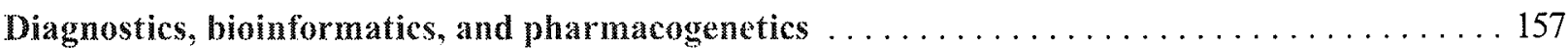

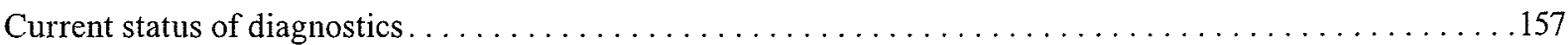

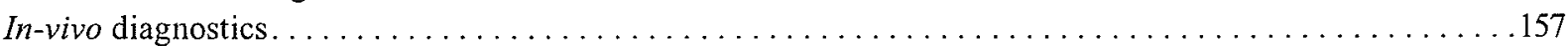

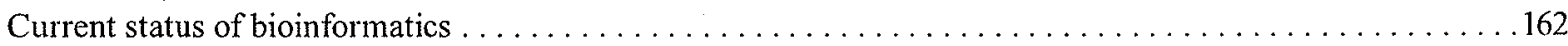

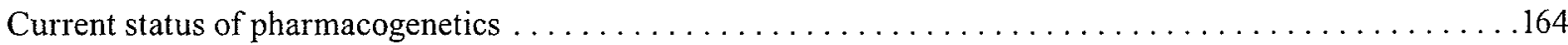

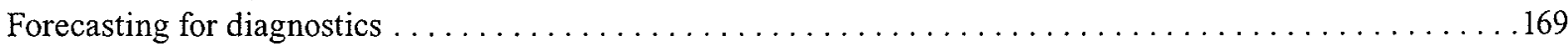

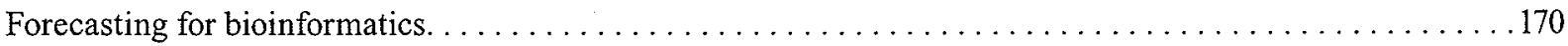

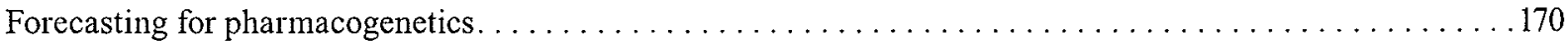

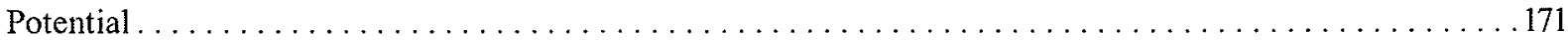

Diagnostics, bioinformatics, and pharmacogenetics summary $\ldots \ldots \ldots \ldots \ldots \ldots \ldots \ldots \ldots \ldots \ldots \ldots \ldots \ldots$

Miscellaneous: functional foods, nutracenticals and medical devices $\ldots \ldots \ldots \ldots \ldots \ldots \ldots$

Functional foods and nutraceuticals . . . . . . . . . . . . . . . . . . . . . . . . . . . . . . 172

Medical devices . . . . . . . . . . . . . . . . . . . . . . . . . . . . . . . . . . . . . . . . 176

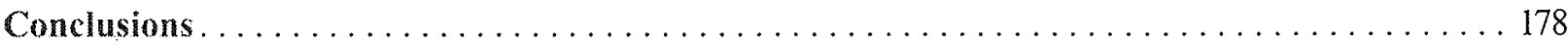

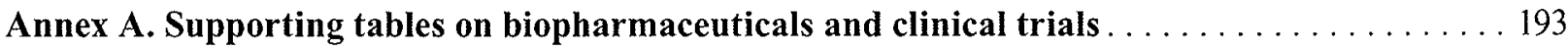

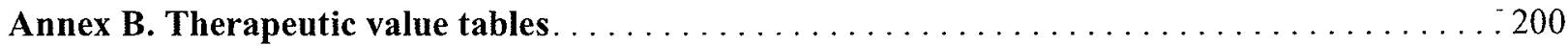

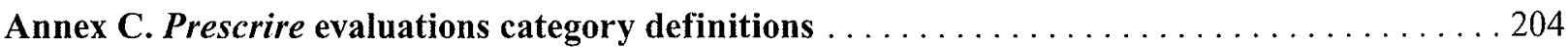

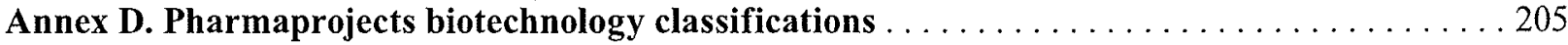

OECD IOURNAL: GENERAL PAPERS - VOLUME 2009/3 O OECD 2009 


\section{Figures}

Figure 1 Number of biopharmaceuticals by nationality of the developer firm, Jan 1989-Jan 2009 ...

Figure 2 Share of biopharmaceuticals (3-year running average) developed by US firms,

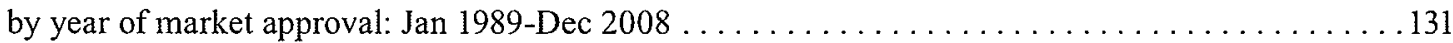

Figure 3 Number of nanotechnology patents in "medicine and biotechnology", by year . . . . . . . . . 141

Figure 4 Active clinical trials and pre-registrations by location of the originator firm for bio-

NMEs as of December 2007 . . . . . . . . . . . . . . . . . . . . . . . . . . . . . . . 146

Figure 5 Number of bio-NMEs products expected to reach registration, by year. . . . . . . . . . . . 150

Figure 6 Observed (1989-2007) and Forecast (2008-2015) share of total biopharmaceuticals

out of total pharmaceuticals ( 3 year running average), by year of first registration . . . . . . . 151

Figure 7 Number of diseases for which genetic testing is available as reported to GeneTests, by year . . . . . 160

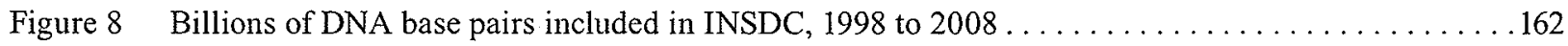

Figure 9 Types of drug-gene relationships identified in the PharmGKB database $\ldots \ldots \ldots \ldots \ldots \ldots \ldots$

Figure 10 Number of identified drug-gene relationship, 3-year running average, by year of first publication . .167

Figure 11 Number of publications with "pharmacogenetics" and "pharmacogenomics" as keywords . . . . . 168

Figure 12 Labels of FDA approved drugs with pharmacogenomic information. . . . . . . . . . . . . 169

\section{Tables}

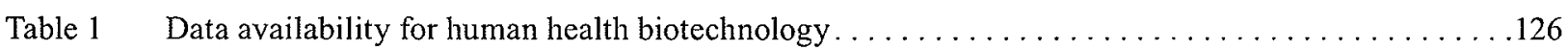

Table 2 Basic economic indicators for pharmaceutical manufacturing (PM) sector:

2004 or nearest available year . . . . . . . . . . . . . . . . . . . . . . . . . . . . 127

Table 3 Basic economic indicators for the health care sector (HC) sector: 2007 or nearest available year. . . 129

Table 4 HAS evaluations of the therapeutic value of biopharmaceuticals and

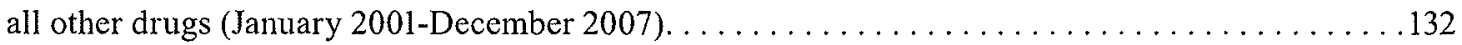

Table 5 Prescrire evaluations of the therapeutic value of biopharmaceuticals

and all other drugs (Jan 1986-April 2008) . . . . . . . . . . . . . . . . . 133

Table 7 Therapeutic value of biopharmaceuticals by the type of firm that developed the drug,

using data from Prescrire . . . . . . . . . . . . . . . . . . . . . . . . . . . . 135

Table 6 Therapeutic value of biopharmaceuticals by the type of firm that developed the drug, using data

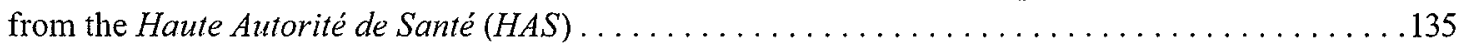

Table 8 Experimental therapies in clinical trials or pre-registration, by country: as of March $2008 \ldots \ldots .136$

Table 9 Experimental therapies in clinical trials or pre-registration, by phase: as of March $2008 \ldots \ldots \ldots 137$

Table 10 Use of biotechnology in small molecule (SM) drug development and therapy. . . . . . . . . . . . . 144

Table 11 Types of bio-NMEs in clinical trials or pre-registration as of June $2007 \ldots \ldots \ldots \ldots \ldots \ldots . \ldots 147$

Table 12 Share of all biotechnology clinical trials in experimental therapies, by country . . . . . . . . . 148

Table 13 Number and share of bio-NMEs with reliable data in Phase I-III or pre-registration . . . . . . . . . 149

Table 14 Number and share of Non-bio NMEs with reliable data in Phase I-III or Pre-registration . . . . . . . 151

Table 15 Number of patients potentially treatable with biopharmaceuticals $\ldots \ldots \ldots \ldots \ldots \ldots \ldots \ldots \ldots \ldots$

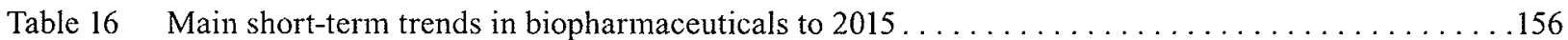

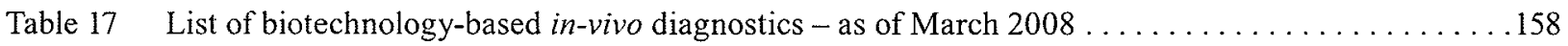

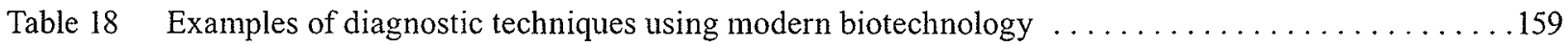

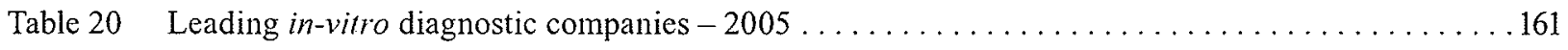

Table 19 Estimate of biotechnology-based diagnostics and in-vitro diagnostics revenues $-2004 \ldots \ldots \ldots 161$

Table 21 Examples of pharmacogenetic tests...................................... 165

Table 22 Valid FDA genomic biomarkers and genetic testing requirements - October 2006 and April 2008 . 168

Table 23 Main short-term trends in biotechnology-based diagnostics, bioinformatics and

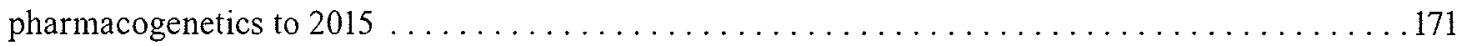

Table 24 Employment in the functional food and nutraceutical (FFN) sector in Canada . . . . . . . . . 172 


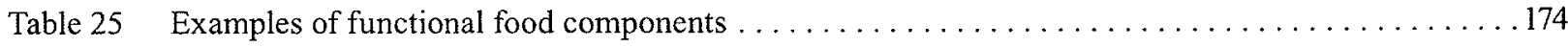

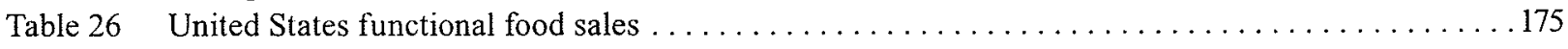

Table 27 List of 155 biopharmaceuticals that received market approval between

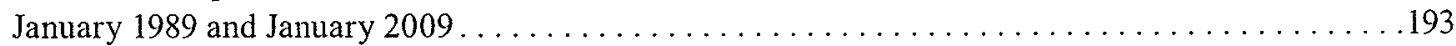

Table 28 Number of biotechnology clinical trials and pre-registrations by country $\ldots \ldots \ldots \ldots \ldots \ldots \ldots 19$

Table 29 Number of experimental biotechnology therapies in clinical trials and pre-registrations by country . . . 198

Table $30 \quad$ Number of NMEs and bio-NMEs expected to reach registration, by year . . . . . . . . . . . . . 199

Table 31 Highest HAS evaluation and indication for selected biopharmaceuticals. . . . . . . . . . . 200

Table 32 Highest Prescrire evaluation and indication for selected biopharmaceuticals . . . . . . . . . . 202

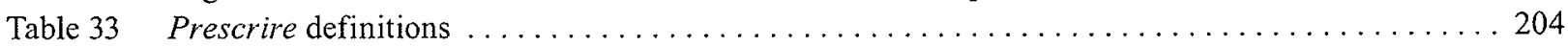




\section{Abbreviations}

\begin{tabular}{ll} 
ADR & Adverse drug reaction \\
AIDS & Acquired immune deficiency syndrome \\
DBF & Dedicated biotechnology firm \\
DDBJ & DNA Data Bank of Japan \\
DNA & Deoxyribonucleic acid \\
EMBL & European Molecular Biology Laboratory \\
EMEA & European Agency for the Evaluation of Medicinal Products \\
EPO & European Patent Office \\
EU & European Union \\
FDA & Food and Drugs Administration (United States) \\
FFN & Functional Food and Nutraceuticals \\
GDP & Gross domestic product \\
GM & Genetic Modification or Genetically Modified \\
HAS & La Haute Autorité de santé (France) \\
HIV & Human Immunodeficiency Virus \\
ICH & The International Conference on Harmonisation \\
IMF & International Monetary Fund \\
IVD & in-vitro diagnostics \\
JPO & Japan Patent Office \\
mAbs & Monoclonal antibodies \\
NME & New molecular entity \\
OECD & Organisation for Economic Cooperation and Development \\
PCR & Polymerase chain reaction \\
PCT & Patent Cooperation Treaty \\
RNA & Ribonucleic acid \\
RNAi & Ribonucleic acid interference \\
SFDA & State Food and Drug Administration (China) \\
SM & Small Molecule \\
UNU-MERIT & United Nations University - Merit \\
USPTO & United States Patent and Trademark Office \\
\hline
\end{tabular}




\section{Executive summary}

This article provides short-term estimates of the number and types of human health products based on biotechnology that are likely to reach the market by 2012-2015. This includes biopharmaceuticals, experimental therapies (e.g. cell/tissue engineering and gene therapy), small molecule therapeutics, diagnostics, bioinformatics (including DNA sequencing and pharmacogenetics), functional food and nutraceuticals, and medical devices.

Data are obtained from publicly available sources such as the Organisation for Economic Cooperation and Development (OECD), the United States Food and Drugs Administration (FDA), the European Agency for the Evaluation of Medicinal Products (EMEA), the published literature, as well as proprietary data sources such as Pharmaprojects and Pharmapredict.

The direct economic effects of the health applications of biotechnology occur in the pharmaceutical manufacturing sector and from biotechnology firms active in the R\&D services sector. Secondary effects occur in the health care services sector, for example if new therapies based on biotechnology increase or decrease total health care costs.

This article does not estimate the biotechnology share of value added or employment in the pharmaceutical manufacturing sector. However, the share of pharmaceuticals in gross domestic product (GDP) and employment gives an indication of the maximum possible contribution of biotechnology to this sector. This would be reached if biotechnology contributed to $100 \%$ of all new therapeutics, vaccines, and diagnostics. In this case, the direct economic impact of health biotechnology would approach the current share of pharmaceuticals in GDP of $1.24 \%$ in the United States and $0.66 \%$ of GDP in the European Union, although these percentages could continue to decline, as they have over the past decade. Biotechnology is unlikely to reach this maximum share of pharmaceutical GDP by 2015, but its increasing use in the development of small molecule therapeutics suggests that close to all value added in the pharmaceutical sector will be partly dependent on biotechnological knowledge by 2030 . The main area that is unlikely to be affected is the manufacture of small molecule generics developed before 2000 .

The biopharmaceutical sector is dominated by 45 American firms that account for $65 \%$ of the 155 biopharmaceuticals that have received market approval, anywhere in the world. Almost all of the remaining biopharmaceuticals have been developed by firms based in other OECD countries, with the exception of seven biopharmaceuticals: three developed in China, three in Cuba, and one in Israel.

The share of biopharmaceuticals out of all pharmaceuticals increased rapidly between 1989 and 1998 and then remained relatively stable at between $12 \%$ and $14 \%$ between 1999 and 2007, with the exception of an increase to $16 \%$ in 2003 .

Biopharmaceuticals offer a greater therapeutic advance, in comparison to existing treatments, than small molecule pharmaceuticals. An analysis of therapeutic evaluations 
by France's Haute Autorité de Santé (HAS) for 53 biopharmaceuticals and 1476 small molecule drugs shows that $47.6 \%$ of biopharmaceuticals provide a "moderate" therapeutic advance or better over existing treatments. In comparison, only $12.4 \%$ of all other drugs provide a moderate therapeutic advance or better. An identical analysis of 68 evaluations of biopharmaceuticals 1915 evaluations of other types of pharmaceuticals from the journal Prescrire produced comparable results.

The factors that support the development of therapeutically valuable biopharmaceuticals are of relevance to both policy and the design of future business models. An important question is who develops therapeutically valuable drugs: small dedicated biotechnology firms (DBFs) or large established pharmaceutical firms? The data from HAS and Prescrire were combined with data on the firm that developed each biopharmaceutical to answer this question. Using the HAS data, $65.4 \%$ of biopharmaceuticals developed by DBFs received an evaluation of a "moderate" advance or better, compared to only $28.6 \%$ of the biopharmaceuticals developed by large firms. The pattern is similar using the Prescrire data, with over double the share of biopharmaceuticals developed by DBFs receiving an evaluation of "some" advance or higher compared to large established pharmaceutical firms $(38.7 \%$ versus 14.3\%). The better performance of DBFs could be due to closer linkages with university researchers that discover new modes of action, or their ability to obtain venture capital financing could allow them to work on riskier projects, rather than concentrating on "me-too" drugs.

\section{Forecasting for health therapies}

The proprietary databases Pharmaprojects and Pharmapredict were used to estimate the number of biopharmaceuticals that are expected to obtain marketing approval by 2015 . The databases cover preclinical studies, clinical trials, and pre-registrations for most countries in the world. Pharmapredict estimates the probability of compounds in each development stage to reach market registration. These success rates are based on historical data for similar compounds. At the time of writing, success rates were not available for new product categories where only a few products had obtained market approval by the end of 2007.

In total, 25 countries have one or more bio-new molecular entities (bio-NMEs) in clinical trials: seven non-OECD countries, the United States, and 17 other OECD countries. Of interest, there are fewer Phase I than Phase II trials, suggesting a dip in the future supply of biopharmaceuticals. This may not be long lasting, since there are a large number of preclinical trials underway.

The United States' share of biopharmaceuticals is estimated to decline slightly from approximately $60 \%$ of market approvals for new biopharmaceuticals between 2000 and 2007 to $54 \%$ between 2008 and 2015 .

The major disease targets for the clinical trials consist of cancer (258 trials), infections (135 trials), cardiovascular diseases (57 trials), arthritis (28 trials), diabetes (18 trials) and asthma (11 trials). Monoclonal antibodies (mAbs) account for $25.1 \%$ of the total clinical trials, followed by recombinant vaccines (18.6\%) and recombinant therapeutics (15.6\%). The remaining four types account for $40.7 \%$ of the total, but few, if any, of these types of bio-NMEs have received market approval, with most of the compounds in Phase II (57\%) or Phase I (28\%) trials. This shows that there is a very strong biotechnology pipeline for these unproven or "experimental" therapies.

Research on experimental therapies is largely undertaken by small DBFs, with few large established pharmaceutical firms active in this area. One possible explanation is 
that access to ample venture capital or other "high risk" capital could explain this pattern. However, this may not be the main cause, as there was no relationship between the availability of venture capital by country and the national share of clinical trials of NMEs due to experimental therapies.

Of 648 biotechnology compounds in clinical trials, there was sufficient data for 399 (61.6\% of total) to estimate the number of expected new registrations between 2008 and 2018. The estimate is that roughly 13 biopharmaceuticals will be registered per year from 2008-2015. This is higher than the average of 8 biopharmaceuticals per year between 2000 and 2007 inclusive, but within the historical range of the number of bio-NMEs approved annually. For example, twelve bio-NMEs were registered in 1998, 2001, and 2006.

This does not translate into a significantly increased percentage of biopharmaceuticals as a share of all pharmaceuticals. Between 2000 and 2007, biopharmaceuticals accounted for slightly more than $12 \%$ of all new pharmaceutical registrations. An analysis of current clinical trials shows that biotechnology's share of all drugs to reach the market between 2008 and 2015 will increase to around $18 \%$ until 2012, but then will probably decrease to approximately $15 \%$. These results provide no evidence for a large surge in biotechnology drugs, or in the share of biotechnology drugs out of all drugs in the coming 5 to 10 years.

Although the share of biopharmaceuticals will not substantially increase in the foreseeable future, the real variable of interest is the effect of future biopharmaceuticals on public health. The evaluation of therapeutic value shows that biopharmaceuticals offer greater therapeutic value than other pharmaceuticals. The large number of experimental biopharmaceuticals, offering new modes of action, also suggests that the future stream of biopharmaceuticals should provide substantial therapeutic advantages over existing therapies.

Experimental therapies include cell and tissue engineering, stem cells, gene therapies, antisense (ribonucleic acid interference) RNAi, nanobiotechnology (drug delivery) and synthetic biology. Several new tissue engineering products are expected to reach the market by 2015 , but only a few other experimental therapies are likely reach the market by this date.

By 2015 the large majority of small molecule drugs in development are likely to partly depend on the use of biotechnology, for instance in the discovery phase (particularly for target identification), to improve the efficiency of clinical trials (application of pharmacogenetics for safety), or to improve prescribing practices. At some point in the near future, the current division between biotechnology firms and biotechnology drugs, and other firms and other types of drugs, is likely to become meaningless, with biotechnology playing a significant role in the development of all drugs.

\section{Forecasting for diagnostics and bioinformatics}

The importance of biotechnology based diagnostic tests is likely to continue to increase to 2015. This is particularly the case for in-vitro diagnostics which are likely to see much stronger product development to 2015 than in-vivo diagnostics. The number of diagnostic tests produced could be strongly influenced by the increased use of pharmacogenetics and preventive medicine.

The continued creation, population, and maintenance of complex health databases will continue to be an important application of bioinformatics to 2015. The variety of information stored in large genetic databases and the number of individuals included in these databases will expand as the price of genome sequencing continues to fall. These trends will support an increase in pharmacogenetic studies and the identification of new gene-drug 
links, as well as an increase in the number of drugs for which prescribing practice will depend on genetic tests to identify clinical response or the probability of an adverse drug reaction (ADR). However, widespread use of pharmacogenetics to identify respondent and non respondent subgroups in clinical trials is unlikely before 2015 .

\section{Functional foods and nutraceuticals}

Functional foods and nutraceuticals (FFN) are products, meant for consumption, that provide physiological benefit or provide protection against chronic disease. In theory, modern biotechnologies could be applied to the production of FFN, but to date, few biotech based FFN applications are on the market. Even by 2015, biotechnology is unlikely to play a large role in the FFN sector.

\section{Conclusions}

The number of biopharmaceuticals expected to reach the market to 2015 is somewhat higher than in the past and biotechnology will play a role (at some point) in the development and use of nearly all large and small molecule therapeutics by 2015 . While these developments will contribute to improved health outcomes, the promise of biotechnology in health is much greater than simply adding new drugs to a doctor's existing arsenal.

Experimental therapies of the kind described in this article and a shift to personalised medicine, through the application of pharmacogenetics, have the potential to drastically improve health by preventing disease before its onset and, in some cases, curing rather than treating debilitating illnesses. Achieving the full potential of these technologies will require appropriate business models and policies. 


\section{Introduction}

The future of biotechnology in health has been the subject of intensive speculation since the first biopharmaceutical obtained marketing approval in $1982,{ }^{1}$ and more recently following the sequencing of the human genome in 2003. While there is little doubt that biotechnology has contributed to health care by providing new and effective therapeutic treatments, the full potential of biotechnology in health is still far off. Many technological and social questions remain to be solved before biotechnology can fulfil its promise to improve health outcomes, provide cures instead of long-term treatment, reduce unwanted side effects from treatment, and increase the efficiency of R\&D.

This article identifies the current uses of biotechnology in health care and the types of products that could reach the market by 2015. The focus is on OECD countries, which have dominated health care research to date, but biotechnological research in developing countries has also produced new therapies. This introduction provides a brief overview of the economic context for the use of biotechnology in health, describes the data sources used in this article, and evaluates the potential economic contribution of health biotechnology. The other chapters examine specific applications of biotechnological knowledge to health.

\section{The use of biotechnology in health}

The health sector is undergoing a long-term increase in demand, driven by increasing incomes in developing countries and demographic change in developed countries. At the same time, the efficiency of pharmaceutical pipelines has been declining, in terms of the number of new drugs (new molecular entities or NMEs) developed per unit of research expenditures. To date, the use of biotechnology in health research may have contributed to the decline in research efficiency by opening up new modes of action that are poorly understood, requiring greater research investments (Hopkins et al., 2007). Future applications could be even more expensive, requiring a convergence in biotechnological advances in a range of disciplines, including gene sequencing, personalised medicine, bioinformatics, protein and cell metabolism, and pharmacogenetics.

The efficiency of pharmaceutical R\&D has been declining for some time. In November 2006, the United States' Government Accountability Office (US GAO) reported that, "the overall number of [new drug applications] - and new molecular entities (NME) in particular - approved annually has generally been declining since 1996", although longer-term trends show that the number of new applications increased slightly after 1996 compared to the previous decade (Cockburn, 2006). Yet over the same period, R\&D expenditures nearly doubled. In addition, between 1993 and 2004, the therapeutic advance offered by new drugs was generally low, with $60 \%$ of new drug applications submitted to the United States' FDA in the lowest class for therapeutic advance, while only $12 \%$ received the highest rating. ${ }^{2}$

These stark statistics showing a decline in both therapeutic value and the efficiency of $R \& D$ pose a serious challenge for both public health and for the pharmaceutical industry. 
Between now and 2030, health care expenditures as a percentage of GDP, in both $\mathrm{OECD}$ and non-OECD countries, are likely to increase significantly. After rapid growth in the early 1970s, health care expenditure levelled through the 1980s. However in the early 1990s, the cost of health care began to rise steeply again and has continued unabated. New health technologies have played a major role in this increase. An OECD working paper (2006a) noted that, "given that pure demographic factors have so far been weak, this upward trend in [healthcare] spending is probably due to the increased diffusion of technology and relative price changes."

Furthermore, technology is expected to drive health care costs into the future. OECD projections of health care expenditure to 2050 separated total health spending into health care expenditure and long-term care. The projections show that "non-demographic factors (including effects from technology and relative prices) play a significant role in upwards pressure on [future] long-term care expenditures, and indeed are the most important driver of the increase in [future, non-long-term] health-care expenditure."

In addition, rising income levels around the globe are likely to exacerbate spending concerns. "Technical progress can be cost-saving and reduce the relative price of health products and services, but its impact on expenditure will depend on the price elasticity of the demand for health care. If it is high, a fall in prices will induce a more than proportionate rise in demand, increasing expenditures. Even if prices do not fall, new technologies may increase demand by increasing the variety and quality of products."

The trend toward constantly increasing costs as a share of GDP has led many OECD Governments to actively search for methods to contain costs, including limiting the cost of prescription drugs. This could lead governments (through their substantial investments in medical research) and firms to search for methods to improve the efficiency of pharmaceutical research. Many experts believe that recent developments in biotechnology could help to reduce drug development costs. For example, knowledge of effective biomarkers could lead to quicker drug identification, while the use of pharmacogenetics to identify respondent and non-respondent patients could reduce clinical trial costs and drug failure rates.

Alternatively, society may be willing to pay for higher health care costs if improvements in health outcomes are commensurate with costs. This would require a significant increase in the therapeutic advance offered by new drugs. Biotechnology, by opening up new modes of action for drug treatment and by improving prescribing practices, could help to improve the efficacy of health treatments.

\section{Estimating the use of biotechnology for health applications}

Health biotechnology is defined here as the use of knowledge on cell functions and genetics at the molecular level, including an understanding of deoxyribonucleic acid (DNA), ribonucleic acid (RNA), proteins and enzymes, to develop new therapeutics and diagnostics. Researchers also use bioinformatics to analyse genomes, proteins, and population health databases (NZ MoRST, 2005).

A brief description of the two main biotechnologies in health is as follows:

- Biotechnology therapies: Compounds and treatments that are produced using modern biotechnology techniques. There are three main categories:

- Biopharmaceuticals: Large molecule therapeutic compounds, usually proteins with molecular weights in the tens of thousands of Daltons, which are produced 
by using monoclonal antibodies (mAbs) or recombinant technology. In the latter case, a gene that codes for the target molecule is inserted into the DNA of a host species, which in turn produces the molecule. The host species can be a microorganism, plant, or animal. Recombinant technology can produce proteins, amino acid chains, mAbs, vaccines, enzymes, and hormones. Some biopharmaceuticals can be produced without using recombinant technology, such as using pigs to produce porcine insulin. These "biologics" are not covered in this paper.

- Experimental treatments: This includes a disparate group of biotechnologies that currently have relatively small markets compared to biopharmaceuticals: tissue engineering, stem cell research, and gene therapy. Tissue engineering is based on knowledge about the growth of cells and includes bone and skin scaffolds and potentially the engineering of other organ complexes. Stem cell research could lead to the production of entire organs. Gene therapy involves the insertion of genes into living cells.

- Small molecule therapeutics: Small molecules are usually produced through chemical synthesis. Biotechnology can be used to identify new therapeutic targets or to improve clinical trials or prescribing practice. In some cases recombinant technology is used to manufacture small molecule precursors or chiral molecules.

- Bioinformatics and diagnostics: ${ }^{3}$ Bioinformatics cover the manipulation and analysis of large datasets of genetic and health information. This article includes several technological fields such as pharmacogenetics and gene sequencing under bioinformatics. The analysis of genetic data, combined with large public databases on health outcomes, prescriptions and treatments could have far reaching implications for health care and delivery systems. To date, most research has used either pharmacogenetic data or large public health databases. ${ }^{4}$

Many diagnostics are based on compounds produced through biotechnology, such as $\mathrm{mAbs}$, or are directed towards identifying genes or alleles associated with disease. A developing area is the identification of protein biomarkers. Diagnostics can be either in-vivo (i.e. invasive), in which case they are closely regulated, as with therapeutics, or in-vitro (i.e. non-invasive) in which case the regulatory requirements are considerably less demanding.

In addition to the above categories, there are several miscellaneous areas where biotechnology could have applications for health. One is functional foods and nutraceuticals (FFN). These are only part of biotechnology if the source material, such as vitamin enriched cereals or foods containing phytosterol or stanols, are produced from plants or micro-organisms that have been altered using biotechnology. Another area is medical devices. Several medical device technologies, such as tissue engineering and diagnostics, are included above, but there are a few additional areas where biotechnology could have applications.

This article provides brief descriptions of the types of biotechnologies of relevance to health applications, data on biotechnology products that are already on the market, and forecast estimates of the number of new products which might reach the market by 2015. The quality of the forecasts varies substantially by product field, depending on data availability. Table 1 gives available data sources for estimating trends in the use of biotechnologies to 2015. The best coverage is for biopharmaceuticals, with several sources of high quality quantitative data. The poorest coverage is for small molecule therapeutics and bioinformatics. 
Table 1. Data availability for human health biotechnology

\begin{tabular}{ll}
\hline Biotechnologies & \multicolumn{1}{c}{ Data sources } \\
\hline $\begin{array}{l}\text { 1. Biotechnology therapies } \\
\text { - Proven treatments }\end{array}$ & UNU-MERIT database of biopharmaceuticals \\
- Biotherapeutics & Pharmaprojects (clinical trials and approved drugs) \\
- Biovaccines & Pharmapredict (clinical trials and approved drugs) \\
- mAbs & Regulatory websites (FDA, EMEA) \\
& HAS and Prescrire evaluations of therapeutic value \\
& Data on the size of the potential target population \\
- Experimental treatments & Literature, FDA/EMEA, clinical trials \\
- Tissue engineering & \\
- Stem cells & \\
- Gene therapy & \\
- Synthetic biology & \\
- Small molecule therapeutics & German survey \\
\hline 2. Diagnostic tests & Literature \\
in-vivo/molecular imaging & In-vivo \& in-vitro: Literature \\
in-vitro & In-vivo: FDA/EMEA, clinical trials \\
3. Bioinformatics & Literature, PharmGKB database \\
\hline 4. Miscellaneous & Literature \\
\hline
\end{tabular}

\section{Maximum potential impact of biotechnology in health}

Most of the direct economic effects of the health applications of biotechnology occur in two sectors: the pharmaceutical manufacturing sector and the R\&D services sector. ${ }^{5}$ The latter includes the activities of biotechnology start-ups that do not have products on the market. ${ }^{6}$ Secondary effects can also occur in the health care services sector, for example if new therapies based on biotechnology decrease the time spent in hospitals (potentially decreasing health care costs) or significantly increase life spans (potentially increasing health care costs).

Data on the value added produced by biotechnology firms in the R\&D services sector are not available for any country, since it is not possible to separate firms active in biotechnology research from firms active in other research activities, such as ICT or engineering. It is also not possible to identify the biotechnology component of the value added produced by the pharmaceutical manufacturing sector. However, data on the share of pharmaceuticals in GDP gives an indication of the maximum possible contribution of biotechnology to this sector, if biotechnology contributed to the development of all pharmaceutical products, including small molecule therapeutics.

Table 2 gives the share of the pharmaceutical manufacturing sector in total value added for the EU-25 countries, the United States, Canada, Mexico, and Norway. No comparable data are available for the share of pharmaceuticals in global value added or GDP. The pharmaceutical sector accounts for $1.24 \%$ of total value added in the United States in 2004 . The share of the pharmaceutical sector in the EU-25 is almost half that for the United States, at $0.66 \%$ of total value-added. Between 1999 and 2004, the share of the pharmaceutical sector in total value added has been growing in the European Union (EU), by an average of $1.43 \%$ per year and declining by an average of $1.89 \%$ per year in the United States. ${ }^{7}$ In 2004 , the value added of the pharmaceutical sector was USD 135.7 billion in the United States and USD 82.9 billion in the EU-25. ${ }^{8}$ For comparison, IMS Health (2007) estimated the global sales of pharmaceutical products to be USD 643 billion in 2006 , or roughly twice 
the value added of the pharmaceutical sector. Approximately $10 \%$ of the sales market is from biopharmaceuticals.

The employment share of the pharmaceutical manufacturing sector is highest in the United States at $0.44 \%$ of total employment. In both the EU-25 and the United States the pharmaceutical share of total employment has been declining, with an average annual decline of $0.01 \%$ in the EU-25 and $0.13 \%$ in the United States. The total hours worked in pharmaceutical manufacturing declined between 1999 and 2004 by $4.6 \%$ in the EU-25 and by $16.1 \%$ in the United States. However, this does not account for gains or losses in employment in the R\&D services sector, where many dedicated biotechnology firms are active.

The maximum contribution of biotechnology to the pharmaceutical sector would be reached if biotechnology contributed to $100 \%$ of all new therapeutics, vaccines, and diagnostics. In this case, the direct economic impact of health biotechnology would approach $1.24 \%$ of GDP in the United States and $0.66 \%$ of GDP in the EU-25, although the actual impact in the United States could be smaller, due to the decline of the share of pharmaceuticals over time in the United States' GDP. This also assumes that the share of the pharmaceutical sector does not increase over time, due to population ageing or rapid growth in the pharmaceutical share of total health care expenditures. To put these data in perspective, the maximum potential contribution of biotechnology to the agriculture and related natural resource sectors (ANR) is approximately $2 \%$ of GDP within the OECD countries (Arundel and Sawaya, 2009).

The maximum contribution of health biotechnology to employment is more difficult to estimate. The pharmaceutical sector accounts for 1.437 million employees, or $0.31 \%$ of total employment in the OECD countries listed in Table 3 (excluding Mexico and Turkey), but there is also extensive biotechnology-related employment in the public research sector

Table 2. Basic economic indicators for pharmaceutical manufacturing (PM) sector: 2004 or nearest available year

\begin{tabular}{|c|c|c|c|c|c|c|}
\hline & GDP (USD billion) & $\begin{array}{l}\text { PM share of total } \\
\text { value-added }(\%)\end{array}$ & $\begin{array}{c}\text { Average annual } \\
\text { change in PM share } \\
\text { of total value added } \\
(\%)\end{array}$ & $\begin{array}{l}\text { Total employment } \\
(000)\end{array}$ & $\begin{array}{l}\text { PM share }(\%) \text { of } \\
\text { total employment }\end{array}$ & $\begin{array}{c}\text { Average annual } \\
\text { change in PM share } \\
\text { of total employment } \\
(\%)\end{array}$ \\
\hline EU-25 & 13100 & 0.66 & 1.43 & 202760 & 0.27 & -0.01 \\
\hline United States & 11712 & 1.24 & -1.89 & 149512 & 0.44 & -0.13 \\
\hline Australia & 645 & & - & 9207 & - & - \\
\hline Canada & 1089 & 0.36 & $\cdot$ & 15314 & 0.19 & 1.15 \\
\hline Iceland & 14 & - & - & 0.159 & - & - \\
\hline Japan & 4911 & - & - & 66222 & 0.18 & 0.34 \\
\hline Korea & 897 & - & - & 21557 & - & - \\
\hline Mexico & 742 & 0.73 & - & - & - & - \\
\hline New Zealand & 99 & - & - & $\{443$ & - & - \\
\hline Norway & 262 & 0.23 & - & 2310 & - & - \\
\hline
\end{tabular}

Source: EU KLEMS database (2007) for the EU-25 and the United States; OECD STAN Structural Analysis Databases (2007a) for all other countries. The two databases are not fully comparable.

Note: 1. Value-added data and Employment are for 2004, except for Canada (2002 for value added and 2003 for employment), Mexico (2003 for value added), Norway (2002 for value added) and Japan (2003 for employment).

2. Average annual change in Pharmaceutical manufacturing share of total GDP and of total employment are for 1995-2004 or 1995 to 2003 , as relevant. 
and in the R\&D services sector. Conversely, an unknown share of current pharmaceutical manufacturing is for small molecule generics and patented drugs that will still be in use in 2015 or even in 2030 . Therefore, the maximum potential estimate of $0.31 \%$ of total employment in the OECD from a biotechnology pharmaceutical sector is unlikely to be achieved by 2015 , but biotechnology is increasingly being used to develop small molecule therapeutics. Consequently, the percentage of pharmaceutical employment and value added that is partly or entirely dependent on biotechnology is likely to rise rapidly and approach $100 \%$ by 2030 .

Table 3 gives basic economic data for the entire health care services sector for 2007. All health care expenditures account for 9.1\% of GDP in the European Union (based on data for 19 countries that account for $98 \%$ of European Union GDP) and for $16 \%$ of GDP in the United States. Health care expenditures as a share of GDP between 2000 and 2007 grew in all OECD countries, with the exception of Iceland. The largest increase was in the United States where healthcare expenditures increased from 13.6\% of GDP in 2000 to $16 \%$ in 2007.

Biotechnology will also contribute to health care services, for example by replacing hospital stays with new therapeutic treatments, or by altering the type of medical intervention, for instance by replacing long-term drug therapies with cures due to gene or stem cell therapy. This will affect the share of pharmaceutical costs in health care spending and the total share of health care services in GDP. The former is influenced not only by drug costs themselves, but also by all other health care costs. One consequence is that pharmaceutical costs are a smaller share of total health care costs in the United States than in Europe, even though pharmaceutical costs are higher in the United States than in Europe as a share of total GDP.

The pharmaceutical share of all health care expenditures varies substantially, from a low of $8.0 \%$ in Norway to $24 \%$ or more in Mexico, Turkey and Korea. It is also higher, at $14.6 \%$, in the European Union than in the United States, at $12.0 \%$. The pharmaceutical share of all health care costs is shown in column D of Table 3 , and the change in that share from 2000 to 2007 is shown in column E. The pharmaceutical share of healthcare costs increased by $1.1 \%$ in the EU-19, $0.7 \%$ in the United States, $0.9 \%$ in Japan, and $4.6 \%$ in Mexico from 2000 to 2007. The share has fallen in Australia, Iceland, Korea, New Zealand, Norway, and Switzerland.

Many of the effects of biotechnology could improve cost-benefit ratios of treatment or potentially reduce or increase the health care share of GDP. However, at this time not enough data are available to estimate the non-pharmaceutical effects of biotechnology in health care value-added. However, treatments based on biotechnology will never approach $100 \%$ of health care costs by 2015 or even 2030 , due to the large share of health care services from long-term chronic care for the elderly. 


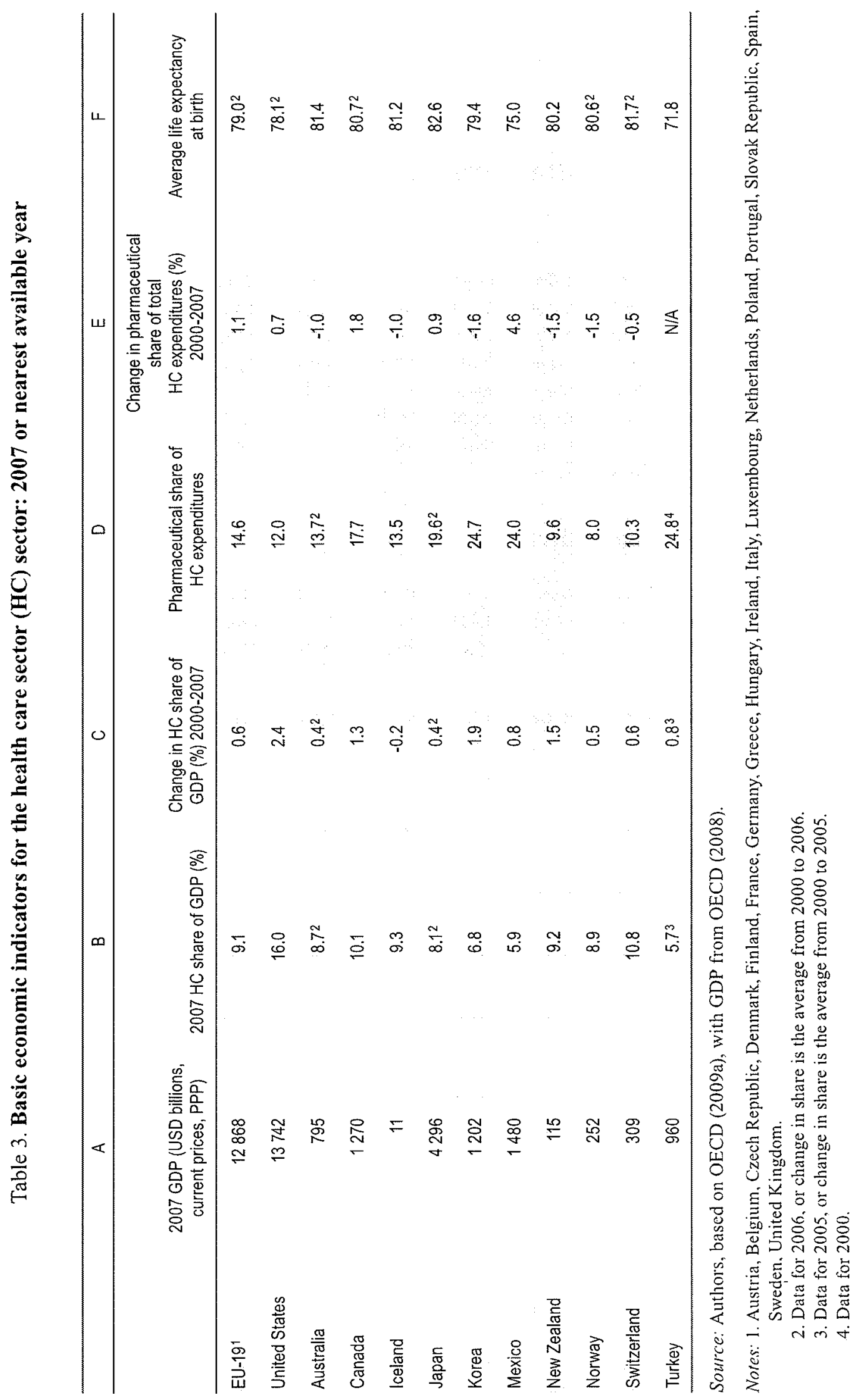

OECD JOURNAL: GENERAL PAPERS - VOLUME 200\%/3 C OECD 2009 


\section{Health therapies}

This section looks at the use of biotechnology to develop therapies to treat disease. These include biotechnologies with products on the market (proven biopharmaceuticals), experimental therapies with products in clinical trials but with very few if any products yet on the market, and small molecule pharmaceuticals in which biotechnology is used during manufacturing or in the drug development process. This article defines a new molecular entity (NME) as a biopharmaceutical or small molecule therapeutic) that is still in development or clinical trials, while a pharmaceutical has obtained marketing approval by a regulatory agency somewhere in the world.

\section{Current status of proven biopharmaceuticals}

The development of biopharmaceuticals is dominated by American firms, both in terms of the number of firms that developed at least one new biopharmaceutical that has received market approval and in terms of the total number of biopharmaceuticals.

Figure 1. Number of biopharmaceuticals by nationality of the developer firm, Jan 1989-Jan 2009

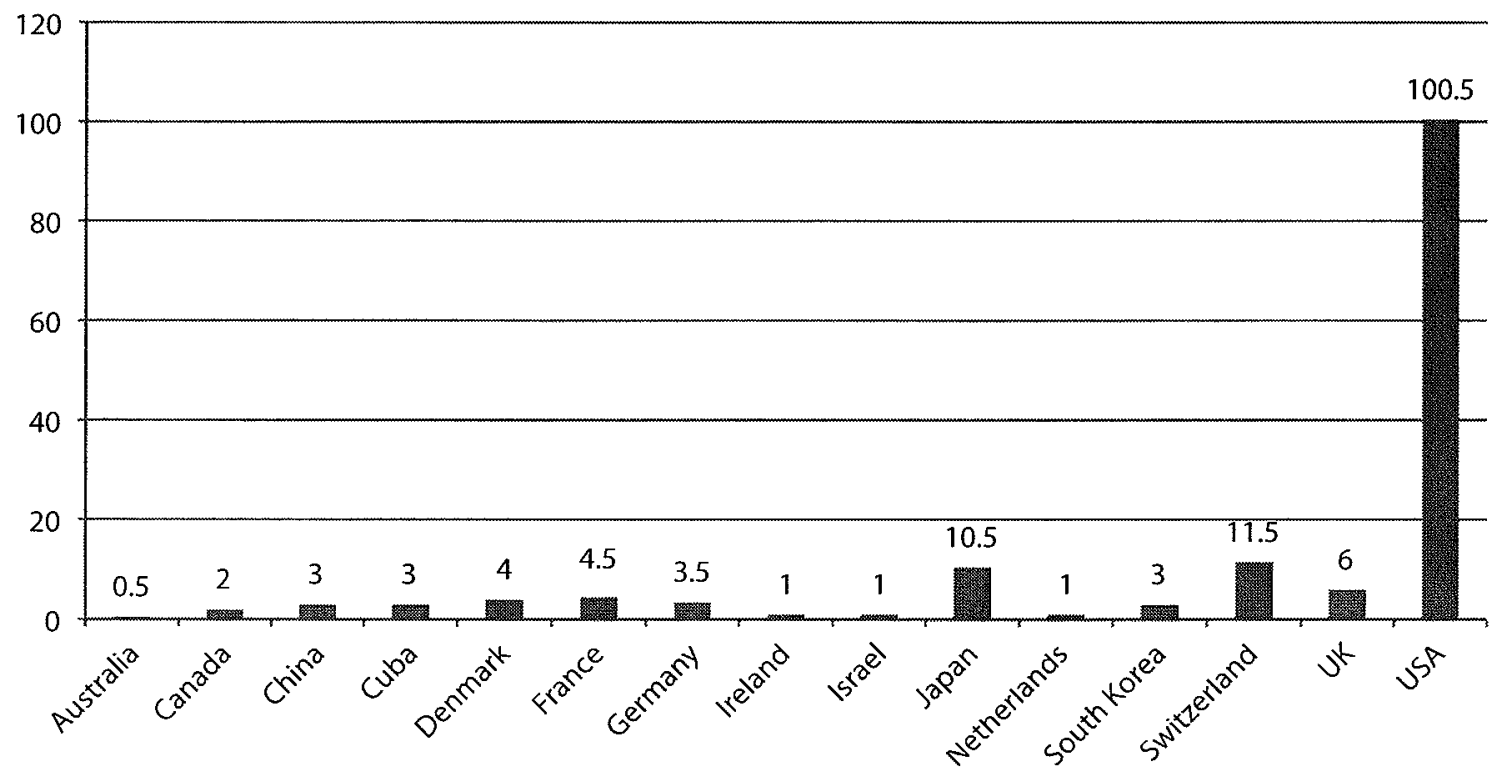

Source: Authors, based on data from Informa (2007a), EMEA, and FDA.

Notes: 1. Biopharmaceuticals are limited to NMEs and exclude biosimilars. See Annex A, Table 27 for a list of the 155 biopharmaceuticals.

2. A rating of 0.5 is given when development was jointly shared by firms in two different countries.

3. Biopharmaceuticals include therapeutics, vaccines, in vivo diagnostics, and experimental therapies. 
Between January 1989 and January 2009, 155 biopharmaceuticals, including therapeutics, recombinant vaccines, in-vivo diagnostics and a few experimental therapies, received marketing approval. Figure 1 gives the number of biopharmaceuticals by the head office country of the developer firm. For approximately $40 \%$ of approved biopharmaceuticals, the firm that developed the drug did not take it all the way through clinical trials and apply for marketing approval. Instead, the developer was purchased by another firm before marketing approval or the drug was licensed to another firm. For a few biopharmaceuticals, development was jointly shared by firms in two countries. In this case each head office country is given a rating of 0.5 . Firms based in the United States developed $100.5(64.8 \%)$ of the 155 biopharmaceuticals, while European firms account for 32 biopharmaceuticals (20.6\%) and Japanese firms for 10.5 biopharmaceuticals (6.8\%).

The share of biopharmaceuticals developed by American firms has declined from over $75 \%$ before 1995 to approximately $60 \%$ after 2006 (see Figure 2). Almost all of the remaining biopharmaceuticals have been developed in other OECD countries, with the exception of three developed in China, three in Cuba, and two in Israel.

\section{Additional therapeutic value of biopharmaceuticals}

An important measure of the impact of new drug approvals on public health is their therapeutic value. This concept refers to the effectiveness of new drugs, compared to existing therapies, for treating disease. For example, a new drug that has a similar effect to an existing drug already on the market provides little additional therapeutic value to available treatments. Examples include the many different versions of cholesterol lowering drugs or insulin on the market. These types of drugs are commonly known as "me-too" drugs. Although effective, they offer no therapeutic advance over existing drugs. Since the early

Figure 2. Share of biopharmaceuticals (3-year running average) developed by US firms, by year of market approval: Jan 1989-Dec 2008

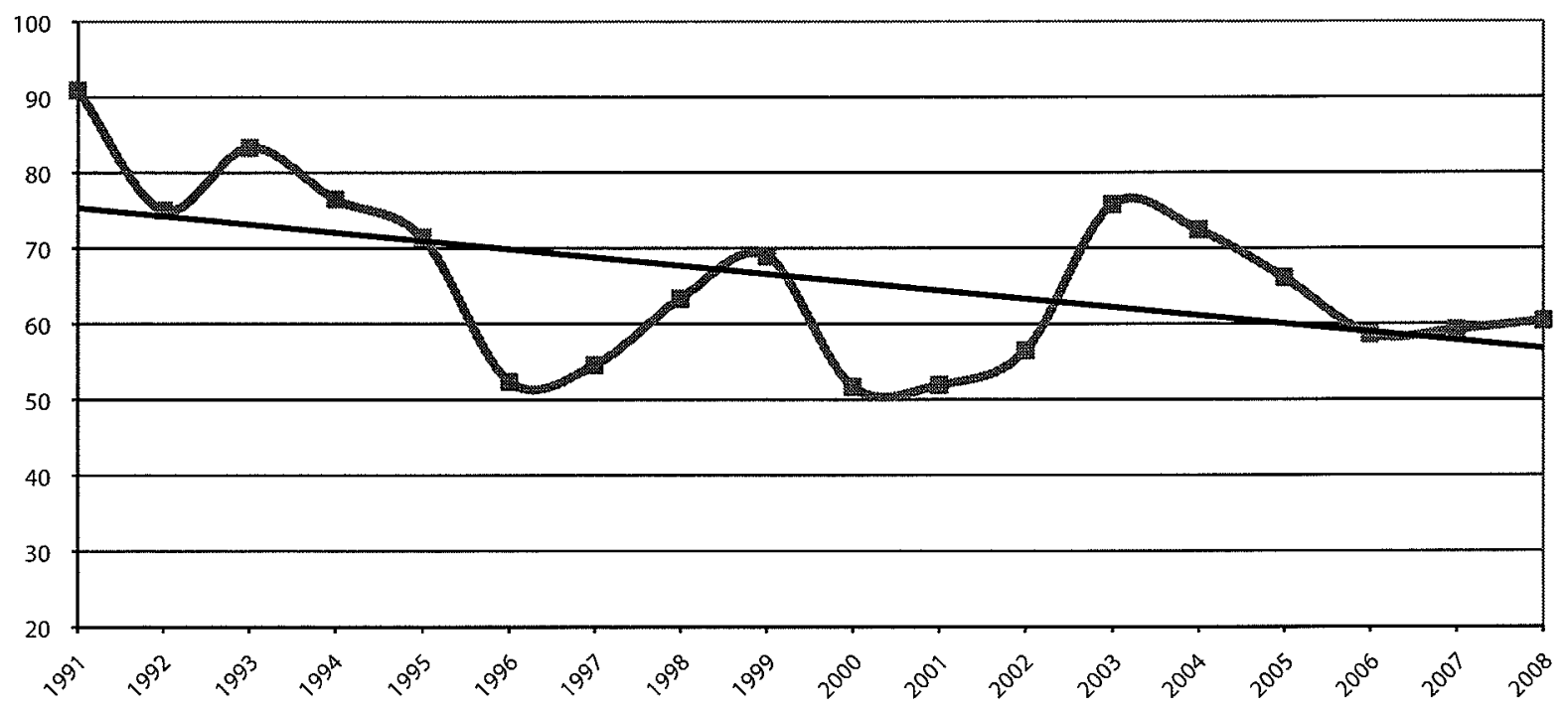

Source: Authors, based on data from Informa (2007a), FDA, EMEA

Notes: 1. See Annex A, Table 27 for a list of all biopharmaceuticals.

2. Data series begins in 1991 with the average for three years: 1989,1990 and 1991. 
1980s, approximately two-thirds of new drugs have been "me too" drugs (US GAO, 2006). An important goal for policy and for pharmaceutical firms is to improve the share of new drugs that offer a therapeutic advance over existing treatments.

Many biopharmaceuticals are based on a new technology with new modes of action (Ashton, 2001). In this respect biopharmaceuticals display some of the characteristics of an emerging technology, in contrast with the "mature" technology characteristics of many classes of small molecule drugs. Consequently, we would expect biopharmaceuticals to offer a greater therapeutic advance, on average, compared to other small molecule pharmaceuticals.

To test this assumption, the therapeutic value of biopharmaceuticals was compared against other types of drugs, using two separate data sources: France's Haute Autorite de Santé and the physician-funded organisation Prescrire. The data were used to compare the therapeutic value ratings for small molecule pharmaceuticals and biopharmaceutical. Both sets of data produced similar results and confirm the hypothesis that biopharmaceuticals, on average, offer greater therapeutic advance than other small molecule pharmaceuticals. The analyses do, however, raise some concerns.

Both analyses indicate that the therapeutic advance of biopharmaceuticals is declining over time as the class takes on the characteristics of a mature technology. The decline in therapeutic advance is partly due to the diffusion of the technology to an increasing number of firms, with competitors bringing comparable biopharmaceuticals onto the market. A good example is interferon, with many different versions currently available.

\section{Analysis of therapeutic value using HAS and Prescrire data}

HAS was set up by the French government in August 2004 as an independent, financially autonomous body. It is tasked with using scientific data to assess the therapeutic value of drugs, medical devices, and procedures. As of the end of 2007, the organisation has evaluated 53 biopharmaceuticals approved for use in the European Union, and 1476 other drugs. ${ }^{9}$ The evaluations are based on indications, ${ }^{10}$ which are the approved use of the drug to treat specific diseases. A single drug can be approved for multiple indications. For example, HAS evaluated 53 biopharmaceuticals for 102 different indications. The results

Table 4. HAS evaluations of the therapeutic value of biopharmaceuticals and all other drugs (January 2001-December 2007)

\begin{tabular}{|c|c|c|c|c|c|c|}
\hline \multirow[b]{3}{*}{ Evaluation Class } & \multicolumn{4}{|c|}{ Biopharmaceuticals } & \multirow{2}{*}{\multicolumn{2}{|c|}{$\begin{array}{l}\text { All other drugs } \\
\text { All indications }\end{array}$}} \\
\hline & \multicolumn{2}{|c|}{ Highest rating } & \multicolumn{2}{|c|}{ All indications } & & \\
\hline & $N$ & $\%$ & $N$ & $\%$ & $N$ & $\%$ \\
\hline Major therapeutic progress & 5 & $9.4 \%$ & 9 & $8.7 \%$ & 35 & $2.4 \%$ \\
\hline Important improvement & 13 & $24.5 \%$ & 22 & $21.4 \%$ & 52 & $3.5 \%$ \\
\hline Moderate improvement & 12 & $22.6 \%$ & 18 & $17.5 \%$ & 96 & $6.5 \%$ \\
\hline Minor improvement & 8 & $15.1 \%$ & 9 & $8.7 \%$ & 105 & $7.1 \%$ \\
\hline No improvement ("me too") & 11 & $20.8 \%$ & 40 & $38.8 \%$ & 1139 & $77.2 \%$ \\
\hline Judgement reserved & 4 & $7.5 \%$ & 5 & $4.9 \%$ & 49 & $3.3 \%$ \\
\hline Total & 53 & $100 \%$ & 102 & $100 \%$ & 1476 & $100 \%$ \\
\hline
\end{tabular}

Source: Authors, based on HAS (2008).

Note: For a full definition of each evaluation category, see the notes to Annex B, Table 31, which also lists each evaluated biopharmaceutical, the HAS evaluation, and the indication that received the highest evaluation. 
are given in Table 4. Results are only given for therapeutics, with in vivo diagnostics and vaccines excluded to improve comparability.

Based on the results for all indications, a higher percentage of biotechnology than all other drugs provide a "moderate improvement" or higher: $47.6 \%$ versus $12.4 \%$ of all other drugs. In addition, only $39.2 \%$ of biopharmaceuticals are rated as offering no therapeutic advance over existing drugs on the market, versus $77.2 \%$ of all other drugs.

The data suggest that the therapeutic advance of biopharmaceuticals as a class is declining over time. The share of biopharmaceutical indications offering some therapeutic advance or greater declined from $52.1 \%$ of 25 indications evaluated between 2001 and 2004 inclusive, to $43.6 \%$ of 24 indications evaluated between 2005 and 2007 . Over this time period, the percentage of "me too" indications also increased from $25.0 \%$ to $50.9 \%$. In absolute terms, however, the number of biopharmaceuticals per year offering a "moderate improvement" or greater has not changed, with an average of 0.5 per year between 2001 and 2007.

Prescrire is an independent French organization that is supported entirely by doctor subscriptions for its journal. Prescrire only evaluates drugs after marketing approval, using all available clinical trial results. It uses a similar evaluation class structure as HAS, except that it has one additional class of "not acceptable" for drugs that the evaluators believed should not have obtained marketing approval. Compared to the HAS results, the distribution of Prescrire evaluations above the category of a "minimal" advance are shifted downwards. For example, HAS gives $8.8 \%$ of biopharmaceuticals an indication of "major therapeutic progress" whereas Prescrire gives none of the evaluated biopharmaceuticals its highest rating of a "major advance". These differences are not important here, as the main purpose of the analyses is to compare the distribution of evaluations for biopharmaceutical and small molecule drugs, rather than the absolute rankings.

Table 5. Prescrire evaluations of the therapeutic value of biopharmaceuticals and all other drugs (Jan 1986-April 2008)

\begin{tabular}{l|rr|rr|rc}
\hline \multirow{2}{*}{ Evaluation Class } & \multicolumn{3}{|c|}{ Biopharmaceuticals } & \multicolumn{2}{c}{ All other drugs } \\
\cline { 2 - 7 } & \multicolumn{2}{|c|}{ Highest rating } & \multicolumn{2}{c|}{ All indications } & \multicolumn{2}{c}{ All indications } \\
\cline { 2 - 7 } Major advance & $\mathrm{N}$ & $\%$ & $\mathrm{~N}$ & $\%$ & $\mathrm{~N}$ & $\%$ \\
Important advance & 0 & $0.0 \%$ & 0 & $0.0 \%$ & 8 & $0.4 \%$ \\
Some advance & 5 & $7.4 \%$ & 7 & $5.1 \%$ & 57 & $3.0 \%$ \\
Minimal advance & 14 & $20.6 \%$ & 21 & $15.2 \%$ & 196 & $10.2 \%$ \\
No advance (me too) & 20 & $29.4 \%$ & 41 & $29.7 \%$ & 449 & $23.4 \%$ \\
Not acceptable & 19 & $27.9 \%$ & 39 & $28.3 \%$ & 964 & $50.3 \%$ \\
Judgment reserved & 8 & $11.8 \%$ & 13 & $9.4 \%$ & 127 & $6.6 \%$ \\
Total & 2 & $2.9 \%$ & 17 & $12.3 \%$ & 114 & $6.0 \%$ \\
\hline
\end{tabular}

Source: Authors, based on data from Prescrire issues between January 1986 and February 2008. All other drugs: 1986 - 2000 data on page 59, Prescrire Jan 2001, 2000 - 2007 data on page 136, Prescrire, Feb 2008; data for 2008 from individual Prescrire issues.

Notes: 1. The evaluations for biopharmaceuticals were subtracted from the totals for all drugs

2. For a full definition of each evaluation category, see Annex C, Table 33 gives each evaluated biopharmaceutical, the highest Prescrire evaluation and the indication that received the highest cvaluation.

3. After 1996, Prescrire separated the therapeutic value of biopharmaceuticals and all other drugs from generic equivalents. In this table, generics are excluded. 
As of the end of April 2008, Prescrire had evaluated 138 indications for 68 biopharmaceuticals approved for use in the European Union, and 1915 other (small molecule) drugs. The results, given in Table 5, only cover therapeutics and exclude diagnostics and vaccines. A full description of each drug evaluation class is given in Annex C.

The second column of Table 5 provides the highest rating given to biopharmaceuticals. Prescrire updates evaluations when new information becomes available, so the highest rating for a biopharmaceutical could be due to either a revised rating for the same indication or to a new indication. The "all indications" column includes all ratings, whether revised or not, in order to maintain comparability with the results for all other drugs, given in the last two columns of Table 5.

Based on the results for all indications, a higher percentage of biotechnology than all other drugs provide "some advance" or higher: $20.3 \%$ versus $13.6 \%$ of all other drugs. In addition, only $28.3 \%$ of biopharmaceutical indications are rated as offering no therapeutic advance over existing drugs on the market, versus $50.3 \%$ of all other drugs.

Of note, the results in Table 5 raise a few concerns. The two categories of "not acceptable" and "judgment reserved" refer to drugs that the evaluators believed should not have received marketing approval, either because the drug is deemed to be more harmful than alternatives or because the available data are insufficient for assessing drug safety and efficacy. Slightly more than one-fifth of biopharmaceutical indications fall in this group, compared to $12.6 \%$ for all other drugs.

Limited to the highest rating, the share of biopharmaceuticals that offer some therapeutic advance or greater declined from $50.0 \%$ of 22 indications evaluated between 1986 and 2000 inclusive, to $22.7 \%$ of 22 indications evaluated between 2001 and 2004 and to $21.1 \%$ of 24 indications evaluated after $2004 .{ }^{11}$ A comparison of the time periods before and after 2001 shows that the percentage of the highest indications receiving a "me too" rating increased from $18.1 \%$ to $37.0 \%$ (there was no substantive difference in the two time periods 2001 to 2004 and after 2004). It is important to note that in absolute terms the number of biopharmaceuticals per year offering some therapeutic advance or greater almost doubled, from 0.7 per year between 1986 and 1999 to 1.3 per year between 2000 and 2006 .

\section{Firm type and therapeutic value}

The factors that support the development of therapeutically valuable biopharmaceuticals are of relevance to both policy and the design of future business models. One possibility is that small DBFs could be more likely than large established firms to develop biopharmaceuticals that offer a therapeutic advance over existing treatments. This could occur either because DBFs have closer linkages with university researchers that discover new modes of action or business models that accept riskier projects. The latter could include close ties with venture capitalists or a goal to license promising drugs at the clinical trial stage.

An analysis was undertaken to determine whether there was a correlation between the type of firm that developed the biopharmaceutical and the therapeutic value of the drugs being developed. Data from HAS and Prescrire were used. In both analyses, small biotech firms had a substantially higher share of drugs providing "some" therapeutic advance or better. Conversely, larger firms had a much higher share than large established firms of biopharmaceuticals that were rated as a "minimal" advance, or which provided no advance ("me too" drugs). ${ }^{12}$ In addition, the analysis of Prescrire data shows that the share of drugs developed by mid-size biotech firms that were deemed "not acceptable" was almost double that of small biotech firms. ${ }^{13}$ 
Table 6. Therapeutic value of biopharmaceuticals by the type of firm that developed the drug, using data from the Haute Autorité de Santé $(H A S)$

\begin{tabular}{|c|c|c|c|c|c|}
\hline \multirow[b]{2}{*}{ Firm type } & \multirow[b]{2}{*}{$\begin{array}{c}\text { Number of } \\
\text { biopharmaceuticals }\end{array}$} & \multicolumn{4}{|c|}{ Therapeutic advance over previous treatments } \\
\hline & & $\begin{array}{l}\text { Major advance, } \\
\text { important or } \\
\text { moderate advance }\end{array}$ & $\begin{array}{l}\text { Minimal or } \\
\text { no advance }\end{array}$ & Judgment reserved & Total \\
\hline Small biotech & 26 & $65.4 \%$ & $26.9 \%$ & $7.7 \%$ & $100 \%$ \\
\hline Established biotech & 13 & $69.2 \%$ & $23.1 \%$ & $7.7 \%$ & $100 \%$ \\
\hline Large / established & 14 & $28.6 \%$ & $64.3 \%$ & $7.1 \%$ & $100 \%$ \\
\hline Total & 53 & $57.7 \%$ & $36.5 \%$ & $5.8 \%$ & \\
\hline
\end{tabular}

Source: Authors, based on HAS (2008) for therapeutic value data and publicly available data on firm size.

Notes: 1. Excludes vaccines and diagnostics.

2. For a full definition of each evaluation category, see the notes to Annex B, Table 31 .

Table 6 gives the distribution of the HAS evaluations of 53 biopharmaceuticals by the type of firm that developed the drug. For example, HAS evaluated 26 biopharmaceuticals that were developed by small dedicated biotech firms. Since their establishment, three dedicated biotechnology firms (Amgen, Genzyme and Genentech) have developed into established biopharmaceutical firms that are much larger and successful than the small biotech firms. Drugs developed by these firms and which received marketing approval 20 years after the establishment date of the firm are assigned to the "established biotech" category. ${ }^{14}$ Large firms consist of pharmaceutical firms that were established before the biotechnology revolution in 1974. Most had over 20000 employees in 2008. Compared to large established firms, a higher share of biopharmaceuticals developed by small biotech firms received an evaluation of "some" advance or better $(65.4 \%$ versus $28.6 \%)$. Conversely, compared to both the small biotech firms and the mid-size firms, large firms had over double the share of biopharmaceuticals that were rated as a "minimal" advance, or which provided no advance ("me too" drugs).

Table 7 gives the distribution of Prescrire evaluations for 68 biopharmaceuticals by the type of the firm that developed the drug. A higher share of biopharmaceuticals developed by small firms received an evaluation of "some" advance or better ( $38.7 \%$ versus $25.0 \%$ for

Table 7. Therapeutic value of biopharmaceuticals by the type of firm that developed the drug, using data from Prescrire

\begin{tabular}{lccccc}
\hline & & \multicolumn{2}{c}{ Therapeutic advance over previous treatments } \\
\hline Firm type & $\begin{array}{c}\text { Number of } \\
\text { biopharmaceuticals }\end{array}$ & $\begin{array}{c}\text { Important or some } \\
\text { advance }\end{array}$ & $\begin{array}{c}\text { Minimal or no } \\
\text { advance }\end{array}$ & $\begin{array}{c}\text { Not acceptable or } \\
\text { judgment reserved }\end{array}$ & Total \\
\hline Small biotech & 31 & $38.7 \%$ & $45.2 \%$ & $16.1 \%$ & $100 \%$ \\
Established biotech & 16 & $25.0 \%$ & $43.8 \%$ & $31.3 \%$ & $100 \%$ \\
Large/ established & 21 & $14.3 \%$ & $85.7 \%$ & $0.0 \%$ & $100 \%$ \\
\hline Total & 68 & $28.4 \%$ & $58.2 \%$ & $13.4 \%$ & \\
\hline
\end{tabular}

Source: Authors, based on Prescrire (various) for therapeutic value data and publicly available data on firm size.

Notes: 1. For a definition of each evaluation category, see Annex C, Table 33.

2. Small biotech firms were established after 1974 specifically to develop biotechnological applications in health. Established biotech firms primarily consist of Amgen, Genzyme, and Genentech that were originally small dedicated biotech firms. They are assigned to the mid-size firms 20 years after the year of establishment. Elan and Organon are also assigned to this category (1 drug each). Large firms either have over 20000 employees in 2007 or were multi-product chemical and pharmaceutical firms established before the advent of biotechnology in 1974 
mid-size firms and $14.3 \%$ for large firms. Large established firms developed the highest share of biopharmaceuticals with a therapeutic value rating of "minimal advance" or "no advance" (85.7\%). The established biotech firms developed the highest share of biopharmaceuticals that were rated as "not acceptable" or "judgement reserved" $(31.3 \%)$.

\section{Conclusions for therapeutic value}

The analyses of the HAS and Prescrire data consistently show that biopharmaceuticals offer a notable "therapeutic advantage" over small molecule pharmaceuticals, although the level of the advantage has been declining over time. DBFs have also been the major contributor for therapeutically valuable new biopharmaceuticals. The decline in the therapeutic advantage over time could be reversed in the future, if research into experimental therapies results in clinically successful new drugs (see below).

\section{Current status of experimental therapies}

In addition to the biopharmaceuticals that have entered the market over the last two decades, many new experimental biotechnologies are being developed. These have the potential to produce new treatments that could treat or cure diseases or improve the quality of life. At present, there are only a few relevant products on the market, mostly outside the OECD countries. Research and development is ongoing however and there are products in all phases of clinical trials. Some have completed phase III clinical trials and are in the pre-registration phase.

American firms account for 119 of 197 clinical trials or pre-registrations of experimental therapies, as shown in Table 8 . Table 29 provides results by country for the number of clinical trials in Phases I, II and III.

Table 9 presents the experimental therapies by clinical trials phase. There are 55 and 112 experimental trials in Phase I and Phase II, respectively. This represents approximately $85 \%$ of all experimental therapy trials. While this indicates a very robust pipeline, many of the experimental therapies have performed poorly in clinical trials and will have success rates far below that of traditional biotherapeutic products.

Table 8. Experimental therapies in clinical trials or pre-registration, by country: as of March 2008

\begin{tabular}{|c|c|c|c|c|c|c|c|c|c|c|c|c|c|c|c|c|c|c|c|c|}
\hline Therapy Type & 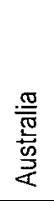 & $\frac{\frac{\pi}{2}}{\frac{5}{2}}$ & 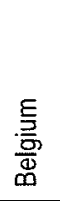 & $\begin{array}{l}\overline{\bar{N}} \\
\text { 过 } \\
\text { D. }\end{array}$ & $\begin{array}{l}\stackrel{\mathbb{J}}{\mathbb{\Xi}} \\
\stackrel{\mathbb{J}}{J}\end{array}$ & $\frac{\stackrel{\mathbb{E}}{E}}{0}$ & 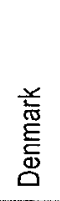 & 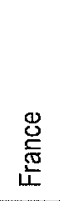 & 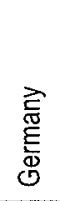 & $\begin{array}{l}\overline{\mathbb{d}} \\
\underline{\underline{w}} \\
\underline{\underline{\omega}}\end{array}$ & 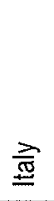 & 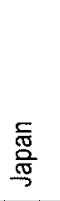 & $\frac{\mathbb{W}}{\sum}$ & 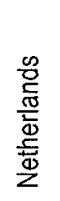 & 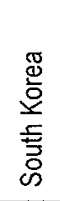 & $\frac{\sqrt{\bar{\pi}}}{\frac{D}{D}}$ & 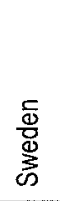 & 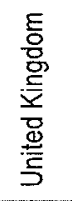 & 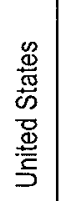 & $\underset{5}{\stackrel{5}{5}}$ \\
\hline Antisense & 2 & 0 & 0 & 0 & 6 & 0 & 2 & 0 & 1 & 0 & 0 & 0 & 0 & 1 & 0 & 0 & 1 & 2 & 19 & 34 \\
\hline Cell \& tissue, non stem cell & 2 & 0 & 1 & 1 & 1 & 0 & 2 & 3 & 2 & 0 & 1 & 1 & 0 & 2 & 1 & 1 & 0 & 6 & 32 & 571 \\
\hline Stem cell & 1 & 0 & 0 & 0 & 0 & 0 & 0 & 0 & 3 & 2 & 0 & 0 & 0 & 0 & 2 & 0 & 0 & 0 & 15 & 23 \\
\hline Gene therapy & 0 & 1 & 0 & 0 & 1 & 1 & 1 & 5 & 1 & 2 & 3 & 1 & 1 & 1 & 5 & 0 & 0 & 6 & 49 & 78 \\
\hline RNA interference & 0 & 0 & 0 & 0 & 0 & 0 & 0 & 0 & 0 & 0 & 0 & 0 & 0 & 0 & 0 & 0 & 0 & 2 & 4 & 6 \\
\hline TOTAL & 5 & 1 & 1 & 1 & 8 & 1 & 5 & 8 & 7 & 4 & 4 & 2 & 1 & 4 & 8 & 1 & 1 & 16 & 119 & 197 \\
\hline
\end{tabular}

Source: Authors, based on data from Informa (2007a).

Note: 1 . There was one cell therapy for which the country was not specified. 
Table 9. Experimental therapies in clinical trials or pre-registration, by phase: as of March 2008

\begin{tabular}{lccccc}
\hline Therapy Type & Phase I & Phase II & Phase III & Pre-registration & Total \\
\hline Antisense & 10 & 21 & 2 & 1 & 34 \\
Cell \& tissue, non stem cell & 11 & 37 & 6 & 2 & 57 \\
Stem cell & 12 & 7 & 4 & 0 & 23 \\
Gene therapy & 20 & 44 & 12 & 2 & 78 \\
RNA interference & 2 & 3 & 1 & 0 & 6 \\
\hline TOTAL & 55 & 112 & 25 & 5 & 197 \\
\hline
\end{tabular}

Source: Authors, based on data from Informa (2007a).

The following sections summarize the current state of activity in cell and tissue engineering (including stem cells), gene related therapies (including gene therapy, antisense and RNAi), and synthetic biology and give some examples of potential applications for the health sector.

\section{Cell and tissue engineering}

These technologies involve techniques that replace or act directly on cells and tissues in the body.

\section{Cell and tissue engineering}

In general, cell therapies replace, "diseased or dysfunctional cells with healthy, functioning ones (MedicineNet, 2001)." This refers to the replacement of individual cells with new, living cells. In comparison, tissue engineering develops "biological substitutes to restore, maintain and improve [human] tissue functions (NSF, 2007)." This can include new living tissues attached to inert substrates.

A review for the European Commission reports that approximately 40 tissue engineering products are on the market, "mainly autologous ${ }^{15}$ skin replacements, cartilage, and bone products, generating sales of about EUR 60 million/year (JRC, 2007)." Most of these however, do not require intensive clinical trials due to their non-invasive nature (e.g. wound coverings). Several tissue engineering products for the treatment of diabetic and other skin ulcers have been available in several OECD countries for a decade. Examples include Apligraf ${ }^{\mathrm{TM}}$ and Dermagraft ${ }^{\mathrm{TM}}$.

Presently, 57 cellular therapies are currently in clinical trials including 12 in phase I, 37 in phase II, 6 in phase III and 2 in pre-registration. Thirty are for treating cancer and 30 use autologous (usually dendritic) cells. Eleven use a single cell type to replace or improve existing tissue: heart muscle, blood vessels, cartilage, diabetes islet cells, etc. All of these, with the exception of porcine diabetes islet cells, use autologous cells. There are also nine engineered tissues (mostly skin tissue, mostly not autologous), as well as three trials for immune disorders (alopecia, rheumatoid arthritis, MS), two for incontinence (anal and urinary), one for Parkinson's disease and one for ocular disorder. Except for the nine engineered tissues, all use a single cell type. Even for the engineered tissues, only a few use more than one living cell type (keratinocytes and fibroblasts). 


\section{Stem cell therapy}

Stem cells in particular have garnered a lot of attention as a form of cell therapy. A stem cell can make exact copies of itself indefinitely and is generic, with the ability to produce specialized cells for various tissues in the body, such as heart muscle, brain tissue, and liver tissue. There are two basic types of stem cells. The first type is the embryonic stem cell, which is obtained from either aborted foetuses or fertilized eggs that are left over from in vitro fertilization. Embryonic stem cells are useful for medical and research purposes because they can produce cells for almost every tissue in the body, but ethical concerns have placed legal or financial limitations on research using them. The second type is the adult stem cell, which is not as versatile for research purposes because it is specific to certain cell types, such as blood, intestines, skin, and muscle (eJournalUSA, 2005).

Bone marrow transplants, which have been practiced for 40 years, are a type of stem cell treatment. The only more advanced treatment that has received marketing approval to date is OTI-050, which entered the United States' market in 2005, and is used to regenerate bone before dental implantation. The process uses stem cells but the principle is similar to the other cellular therapies described above.

Currently 23 (twelve in phase I, seven in phase II and four in phase III) stem cell therapies are in clinical trials (see Table 9). Four target myocardial infarction, four target ischaemia, three are focused on regeneration and transplantation, and the rest target a variety of other diseases. The vast majority of all clinical trials underway are focused on adult stem cells.

The future promise of stem cells is based on the ability to produce more complex structures, such as teeth, complex tissues, or organs, that are not possible to produce with other cellular therapies. The New Zealand Ministry of Research Science and Technology has identified several technical bottlenecks for stem cell development as an advanced treatment option:

- "Understanding the mechanisms regulating stem cell growth and differentiation into tissue;

- Eliminating the risk of stem cell differentiation into cancer cells; and

- Overcoming the risk of immune rejection which may arise when a patient is receiving stem cells from a donor - as would be the case with embryonic stem cell derivation (NZ MoRST, 2005)."

\section{Gene-related therapies}

These technologies either use or act directly on nucleic acids, which are the molecules that serve as the building blocks for DNA and RNA.

\section{Gene therapy}

Gene therapy is " $[t]$ he insertion of normal or genetically altered genes into cells, usually to replace defective genes especially in the treatment of genetic disorders (IFOPA, 2007)." Although clinical trials began in 1990, there are still no gene therapies approved by the FDA or EMEA, although, as of March 2006, two have been approved in China (Jia, 2006).$^{16}$ Gene therapy still faces technical difficulties, as shown by serious side effects, including the deaths of several patients in clinical trials (Edelstein, Abedi, Wixon, 2007). 
The US Human Genome Program has identified four primary reasons that gene therapy has not become a successful treatment option:

- Short-lived nature of gene therapy: Problems with integrating therapeutic DNA into the genome and the rapidly dividing nature of many cells prevent gene therapy from achieving any long-term benefits.

- Immune response: Since gene therapy introduces a foreign object into human tissues, the immune system is stimulated in a way that can reduce gene therapy effectiveness. Furthermore, the immune system's enhanced response to known invaders makes it difficult for gene therapy to be repeated in patients.

- Problems with viral vectors: Viruses, while the carrier of choice in most gene therapy studies, present a variety of potential problems to the patient: toxicity, immune and inflammatory responses, and gene control and targeting issues.

- Multigene disorders: The best candidates for gene therapy are mutations due to single gene, whereas most conditions are multigene disorders (US DOE, 2007).

Despite these hurdles, research is ongoing and a total of 78 gene therapies are in clinical trials or pre-registration: 20 in phase I, 44 in phase II, 12 in phase III, and two in preregistration (see Table 9). Of these clinical trials, 44 target cancer, 13 target cardiovascular diseases, seven target peripheral vascular disease, four target Parkinson's disease, and all the remaining gene therapies focus on individual indications.

\section{Antisense therapy}

Antisense therapy is, "[t]he in vivo treatment of a genetic disease by blocking translation of a protein with a DNA or an RNA sequence (an oligonucleotide) that is complementary to a specific mRNA (FAO, 1999)." There is currently one antisense therapy (fomivirsen sodium) that received regulatory approval in 1998 in the United States. Developed by Isis Pharmaceuticals, the drug, administered via injection into the eyeball, was used to treat CMV retinitis which can cause blindness in people with impaired immune systems such as those with acquired immune deficiency syndrome (AIDS). The market is very small. The drug was approved for use in the European Union in 1999, but withdrawn from the market in 2002.

Antisense therapy faces several technical difficulties. As with gene therapy, the immune system can react to the introduction of a foreign antisense oligonucleotide into the body. In addition, antisense faces several other technical challenges, "including, oligonucleotide stability versus binding affinity, [and] delivery of oligonucleotides to the target cells (Tamm, Dörken, and Hartmann, 2001)." One of the reasons that formiversen may be an early entrant on the market is that delivery to the target cells was straightforward, due to direct injection into the eye.

There are currently 34 anti-sense therapies in clinical trials: ten in Phase I, 21 in Phase II, two in Phase III and one in pre-registration (see Table 9). Fourteen of the antisense therapies target cancer, five target cardiovascular diseases, three target restenosis, two target diabetes, two target human immunodeficiency virus (HIV)/AIDS and the rest target other individual indications. 


\section{RNA interference}

RNA interference (also known as RNAi, small interference RNA, or siRNA) is a, "gene-silencing process in which double-stranded RNAs trigger the destruction of specific RNAs (National Institute of General Medical Sciences, 2006)." There are currently no RNAi therapies that are approved for sale and only six RNAi drugs in clinical trials: two in Phase I, three in Phase II, and one in Phase III (see Table 9). Three RNAi therapies are aimed at treating macular degeneration, two are indicated for the treatment of infections (respiratory and hepatitis B) and one targets renal failure disease.

Though the RNAi process was only described in 1998, research on the topic has flourished (Howard, 2003). It also appears that many large pharmaceutical companies are betting that RNAi will lead to new discoveries and large pay-offs, as both Roche and Merck recently completed acquisitions and licensing agreements with specialty RNAi firms that could reach over USD 1 billion (IHT, 2007).

\section{Nanobiotechnology}

Nanotechnology is the manipulation and design of particles at the nanoscale. While there are myriad potential uses of nanotechnology in medicine, known as nanomedicine, this section refers to a subset of these health technologies, dubbed nanobiotechnology, dealing with the convergence of nanotechnology and biotechnology. Definitions in this area can be unclear, but generally nanobiotechnology is used for drug delivery and regenerative medicine. In addition, as discussed in the sections on diagnostics, some biotechnology diagnostics use nanotechnology to detect DNA sequences, proteins, etc.

Nanotechnology holds a great deal of promise as a novel drug delivery technology. This is attractive for small molecule therapeutics because it can provide more targeted distribution of active compounds, particularly in oncology, as well as solving some solubility and metabolism issues of drugs inside the body. There is also an advantage for drug developers in that a nano-formulation may extend the patent life of a drug.

These delivery technologies can also be applied to biotherapeutics and particularly some experimental therapies such as gene, anti-sense, and RNAi therapies. As noted previously, one of the challenges facing the exploitation of these experimental therapies is the immune system response to the delivery vector. Experts believe that nanoparticles may not induce such a strong immune reaction and that the minute particles may better penetrate cell walls. However despite the promise, it is not clear that nano-delivery systems will be more effective for experimental therapies than traditional delivery vectors. Furthermore, given different material properties at the nano-scale, there remain unanswered questions about potential toxicity of certain nano-materials in the body.

Due to the structural and self organising properties of some nanoparticles, in the future there may also be nano-applications for cell and tissue engineering. For example, nanobiotechnology could produce tissue scaffolds to facilitate blood flow in the body and replace failing cardiovascular tissue (NZ MoRST, 2005).

There is evidence that nanobiotechnology research is producing results. As shown in Figure 3, the number of nanotechnology patents filed for "medicine and biotechnology" applications has increased nearly 3 fold between 1995 and 2004. While it is not possible to identify the percentage of patents for nanobiotechnology applications, it seems reasonable, given known activities in the area, that the number of those patents has also increased (though perhaps not at the same rate) over the same period. 
Figure 3. Number of nanotechnology patents in "medicine and biotechnology", by year

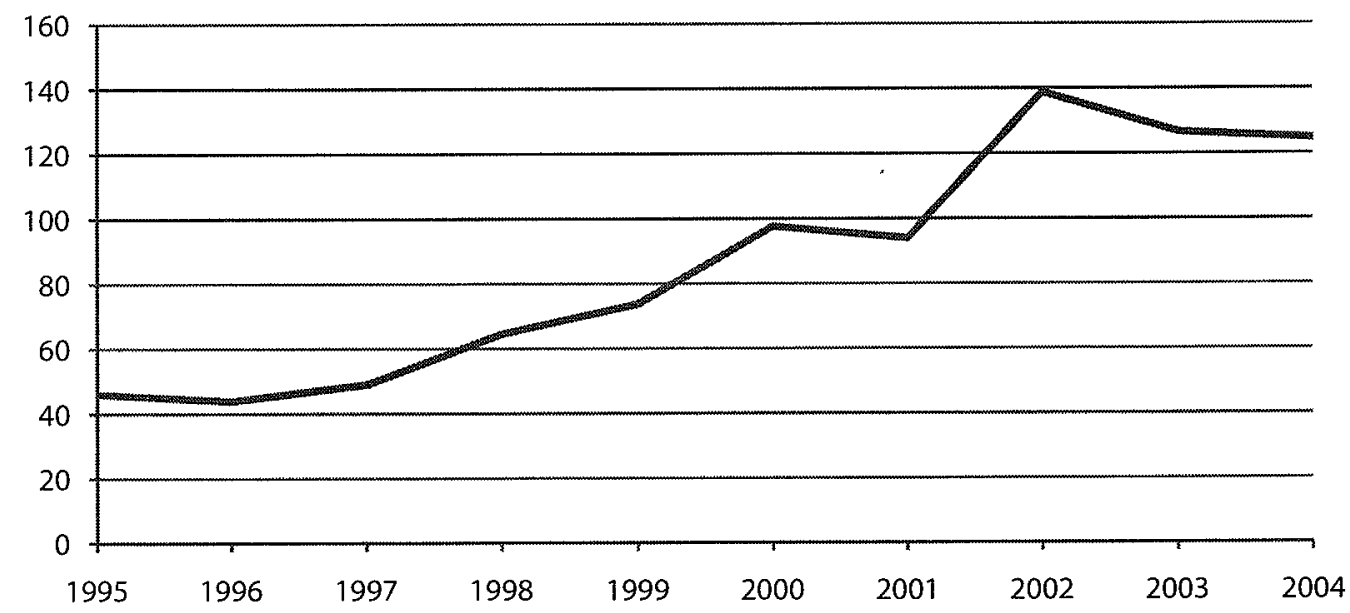

Source: Authors, based on OECD (2007b) Patent Database.

Notes: 1. Nanotechnology patents identified by tag Y01N in the European Patent Office (EPO) database EPODOC; see Scheu et al. (2006).

2. Patent applications filed under the Patent Cooperation Treaty (PCT), at international phase, designating the EPO.

3. The graph only covers countries/economies with more than 250 patents filed under PCT for the period 2002-04.

While patents are a good indicator of research activity, they do not necessarily translate into products. It is not clear if there are any nanobiotechnology products on the market to date, including therapeutics, cell or tissue engineering products that use nanotechnology. Some analysts include PEGylated biotherapeutics, involving the attachment of Polyethylene glycol strands to proteins in order to increase the metabolic half-life, under nanobiotechnology. However, including PEGylated molecules as nanotherapy products would suggest that any method to reformulate molecules to enhance their activity in the body would count as nanobiotechnology.

There is some measurable nanobiotechnology activity in the clinical trial pipeline. The Pharmaprojects database contains 66 active nanoparticle formulation drugs. ${ }^{17}$ Of these, seven are nano-formulations of biotechnology therapeutics: four are in preclinical testing, two in Phase I trials, and one in Phase II. It is not possible to determine if there are new (i.e. non-formulation) bionano-therapeutics under development.

\section{Synthetic biology}

Synthetic Biology is "the design and construction of new biological parts, devices and systems that do not exist in the natural world and also the redesign of existing biological systems to perform specific tasks (ETC Group, 2007)". Though still in its infancy, synthetic biology has caused quite a stir, with many claiming that it is the future of biotechnology and even life itself. At present, synthetic biology is confined to the research stage, with no products near the market. 
Drew Endy, a leading synthetic biology researcher, has identified four challenges that presently limit the engineering of biology:

- "an inability to avoid or manage biological complexity"

- "the tedious and unreliable construction and characterization of synthetic biological systems"

- "the apparent spontaneous physical variation of biological system behaviour"

- "evolution" (Endy, 2005)

Craig Venter, well known for his role in deciphering the human genome, is expected in the near future to announce the creation of the world's first artificial life form. Using labmade chemicals, Venter and a team of scientists have synthetically constructed a chromosome that will be inserted into a living bacterial cell and in the final stage of the process it is expected to take control of the cell and in effect become a new life form. The new organism will depend upon the existing cell for functions such as metabolism and reproduction, but the DNA will be artificial (The Guardian, 2007).

Some synthetic biologists are also working to transform biology into a traditional engineering design discipline by standardizing biological "parts" in much the same way that transistors and capacitors have been standardized for electrical and computer design. MIT has begun a library of several hundred standard biological parts (called BioBricks) that can be assembled into various biological devices (iGEM, 2007a). This could pave the way for an era in which "biodesign" can be carried out by people with expertise in systems design rather than biology.

These BioBricks facilitate the International Genetically Engineered Machine (iGEM) competition which is an arena where student teams compete to design and assemble engineered machines using advanced genetic components and technologies. Contest participants have produced systems ranging from biological thermometers and timers to photographic biofilm and biological sketch pads to bacteria that smell like wintergreen or bananas. They have also used engineered cells to intercept the body's excessive response to infection, which can lead to a fatal inflammation condition called sepsis (iGEM, 2006a, 2006b, 2007b; ScienceDaily, 2006).

The use of synthetic biology has many applications in health, notably in the areas of drug production and therapeutics.

By redesigning cells to produce various compounds, synthetic biology could lead to a way to economically mass produce drugs. The method is an advance over recombinant technology, as it redesigns a specific gene rather than transposing existing genes across species. The Bill \& Melinda Gates Foundation recently granted USD 42.6 million to the Institute for OneWorld Health (in partnership with the University of California, Berkeley, and Amyris Biotechnologies), to develop a more affordable cure for malaria. The project aims to create a new enzyme to produce artemisinin (Institute for OneWorld Health, 2004) (also see the section on "Manufacturing"). The team of scientists are working to have artemisinin ready for mass distribution in late 2009 or early 2010 (Zimmer, 2006). Other drugs, derived from expensive or limited natural sources, such as taxol (anti-cancer) and prostratin (anti-HIV) could be produced in the same manner.

Researchers are also examining the use of synthetic biological devices that can communicate with cells inside the body, detect diseases, and produce the compounds necessary to treat the sickness. This would act as, "a kind of autonomous, molecular-scale "physician" 
that can combat disease at a very early stage in its development (EC, 2005)." Similar techniques could be applied to repairing genes and tissues in the body. Furthermore, synthetic viruses could be developed that lead to treatments or cures for many diseases.

Despite the promise, it is unlikely that there will be any synthetic biology therapeutic products on the market before 2015 , as the field is still in the early research stage.

\section{Current status of small molecule therapeutics}

Small molecule drugs, usually of less than 500 Daltons in weight (Cheng et al., 2007), account for approximately $86 \%$ of all NMEs approved since 1999 and for approximately $90 \%$ of global sales of prescription drugs in 2006 (578 billion out of total sales of USD 643 billion) (IMS Health, 2007). Even with the predicted increase in large molecule biopharmaceuticals up to 2015, small molecule drugs will account for over $80 \%$ of NMEs.

The number of small molecule drugs reaching the market, based on US FDA approvals, has increased slightly since the 1980 s, but R\&D expenditures have increased far more rapidly, creating a fall in $R \& D$ productivity. ${ }^{18}$ This has been a frequent outcome for successive waves of new drug development techniques, such as the decline in the 1960s in the productivity of screening molecules produced by synthetic chemistry or extracted from natural products. Biotechnology was believed to provide new methods of drug development that would overcome the decline in R\&D productivity, but this has not happened to the extent that was originally expected with the advent of recombinant DNA drugs and mAbs (Pisano, 2006).

Biotechnological knowledge can also be applied to develop, produce, test, and manage the use of small molecule drugs. This creates opportunities to improve the productivity of small drug development. Currently, there are four relevant application areas of biotechnology for small molecules: manufacturing, drug discovery, clinical trials, and patient care.

\section{Manufacturing}

In order to be financially viable, the manufacturing costs for small molecule drugs must match market requirements. For example, production costs for a mass market drug must be low enough for the drug to be marketed at a price that will maximize sales. ${ }^{19}$ For some drugs, such as Tamiflu and the anti-malarial artemisinin, the cost of producing precursors derived from plant sources has been unacceptably high. Recombinant microorganisms have been developed to produce shikimic acid, a precursor derived from star anise for Tamiflu, and artemisinic acid, a precursor for artemisinin derived from the leaves of Artemisia annua (Ro et al., 2006) (a relative of sagebrush and wormwood). Other small molecule drugs have been produced using recombinant micro-organisms to obtain chiral forms, although chiral molecules can also be synthesized. Genetically modified (GM) bacteria have also been used to improve the characteristics of drug candidates. An example is the kinase inhibitor rapamycin. Recombinant bacteria were used to increase the potency and improve the metabolic stability of this drug candidate (GEBN, 2006).

\section{Drug discovery}

One of the most important applications of biotechnology to small molecule drugs is in the drug discovery process, particularly the identification of drug targets. The number of identified drug targets, largely due to the application of biotechnology, increased from approximately 500 in the mid 1990s to about 1500 today (Hopkins et al., 2007). 
One relevant application of biotechnology to small molecule drug discovery is the use of genomics and genetic databases, plus analytical methods such as gene transfer, gene expression profiling, and gene knock-out techniques such as RNAi, to identify human drug targets (Pisano, 2006; Hopkins et al., 2007). The same methods are also used to understand the genetics of infectious micro-organisms and parasites that cause disease, in order to identify targets for drugs to attack the organism. In addition, rDNA techniques are used to synthesize target receptors and enzymes that are used in models to search for new drugs.

Table 10 give several examples of the use of biotechnology in the discovery process for small molecule drugs.

Table 10. Use of biotechnology in small molecule (SM) drug development and therapy

\begin{tabular}{|c|c|c|c|}
\hline Main Biotechnology & Other technologies & Purpose & Effect on SM \\
\hline Genomics & $\begin{array}{l}\text { Genome mapping, mapping } \\
\text { human genetic variation, genome } \\
\text { sequence analysis }\end{array}$ & $\begin{array}{l}\text { Identify genes and variations in } \\
\text { populations }\end{array}$ & Identify drug targets \\
\hline $\begin{array}{l}\text { Gene expression profiling, } \\
\text { comparative and genetic studies } \\
\text { of model organisms }\end{array}$ & $\begin{array}{l}\text { Interference with gene expression, } \\
\text { adding genes of unknown function }\end{array}$ & $\begin{array}{l}\text { Identify genes involved in disease } \\
\text { pathways }\end{array}$ & Identify drug targets \\
\hline $\begin{array}{l}\text { Human clinical association } \\
\text { studies }\end{array}$ & $\begin{array}{l}\text { Bioinformatics, gene based } \\
\text { diagnostics }\end{array}$ & $\begin{array}{l}\text { Correlation of genomic markers } \\
\text { with clinical phenotypes }\end{array}$ & Identify drug targets \\
\hline Toxicogenomics & In vitro pharmacogenetic studies & $\begin{array}{l}\text { Study relationship between genetic } \\
\text { variation and drug response }\end{array}$ & $\begin{array}{l}\text { Improve clinical trials and } \\
\text { prescribing practice }\end{array}$ \\
\hline Pharmacogenetics & Clinical association studies & $\begin{array}{l}\text { Study relationship between genetic } \\
\text { variation and drug response }\end{array}$ & $\begin{array}{l}\text { Improve clinical trials and } \\
\text { prescribing practice }\end{array}$ \\
\hline Gene-based diagnostics & & $\begin{array}{l}\text { Identify population sub-groups that } \\
\text { respond differently to drug therapy }\end{array}$ & $\begin{array}{l}\text { Improve clinical trials and } \\
\text { prescribing practice }\end{array}$ \\
\hline
\end{tabular}

Source: Adapted from Martin, Hopkins and Nightingale (2008).

\section{Clinical trials}

Biotechnological knowledge, such as pharmacogenetics, toxicogenomics and genebased diagnoses (see Table 10) have many applications to improve the safety and efficacy of drug development and clinical trials.

Toxicogenomics is used in pre-clinical research to identify possible safety problems and consequently improve the selection of drug candidates. Pharmacogenetics can be used to stratify patients for clinical trials, with the method applied both to patients and, for infectious diseases, to the type of organism. For example, patients with a specific strain of HIV virus may not respond to drug A, but research could find that drug B will work. Pharmacogenetics applied to the patients can identify genetic differences that influence whether or not patients will respond positively to a specific drug, if they have an increased risk of adverse reactions, ${ }^{20}$ or if they metabolize drugs at a rate that requires an adjustment to the dose.

The benefits of pharmacogenetics to clinical trials are currently limited by a lack of validated genes and protein or metabolic biomarkers that can be used to identify "responding" versus "non responding" patient groups. Part of the challenge is to identify genetic factors that can accurately differentiate between responders and non-responders. 
An example is Astra Zeneca's lung cancer drug candidate Iressa (a kinase inhibitor), which failed to receive marketing approval due to a lack of effectiveness. Astra Zeneca tried to use pharmacogenetics to identify genetic factors that could identify respondent patients, but was unsuccessful. Generally, kinase inhibitors only work in a small percentage of people because of the large number of potential kinase pathways, which are also influenced by the type of tumour. In order to identify respondent patients, pharmaceutical firms need to profile both the patient and the tumours to find out which kinase pathways are active. This will require validated biomarkers (Bogdanovic and Langlands, 2006).

A second application of pharmacogenetics is to improve safety by reducing the incidence of serious adverse effects from specific drugs. This requires identifying genetic risk factors for adverse reactions.

\section{Prescribing practices}

The same uses of biotechnology to improve clinical trials also apply to post marketingapproval prescribing practices. Regulators can restrict or recommend the market approval of a specific drug for patients that have identified genes or alleles. Examples include warfarin, with the recommended dose depending on genetic differences in drug metabolism rates, the use of Herceptin (trastuzumab) to treat breast cancer (effectiveness depends on the presence of a gene to overexpress the HER2 protein), and carbamazepine, where the presence of the allele HLA-B*1502 increases the risk of serious side effects.

\section{Convergence}

The value of biotechnology for drug discovery and clinical trials for both small molecule drugs and biopharmaceuticals is leading to a convergence in the research strategies adopted by both large pharmaceutical firms such as GSK, Roche and Novartis (Emerton and Belsey, 2006), with traditional strengths in small molecule drugs, and in biotechnology firms such as Amgen and Genentech, both of which have formed alliances to improve small molecule drug discovery and development (Jarvis, 2007).

The convergence is due to synergies in the drug development process for related drug targets. For example, Genenetech developed trastuzumab (a biopharmaceutical) to target the HER2 receptor, but GSK has been able to develop a small molecule drug, Tykerb (lapatinib), that acts on the same metabolic pathway (FDA, 2007). The modes of action are not identical, as trastuzumab works on the cell wall while Tykerb works within the cell, and Tykerb has so far only been approved for women which do not respond to trastuzumab. Small molecule drugs that can act on the same target or pathway as a biopharmaceutical are attractive to firms because they can take over biopharmaceutical markets, due to being easier to use. ${ }^{21}$ Once a drug target is identified, there can be a race to find a small molecule drug with the same therapeutic effect as a biopharmaceutical. Since in-depth knowledge of the drug target improves the ability to find both biopharmaceuticals and small molecule drugs, firms that specialise in one of these two drug types have a strong incentive to build up capabilities in the other type. ${ }^{22}$ For example, Genentech used its expertise with the HER family of receptors to develop Tarceva (erlotinib), a small molecule drug for lung and pancreatic cancer.

Of note, pharmaceutical firms will continue to develop both biopharmaceuticals and small molecule drugs, as they have different advantages. Biopharmaceuticals can act as agonists that stimulate function (such as Factor VIII or insulin), while small molecules are usually antagonists that inhibit biological function. Furthermore, firms continue to focus 
on small molecules because of the ease of dose administration and because small molecules can enter cells and pass the blood/brain barrier, reaching central nervous system targets (Cheng et al., 2007).

\section{Forecasting for health therapies}

The proprietary databases Pharmaprojects and Pharmapredict include data on all preclinical studies, clinical trials, and pre-registrations of biotechnology compounds for most countries in the world. Additional information in these two databases on expected success rates from one phase to another, plus expected registration and launch times, permit forecasting of the number of biotechnology products that should reach the market by 2015 . Information is available for 1173 preclinical studies, 724 clinical trials, and 18 products in the pre-registration process.

Figure 4 gives the number of pre-registrations and clinical trials by the location of the head office of the firm that owns the bio-NME. ${ }^{23}$ Results are given for three regions: non OECD countries, the United States, and other OECD countries excluding the United States. In total, firms located in 25 identified countries have one or more bio-NMEs in clinical trials: seven non-OECD countries, the United States, and 17 other OECD countries. The lower number of Phase I than Phase II trials could be due to several Phase II trials for different indications for drug candidates that have passed Phase I and to cytotoxic drugs for cancer which can move directly from the pre-clinical stage to Phase II.

Figure 4. Active clinical trials and pre-registrations by location of the originator firm for bio-NMEs as of December 2007

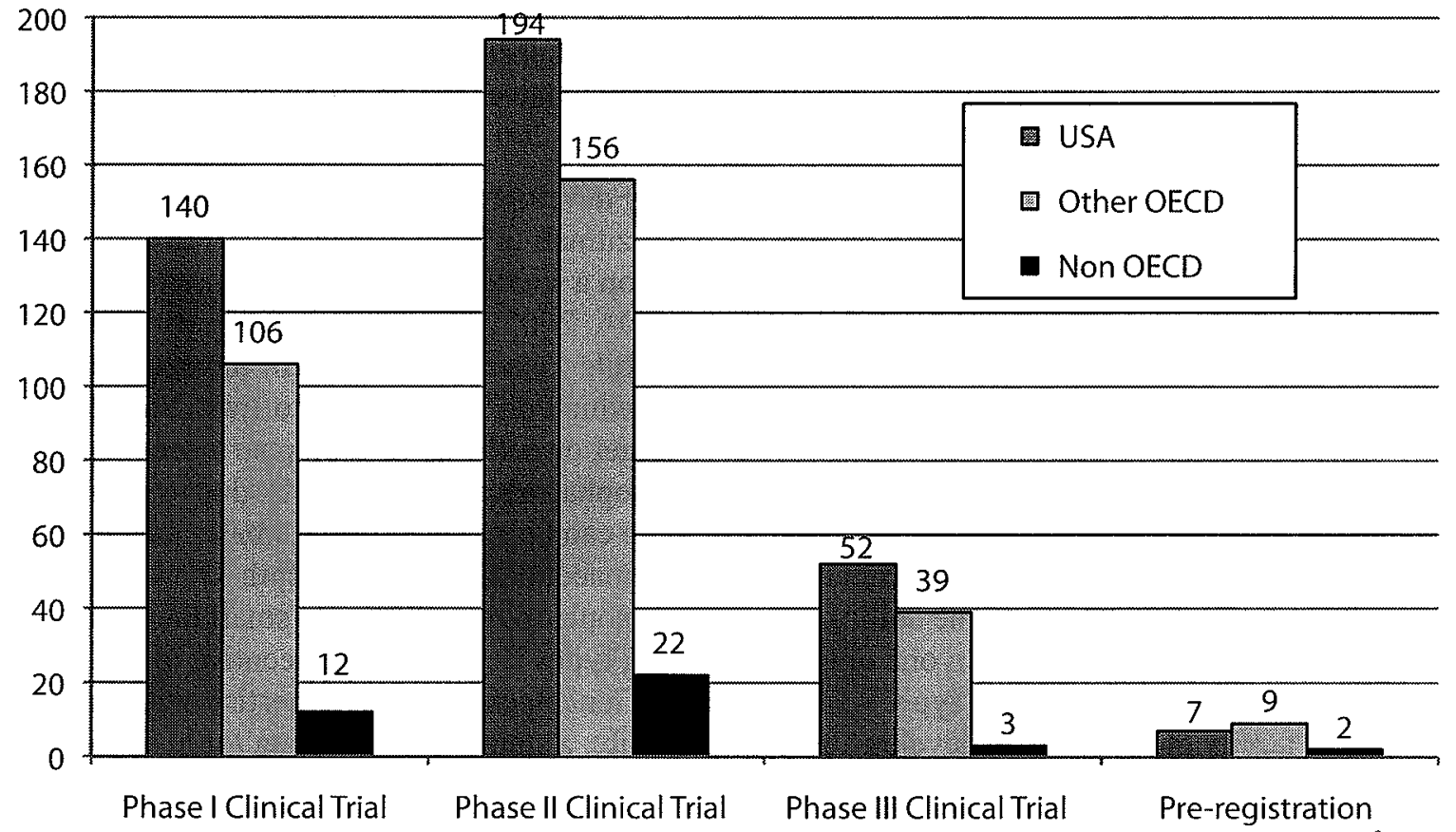

Source: Authors, based on data from Informa (2007a).

Notes: 1. See Annex A, Table 28 for full data.

2. Location is defined by the head office of the originator firm 
As shown in Figure 2, American firms developed 57.8\% of all biopharmaceuticals that reached the market after 2000. The American share of bio-NMEs in the pre-registration phase is $38.9 \%$, suggesting a short-term dip in the next few years for the American share. However, the American share of products in clinical trials is approximately $55 \%$ for phases I to III. ${ }^{24}$ This suggests that the American share of all bio-NMEs will only decline slightly over the next decade.

The major disease targets for the clinical trials consist of cancer (255 trials), infections (134 trials), cardiovascular diseases (54 trials), arthritis (28 trials), diabetes (18 trials) and asthma (11 trials).

The number of clinical trials in most countries is increasing from Phase III to Phase I, suggesting a continuing presence in biotechnology activity, whereas in other countries the pipeline is decreasing. Countries with a negative pipeline (more trials in Phase III than in Phase I) include Israel and Sweden. There are too few trials to estimate pipeline trends for Brazil, Finland, India and Malta.

Table 11 gives the type of bio-NME by phase. mAbs account for $25.1 \%$ of the total, followed by recombinant vaccines $(18.6 \%)$ and recombinant therapeutics $(15.6 \%)$. The remaining categories - experimental therapies and other - account for $40.7 \%$ of the total. A large majority of experimental therapies are in Phase II (54.6\%) or Phase I (31.5\%) trials. This indicates that there is a very strong biotechnology pipeline for these unproven or "experimental" therapies.

Research on experimental therapies is largely undertaken by small DBFs with only a few bio-NMEs in clinical trials. "Major" pharmaceutical firms (including the established biopharmaceutical firms of Amgen, Genentech and Genzyme) are defined here as firms with five or more bio-NMEs in clinical trials. ${ }^{25}$ The majors only account for 18 of the 251 $(7.2 \%)$ clinical trials or pre-registrations of experimental therapies. In comparison, the

Table 11. Types of bio-NMEs in clinical trials or pre-registration as of June 2007

\begin{tabular}{|c|c|c|c|c|c|c|}
\hline Therapy Group & Phase I & Phase II & Phase III & Pre-registration & Total & $\begin{array}{c}\text { Total share } \\
\text { of all clinical trials }\end{array}$ \\
\hline Antisense therapy & 10 & 21 & 2 & 1 & 34 & $4.6 \%$ \\
\hline Cellular therapy 1 & 12 & 37 & 6 & 2 & 57 & $7.7 \%$ \\
\hline Gene therapy & 20 & 44 & 12 & 2 & 78 & $10.5 \%$ \\
\hline Monoclonal antibody & 79 & 78 & 25 & 4 & 186 & $25.1 \%$ \\
\hline Recombinant therapeutics & 24 & 63 & 22 & 7 & 116 & $15.6 \%$ \\
\hline Recombinant vaccine & 60 & 66 & 12 & 0 & 138 & $18.6 \%$ \\
\hline RNA interference & 2 & 3 & 1 & 0 & 6 & $0.8 \%$ \\
\hline Stem cell therapy & 12 & 7 & 4 & 0 & 23 & $3.1 \%$ \\
\hline Other ${ }^{2}$ & 39 & 53 & 10 & 2 & 104 & $14.0 \%$ \\
\hline TOTAL & 258 & 372 & 94 & 18 & 742 & $100.0 \%$ \\
\hline
\end{tabular}

Source: Authors, based on data from Informa (2007a).

Notes: 1 . Non-recombinant cultured mammalian therapeutic cells other than stem cells. Includes products such as dendritic cells, pancreatic islet implants, cultured wound healing products and cultured T-lymphocytes.

2. Includes gene delivery vectors, immunoconjugates, immunotoxins (toxins conjugated with mAbs), lyctic viruses and non-antisense, non-RNAi oligonucleotides.

3. Shaded rows are experimental therapies. 
major pharmaceutical firms account for $89(25.5 \%)$ of clinical trials for proven therapies using $\mathrm{mAbs}$, recombinant vaccines and recombinant therapeutics.

The large number of small DBFs active in experimental therapies suggests that access to ample high-risk venture capital could be an essential factor. If true, the supply of venture capital in the life sciences (the leaders are Sweden, Denmark, Switzerland, Canada and the United States in that order) should be positively correlated with the national share of clinical trials in experimental therapies. However, there is no evidence to support a link between the supply of venture capital and the share of all clinical trials of biopharmaceuticals due to experimental therapies (see Table 12). There is no relationship with either the national share of GDP from venture capital investments in the life sciences or with the absolute level of venture capital for the life sciences in each country. ${ }^{26}$ This could be because biotechnology firms draw on an international pool of venture capital, or because other factors, such as the number of years since establishment, determine the types of biopharmaceuticals developed by firms.

Table 12. Share of all biotechnology clinical trials in experimental therapies, by country

\begin{tabular}{|c|c|c|c|}
\hline & All biotech clinical trials & $\begin{array}{l}\text { Biotech clinical trials in } \\
\text { experimental therapies }\end{array}$ & $\begin{array}{l}\text { Experimental therapies share } \\
\text { of all biotech clinical trials }\end{array}$ \\
\hline Australia & 14 & 5 & $35.7 \%$ \\
\hline Austria & 9 & 1 & $11.1 \%$ \\
\hline Belgium & 6 & 1 & $167 \%$ \\
\hline Bermuda & 4 & 0 & $0.0 \%$ \\
\hline Brazil & 2 & 1 & $50.0 \%$ \\
\hline Canada & 22 & 8 & $36.4 \%$ \\
\hline China & 11 & 1 & $9.1 \%$ \\
\hline Denmark & 25 & 5 & $20.0 \%$ \\
\hline Finland & 2 & 0 & $0.0 \%$ \\
\hline France & 24 & 8 & $33.3 \%$ \\
\hline Germany & 38 & 7 & $18.4 \%$ \\
\hline India & 2 & 0 & $0.0 \%$ \\
\hline Ireland & 3 & 0 & $0.0 \%$ \\
\hline |srael & 10 & 4 & $40.0 \%$ \\
\hline Italy & 14 & 4 & $28.6 \%$ \\
\hline Japan & 21 & 2 & $9.5 \%$ \\
\hline Malta & 1 & 1 & $100.0 \%$ \\
\hline Netherlands & 13 & 4 & $30.8 \%$ \\
\hline Russian Federation & 4 & 0 & $0.0 \%$ \\
\hline South Korea & 15 & 8 & $53.3 \%$ \\
\hline Spain & 1 & 1 & $100.0 \%$ \\
\hline Sweden & 6 & 1 & $16.7 \%$ \\
\hline Switzerland & 27 & 0 & $0.0 \%$ \\
\hline United Kingdom & 70 & 16 & $22.9 \%$ \\
\hline United States & 393 & 119 & $30.3 \%$ \\
\hline Total & 737 & 197 & $26.7 \%$ \\
\hline
\end{tabular}

Source: Authors, based on data from Informa (2007a)

Note: Includes drugs in clinical trial phases I, II, or III and pre-registration. 


\section{Forecasting for proven biopharmaceutical using Pharmapredict}

Using the Pharmapredict database, ${ }^{27}$ estimates were taken of the number of bio-NMEs expected to be registered between 2008 and 2018. The database gives information, by therapy group, on the number of drugs in different phases of development, success rates (the probability of reaching the market from Phase I, II and III clinical trials), and estimates (by quarter) for when they may reach the market. ${ }^{28}$

As shown in Table 13, Pharmapredict lists a total of 648 bio-NMEs in Phase I, Phase II, or Phase III clinical trials or pre-registration (Informa, 2007b). These 648 compounds were then categorized as therapeutics, vaccines, diagnostics or other. Given limitations in Pharmapredict methodologies and unavailable information, the following criteria were used to exclude some of the trials from the analysis:

- Phase I to market time was given as less than the minimum observed for Phase II to market \& Phase III to market combined ( 2.25 years).

- Phase II to market time was given as less than minimum observed for Phase III to market (2 years).

- The estimated time to market was before 2008 or after 2018.

- Trials for experimental therapies where there was insufficient historical data to predict the registration date or the success rate.

For all biotechnology products, just over $61 \%$ had suitable data (see Table 13). This ranged from approximately $34.5 \%$ for "other" products to nearly $90 \%$ of bio-vaccines. The sizeable majority (186 products, or $75 \%$ ) of the 249 products without suitable information were due to a lack of historical data for the particular biotechnology therapy (rather than an unrealistic timeline from Phase I or II to registration). Due to these exclusions, the final results underestimate the number of bio-NMEs that are likely to reach the market up to 2018 .

Pharmapredict estimates that biopharmaceuticals spend an average of seven months, and all pharmaceuticals an average of ten months, between registration and market launch. Therefore, two quarters (six months) were subtracted from the estimated launch date to arrive at an estimated registration time for biopharmaceuticals. By year of estimated registration, each product was multiplied by the historical success rate for the class of bio-NME from the phase it was in (e.g. Phase I, II, or III).

These products were then summed to produce Figure 5, which shows the number of bio-NMEs (therapeutics, vaccines, and other) expected to reach registration between 2008 and 2018. As expected given the methodology, the number of products registered decreases to near zero for all types after 2015. There are two principal reasons for this. First, preclinical trials were not included in the analysis due to the focus to 2015. Some products in

Table 13. Number and share of bio-NMEs with reliable data in Phase I-III or pre-registration

\begin{tabular}{lcccc}
\hline & Therapeutics & Vaccines & Other & All biotech \\
\hline Total compounds in trials & 432 & 129 & 87 & 648 \\
Compounds with reliable data & 253 & 116 & 30 & 399 \\
Percentage with usable data & $58.6 \%$ & $89.9 \%$ & $34.5 \%$ & $61.6 \%$ \\
\hline
\end{tabular}

Source: Authors, based on data from Informa (2007b).

Note: All results exclude formulations. 
the later stages of preclinical trials, given the approximately 11.5 year average time from preclinical to registration for bio-NMEs, may be registered around 2018. Second, as noted, many experimental products omitted from the research, due to a lack of data, would not be expected to be registered until after 2015. It is important to note that, although these estimates are based on a robust historical data set, they are unable to take into account challenges (e.g. technical, safety, or regulatory) or unexpected successes arising during individual R\&D projects. For instance, the predicted rate of 8.43 bio-NMEs reaching the market in 2008 was a small overestimate, as only 7 products reached the market.

The current estimate of the total number of bio-NMEs registrations (roughly 13 bioNMEs per year from 2008-2015) is higher than the average of eight bio-NMEs per year between 2000 and 2007 inclusive (see Annex A, Table 27 for comparative data), but within the range of past approvals per year. There were 12 bio-NMEs registered in 1998, 2001, and 2006. If this increase in bio-NME approvals occurs, however, it does not necessarily translate into a significantly increased percentage of biopharmaceuticals as a share of all pharmaceuticals, as compared to historical trends (see the following section).

\section{Forecasting the share of biopharmaceuticals out of all pharmaceuticals}

Between 2000 and 2007, biopharmaceuticals accounted for slightly more than $12 \%$ of all pharmaceuticals (OECD, 2009b). To estimate the future share of bio-NMEs out of all NMEs, the Pharmapredict database was used. The same analysis was performed on all non-bio NMEs as for bio-NMEs, with one exception. The Pharmapredict data indicate that non-bio NMEs require three months longer to move from registration to market (as opposed to two quarters for bio-NMEs). Nine months were therefore subtracted from the estimated launch date to arrive at an estimated registration time.

Figure 5. Number of bio-NMEs products expected to reach registration, by year

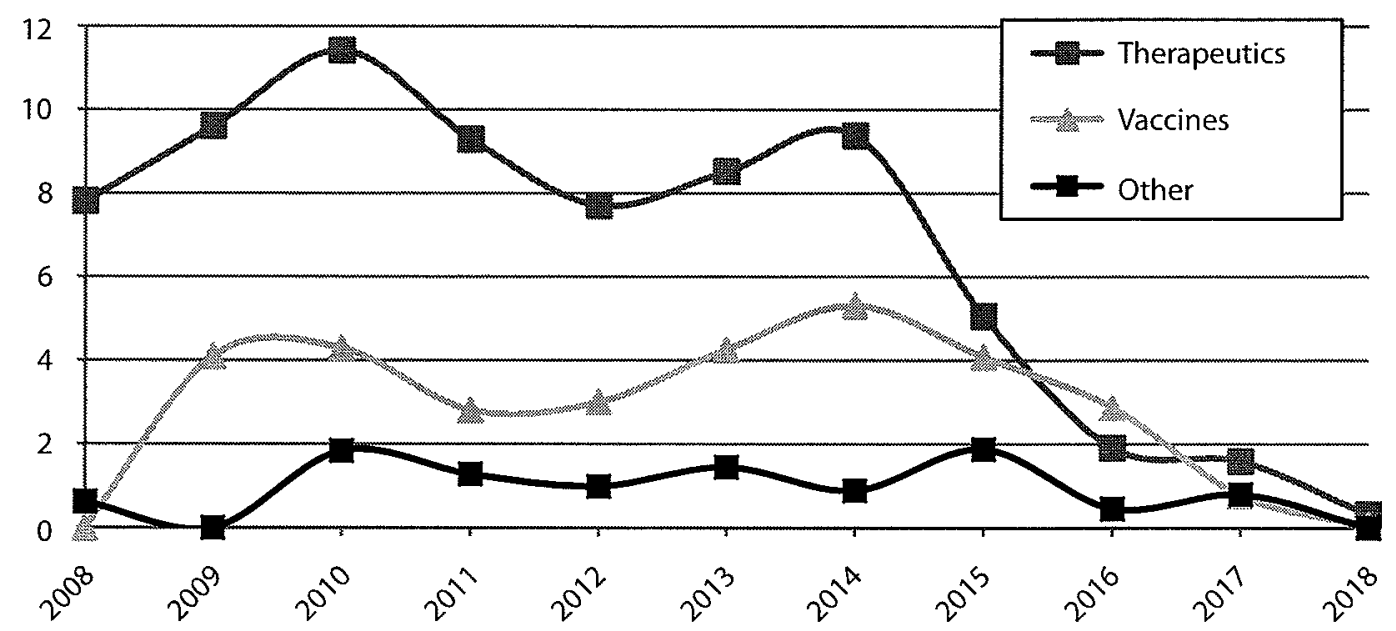

Source: Authors, based on data from Informa (2007b).

Notes: 1. All results exclude formulations.

2. Other includes gene delivery vectors, immunoconjugates, immunotoxins (toxins conjugated with $\mathrm{mAbs}$ ), lyctic viruses and non-antisense, non-RNAi oligonucleotides.

3. The steep drop off in products following 2015 is due to the methodology, and not an expected decline in biopharmaceuticals. See text for details. 
Table 14 summarizes the data used in the analysis. The same exclusion criteria were used as for bio-NMEs. A higher percentage of the data ( $85 \%$ as opposed to $62 \%$ for bioNMEs) was usable in the analysis. The lower share of useable data for bio-NMEs could underestimate the bio-NME share in the future by up to 6 percentage points if the success rate for experimental biotherapies (the major cause of a lack of useable data) quickly approaches the average for other types of bio-NMEs (this is very unlikely). ${ }^{29}$ As with the estimates for bio-NMEs, the reliable data were multiplied by the historical success rate for the relevant class of NME (e.g. anticancer, anti-infective, cardiovascular) by phase (e.g. Phase I, II, or III).

Table 14. Number and share of Non-bio NMEs with reliable data in Phase I-III or Pre-registration

\begin{tabular}{lccccc}
\hline & Phase I & Phase II & Phase III & Pre-registration & Total \\
\hline Total compounds in trials & 778 & 923 & 215 & 58 & 1974 \\
Compounds with reliable data & 715 & 766 & 164 & 37 & 1682 \\
Percentage with usable data & $91.9 \%$ & $83.0 \%$ & $76.3 \%$ & $63.8 \%$ & $85.2 \%$ \\
\hline
\end{tabular}

The results of the analysis are presented in Figure 6, which includes historical data up to 2007. While the share of biopharmaceuticals increases to $2010-2011$, this should decrease to near historical levels afterwards. These results provide no evidence for a large surge in biotechnology drugs, or in the share of biotechnology drugs out of all drugs in the coming 5 to 10 years. Instead, the share of biotechnology drugs appears to be increasing gradually, as shown by the trendline in Figure 6 .

Figure 6. Observed (1989-2007) and Forecast (2008-2015) share of total biopharmaceuticals out of total pharmaceuticals ( 3 year running average), by year of first registration

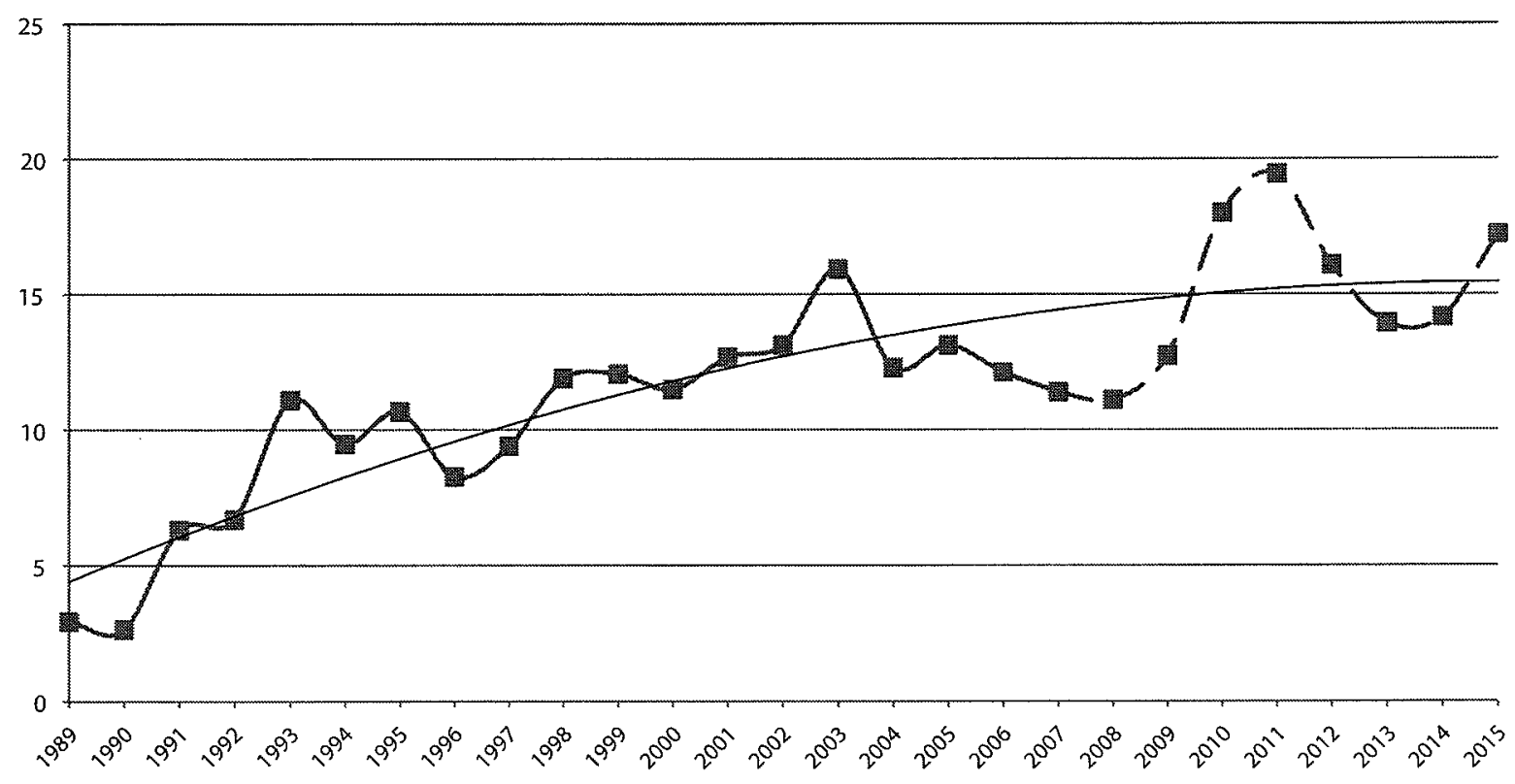

Source: Authors, based on Informa (2007a, 2007b).

Note: See Annex A, Table 27 for full information on the observed data and Annex A, Table 30 for projected data. 
The only factors that could cause a significant change in biotech's share of all pharmaceuticals are either an increase in the success rate or a significant decrease in development time, as compared to non-bio-NMEs.

Although the biopharmaceutical share of all pharmaceuticals will probably remain relatively constant or only increase gradually in the foreseeable future, the real variable of interest is the effect of future biopharmaceuticals on public health. This is not possible to determine, but the HAS and Prescrire evaluations for therapeutic value (see Tables 4 and 5) show that biopharmaceuticals offer greater therapeutic value than other pharmaceuticals. The large number of experimental biopharmaceuticals, offering new modes of action, suggests that the future stream of biopharmaceuticals should provide substantial therapeutic advantages over existing therapies.

\section{Forecasting for experimental therapies}

It is impossible to generate an accurate historical success rate for experimental therapies because there are very few of these products on the market. Assuming, however, that development times and success rates in these areas will roughly mirror that of more established biotherapeutics, some products currently in Phase II and Phase III clinical trials could reach the market before 2015. The probability of this occurring would increase both as technical problems related to delivery and safety are overcome, and as more products come to market allowing regulatory agencies to gain more experience in the approval of such products.

\section{Cell and tissue engineering forecasting}

There are a number of cell and tissue engineering products in phase II (37) and III (6) clinical trials and two in pre-registration. Given the relatively large number of these products already on the market, several additional products should appear on the market by 2015 . It is also possible that a number of non-invasive tissue engineering products, such as wound coverings, will be marketed by 2015 .

\section{Stem cell forecasting}

Almost all of the stem cell trials in phase II or phase III (and therefore with a reasonable chance of reaching the market by 2015) use adult stem cells and are aimed at regenerating bodily tissue, similar to the one stem cell product already on the market. The other four are aimed at heart related diseases such as ischaemia and myocardial infarction.

Further research into the manipulation and use of embryonic stem cells could conceivably produce large therapeutic advances. However, even if rapid and successful development occurs, most of these products would arrive on the market after 2015 unless obvious efficacy and safety was apparent. In addition, recent advancements that can turn skin cells into cells behaving like embryonic stem cells may help skirt ethical concerns related to the destruction of embryonic stem cells and encourage further research in the area.

\section{Gene therapy forecasting}

Many experts believe that gene therapy will play a significant role in future medical treatment. A report by the Japanese National Institute of Science and Technology Policy (NISTEP, 2005) predicted that gene therapy for localized atheroclerotic lesions will be available in 2015 with gene therapies for familial hypercholesterolemia, diabetes mellitus, and cancer following in 2016 to 2018 (NISTEP, 2005). Given the strong research pipeline 
for gene therapies (there are 44 gene therapies in Phase II, 12 in Phase III, and two in preregistration) this may prove true, but historically, with the exception of China, these treatments have been totally unsuccessful in receiving regulatory approval.

\section{Antisense therapy forecasting}

In 2000 , shortly after the release of the first and only antisense drug on the market, a report predicted that, " $[t]$ he target year for antisense therapeutics achieving their remaining potential is 2010, although some among them may actually realise their potential earlier (Jain, 2000)." Presently, this forecast appears rather optimistic since no other anti-sense therapies have been approved, and none of the antisense therapies are beyond phase II clinical trials. This would indicate, given an average of 55 months from the start of phase III trials to market entry for biotech products, ${ }^{30}$ that few, if any anti-sense drugs will reach the market prior to 2010 .

\section{RNA interference forecasting}

Given the relative newness of RNAi technology, there has been a great deal of activity in the area. With one product in Phase III trials and three in Phase II trials, it is conceivable that some products may receive regulatory approval by 2015. If this is indeed the case, a significant increase in RNAi therapies in clinical trials would be likely.

\section{Nanobiotechnology forecasting}

Analysts anticipate that the nanomedicine market will experience strong growth to 2015; however estimates of the actual size vary greatly due to measurement and definitional challenges. One study predicts the nanomedicine market to grow to USD 53 billion in 2011 and continue increasing to USD 110 billion in 2016, of which pharmaceuticals, diagnostics, and medical supplies and devices will make up USD 82 billion, USD 12.3 billion, and USD 16.2 billion, respectively (Global Information, 2007). Another study estimates the market to be much smaller, estimating that the combined market for nanotechnology in the life sciences (including environmental sciences and agriculture) will reach only USD 3.4 billion by $2010,60 \%$ of which will be in medical applications (BCC Research, 2005a). Neither of these estimates identifies the nanobiotech share, but it is likely that the segment will also experience strong growth over the same period.

Given the small number of products in clinical trials and the average timescale needed to reach the market from clinical trials ( 7.5 years from end-phase I and 4.5 years from end-phase II), it is very unlikely that there will be more than one, or possibly two, nanoformulations of biotechnology therapeutics arriving on the market by 2015. Even this is highly dependent on the success of the three products in clinical trials at present and with immature regulatory guidelines for nanobiotech products, this is doubtful. There may be some other non-formulated nanobiotherapuetics reaching the market, but, this is unlikely to be a large number, and it is impossible to give an accurate estimate due to lack of data.

\section{Synthetic biology}

Synthetic biology is a new area of research and, at present, no products have even reached clinical trials. It is therefore very unlikely that any synthetic biology therapeutic will reach the market by 2015. A more likely outcome is that a few drugs, in part based on synthetic biology principles, could be "pharmed" from synthetic cells and available as soon as 2009 or 2010 (Zimmer, 2006). An example is artemisinin. 


\section{Forecasting for small molecule therapeutics}

There are no databases that provide data on the use of biotechnology in the manufacture, discovery, clinical trials, or prescribing patterns for small molecule drugs. Consequently, it would be very difficult to accurately predict the effect of biotechnology on the development of small molecule drugs up to 2015. The only available information is from interviews with pharmaceutical firm executives or from small surveys.

An unpublished German survey of biotechnology firms in 2006 found that $27 \%$ of firms active in the health sector were using biotechnology for target validation for NCEs in development and 33\% were using biotechnology for target validation for diagnostics development. The results cover both diagnostic and pharmaceutical firms combined, so the actual percentage when limited to pharmaceutical firms alone is likely to be much higher. ${ }^{31}$

Interviews by Michael Hopkins with three large pharmaceutical firms found a range in approaches to the use of biotechnology in small molecule drug development. An executive from one firm commented that "Everything in the pipeline is touched by genomics one way or another", although some of the products could have still been developed without the use of genomics. One of the other firms is using biotechnology in small molecule development, but has so far invested less in its use.

Due to a lack of consistent information, it is impossible to forecast the percentage of small molecule drugs that will receive market approval, between 2007 and 2015, for which biotechnology was used in manufacturing, drug development, or clinical trials. Nevertheless, biotechnology is very likely to be increasingly used somewhere in the development process for almost all NMEs. At some point in the near future, the current division between biotechnology firms and biotechnology drugs, and other firms and other types of drugs, is likely to become meaningless, with biotechnology playing a significant role in the development of all drugs. At this point all value added in the pharmaceutical sector will be partially dependent on biotechnological knowledge.

\section{Potential}

Biopharmaceuticals will not account for $100 \%$ of pharmaceuticals by 2015 or even by 2030 , due to the ongoing production of both generic and new small molecule drugs. Consequently, biopharmaceuticals will not account for $100 \%$ of employment or revenues in the pharmaceutical sector. However, the rapid increase in the use of biotechnological knowledge in small molecule drug development suggests that the "pharmaceutical" sector by 2030 will more accurately be described as the "biopharmaceutical" sector.

An alternative non-economic measure of the potential of biotechnology is to assess its impact on public health. One method is to estimate the target population of people with diseases that are treatable with current biopharmaceuticals or which could be treated with biopharmaceuticals that are expected to reach the market by 2015. This section provides some preliminary results for current treatments.

Table 15 gives the rate for specific diseases that are already treatable using biopharmaceuticals on the market plus an estimate of the potential population of patients in Australia, Canada, Japan, the United States, and the 25 member states of the European Union in 2003, with a total population of 960 million in 2003 . The estimates are limited to these countries because of data availability and because these countries have the financial resources to pay for biopharmaceuticals. The estimates in bold are for chronic diseases and are based on prevalence rates, while the estimates in italics are for diseases that are treated over the short term and are based on incidence rates. 
The largest market for biopharmaceuticals for chronic diseases is for Type II diabetes, with an estimated 56.5 million patients, followed by asthma with 54.8 million. The chronic diseases include a number of rare orphan diseases with less than 100000 patients.

Biopharmaceuticals are frequently not the first line treatment for many of the chronic diseases listed in Table 15, such as Type II diabetes, asthma, psoriasis, and rheumatoid arthritis, nor for many acute diseases, including cancer. Consequently, the actual population of potential patients will be much lower than the total populations listed in the table. Nevertheless the results highlight the range of available treatments using biopharmaceuticals and their success in treating several severe orphan diseases.

Table 15. Number of patients potentially treatable with biopharmaceuticals

\begin{tabular}{|c|c|c|}
\hline \multirow[b]{2}{*}{ Diseases } & \multicolumn{2}{|c|}{ Number of patients in selected developed countries } \\
\hline & Number in thousands & Rate per 1000 population \\
\hline Diabetes, Type II $^{1}$ & 56492.9 & 58.80 \\
\hline Asthma1 & 54763.5 & 57.00 \\
\hline Age-related Macular degeneration 1 & 35548.2 & 37.00 \\
\hline Osteoporosis! & 35327.3 & 36.77 \\
\hline Infarction, myocardial 1 & 26690.0 & 27.78 \\
\hline Infertility 1 & 21809.3 & 22.70 \\
\hline Psoriasis 1,7 & 14613.2 & 15.21 \\
\hline Anaemia, general 1,8 & 14.401 .8 & 14.99 \\
\hline Arthritis; rheumatoid 1 & 8896.7 & 9.26 \\
\hline Virus, hepatitis-C1 & 7.061 .6 & 7.35 \\
\hline Virus, hepatitis-B1 & 5313.0 & 5.53 \\
\hline Foot Ulcer, diabetic ${ }^{2}$ & 4784.6 & 4.98 \\
\hline Crohn's disease ${ }^{1}$ & 1767.8 & 1.84 \\
\hline Multiple sclerosis, relapsing-remitting ${ }^{1}$ & 1373.9 & 1.43 \\
\hline Ankylosing spondylitis 1 & 1.239 .4 & 1.29 \\
\hline Hypoglycemia ${ }^{1}$ & 960.8 & 1.00 \\
\hline Thrombosis, deep vein 6 & 768.6 & 0.80 \\
\hline Cancer, Breast ${ }^{1}$ & 720.6 & 0.75 \\
\hline Angina, unstable ${ }^{2}$ & 576.5 & 0.60 \\
\hline Virus, cytomegalovirus² & 384.3 & 0.40 \\
\hline Lyme disease 1 & 355.5 & 0.37 \\
\hline Arthritis, rheumatoid, juvenile ${ }^{3}$ & 240.2 & 0.25 \\
\hline Cancer, Lymphoma ${ }^{1}$ & 211.4 & 0.22 \\
\hline Cancer, Lymphoma, non-Hodgkin`s 1 & 192.2 & 0.20 \\
\hline Cancer, Melanoma ${ }^{1}$ & 192.2 & 0.20 \\
\hline Diabetes, Type |1 & 124.9 & 0.13 \\
\hline Cancer, Kidney ${ }^{1}$ & 115.3 & 0.12 \\
\hline Cancer, Leukemia 1 & 105.7 & 0.11 \\
\hline Prader-Willi Syndrome ${ }^{1,3}$ & 85.5 & 0.089 \\
\hline Cancer, Thyroid ${ }^{1}$ & 73.0 & 0.076 \\
\hline Hemophilia 1 & 71.1 & 0.074 \\
\hline Cystic fibrosis 1,3 & 69.2 & 0.072 \\
\hline Cervical dystonia 2 & 54.8 & 0.057 \\
\hline Cancer, Myeloma ${ }^{1}$ & 52.8 & 0.055 \\
\hline
\end{tabular}




\section{Table 15. Number of patients potentially treatable with biopharmaceuticals (continued)}

\begin{tabular}{|c|c|c|}
\hline Thrombocytopenia, general ${ }^{1}$ & 52.8 & 0.055 \\
\hline Acromegaly ${ }^{9}$ & 48.0 & 0.050 \\
\hline Growth hormone deficiency ${ }^{1}$ & 44.2 & 0.046 \\
\hline Pompe's disease ${ }^{5}$ & 24.0 & 0.025 \\
\hline Fabry's disease 4 & 17.3 & 0.018 \\
\hline Cancer, Kaposi's sarcoma ${ }^{3}$ & 16.3 & 0.017 \\
\hline Gaucher's disease type $1^{\dagger}$ & 12.5 & 0.013 \\
\hline Colitis, ulcerative ${ }^{1}$ & 11.5 & 0.012 \\
\hline Osteopetrosis, malignant ${ }^{3}$ & 7.2 & 0.0075 \\
\hline Mucopolysaccharidosis type It & 4.3 & 0.0045 \\
\hline Mucopolysaccharidosis type $\mathrm{VI}^{3}$ & 1.5 & 0.0016 \\
\hline Chronic granulomatous disease ${ }^{1}$ & 1.1 & 0.0011 \\
\hline
\end{tabular}

Sources: 1. www:wrongdiagnosis.com 2 2. www clinicalevidence.com $\quad 3$. www orphanet
4. www.ec.europa.eu
5. www.rarediseases.org
6. www.emedicine.com
7. www.fda.gov
8. www.who.int
9. www.pituitary.org.uk

Note: Shaded rows are prevalence rates and non-shaded rows are incidence rates. See www.wrongdiagnosis.com.

\section{Health therapy summary}

Table 16 summarizes the main developments in health therapies that are expected by 2015 .

Table 16. Main short-term trends in biopharmaceuticals to 2015

\begin{tabular}{|c|c|}
\hline & Forecast outcomes \\
\hline Employment & $\begin{array}{l}\text { Current pharmaceutical employment of } 1.43 \text { million in the OECD is likely to continue to decline slowly. } \\
\text { Biotechnology will increasingly have a significant effect on pharmaceutical employment due to its use in the manu- } \\
\text { facture, development and prescribing practices for small molecule drugs. }\end{array}$ \\
\hline \multirow[t]{3}{*}{ New pharmaceuticals } & $\begin{array}{l}\text { Between } 1998 \text { and } 2007 \text {, biopharmaceuticals accounted for approximately } 12.6 \% \text { of all NMEs receiving market } \\
\text { approval. This could increase to an average of } 14.8 \% \text { between } 2008 \text { and } 2015 \text {. }\end{array}$ \\
\hline & $\begin{array}{l}\text { In absolute terms, the number of NME biopharmaceuticals that obtain market approval should increase from an } \\
\text { average of } 8 \text { per year between } 2000 \text { and } 2007 \text { to } 13 \text { per year between } 2008 \text { and } 2015 \text {. } \\
\text { There is a very strong pipeline for experimental biopharmaceuticals, with most of these compounds in Phase I } \\
(28 \%) \text { or Phase II }(57 \%) \text { clinical trials, but these therapies are likely to have low success rates. }\end{array}$ \\
\hline & $\begin{array}{l}\text { The main disease targets for future biopharmaceuticals are cancer ( } 34.8 \% \text { of clinical trials) and infections } \\
\text { (18.2\% of clinical trials). }\end{array}$ \\
\hline Biotechnology "advantage" & $\begin{array}{l}\text { A higher share of biopharmaceuticals than small molecule therapeutics offers a significant therapeutic advance } \\
\text { over existing therapies. Although the biopharmaceutical "advantage" has declined since } 2000 \text {, new experimental } \\
\text { therapies in clinical trials could improve future therapeutic performance. }\end{array}$ \\
\hline American dominance & $\begin{array}{l}\text { American pharmaceutical firms developed } 59 \% \text { of all biopharmaceuticals between } 2000 \text { and } 2007 \text {. This share is } \\
\text { expected to fall slightly to } 54 \% \text { between } 2008 \text { and } 2015 \text {. }\end{array}$ \\
\hline Small molecule drugs & $\begin{array}{l}\text { By } 2015 \text { the majority of small molecule drugs in development are likely to depend, in part, on the use of biotechnol- } \\
\text { ogy for discovery (particularly for target identification), to improve the efficiency of clinical trials (application of phar- } \\
\text { macogenetics for safety), or to affect prescribing practices. The widespread use of pharmacogenetics to identify } \\
\text { respondent and non respondent subgroups in clinical trials is unlikely to occur before } 2015 \text {. }\end{array}$ \\
\hline Experimental therapies & $\begin{array}{l}\text { Experimental therapies include cell and tissue engineering, stem cells, gene therapies, antisense, RNAi, nanobio- } \\
\text { technology (drug delivery) and synthetic biology. Several new tissue engineering products are expected to reach } \\
\text { the market by } 2015 \text {, but most other experimental therapies are likely to produce only a few products that reach the } \\
\text { market by this date (gene therapy, approved drugs manufactured using synthetic biology) or no products (antisense, } \\
\text { RNAi, nanobiotechnology). }\end{array}$ \\
\hline
\end{tabular}




\section{Diagnostics, bioinformatics, and pharmacogenetics}

\section{Current status of diagnostics}

Biotechnology, in addition to being used to develop therapeutics, has made substantial contributions to diagnostics. ${ }^{32}$ Biotechnology based diagnostics are used to identify both genetic and non-genetic diseases. Diagnostics can be either in vivo (invasive and inserted into the body), in which case they are closely regulated through clinical trials, or in vitro (non-invasive) in which case the regulatory requirements are often considerably less demanding.

\section{In-vivo diagnostics}

In-vivo diagnostics require the, "insertion of a substance (like a contrast medium) into the body through the skin or a body orifice (Universidad de Grenada, 2001)." Tests detect pathogenic agents or antibodies to diagnose infectious diseases. Other tests can distinguish cancer cells from normal cells.

Thirteen biotechnology in-vivo diagnostics have been registered or obtained market approval and eleven are in clinical trials (see Table 17). Of the thirteen approved or registered products, eleven were originated by American companies and three by a Cuban institute (Center of Molecular Immunology). Eight of the approved in-vivo products are for the diagnosis of cancer, two for coronary functions, and the others for diabetes, hypoglycaemia and infection.

Originators of diagnostic trials come from a wide geographic range. Four of the ten trials are being undertaken by American companies, three by British firms, one by Danish, one by Brazilian and one by a Japanese enterprise. Of those in clinical trials, seven are in preclinical phase, two are in phase I and one is in phase II. The vast majority of the in-vivo diagnostics in clinical trials aim at detecting cancer.

\section{In-vitro diagnostics}

In-vitro diagnostics (IVD) include any diagnostic procedure which is conducted outside of the body. In general, there are two main types of biotechnology-based in vitro diagnostic tests: immunological (based on the specificity of antibodies to bind to a target molecule) and molecular genetic (based on the binding properties of similar gene sequences). Antibodies specific to a very wide range of molecules can be generated and used to detect signs of diseases or to detect foreign substances in a variety of human fluids, such as blood or urine. A well-known immunological test uses mAbs to detect a hormone in a woman's urine to determine if she is pregnant. 
Table 17. List of biotechnology-based in-vivo diagnostics - as of March 2008

\begin{tabular}{|c|c|c|c|}
\hline Scientific name & Developer company & Country & Diagnosis \\
\hline \multicolumn{4}{|c|}{ Ditgnostics Wint narket approval or registration } \\
\hline arcitumomab & Immunomedics & USA & Diagnosis, cancer \\
\hline capromab pendetide & Cytogen & USA & Diagnosis, cancer \\
\hline glucagon, Lilly & Eli Lilly & USA & Diabetes, general \\
\hline glucagon, ZymoGenetics & ZymoGenetics & USA & Hypoglycaemia \\
\hline Tc $99 \mathrm{~m}$ votumumab & Intracel & USA & Diagnosis, cancer \\
\hline ibritumomab tiuxetan & Biogen Idec & USA & $\begin{array}{l}\text { Cancer, lymphoma, } \\
\text { non-Hodgkin's }\end{array}$ \\
\hline imciromab & Centocor & USA & Diagnosis, coronary \\
\hline ior-cea1 & Center of Molecular Immunology & Cuba & Diagnosis, cancer \\
\hline ior-egf/r3 & Center of Molecular Immunology & Cuba & Diagnosis, cancer \\
\hline satumomab pendetide & Cytogen & USA & Diagnosis, cancer \\
\hline sulesomab & Immunomedics & USA & Diagnosis, infection \\
\hline thyrotropin alfa & Genzyme & USA & Diagnosis, cancer \\
\hline nimotuzumab & Center of Molecular Immunology & Cuba & Diagnosis, cancer \\
\hline Diagnostics in clinical thils. & Oliginator company & & \\
\hline \multicolumn{4}{|l|}{ Preclinical phase } \\
\hline AGT-100 & ArmaGen Technologies & USA & Diagnosis, CNS \\
\hline anti-TEM7 MAb, Kirin & Kirin Pharma & Japan & Unspecified \\
\hline COU-1 antibody, Natlmmune & Natlmmune & Denmark & Diagnosis, cancer \\
\hline HuHap-1/78, Wyeth & Wyeth & USA & Diagnosis, hepatic \\
\hline MFECP1 & Cancer Research Technology & UK & Cancer, general \\
\hline MUC-1 aptamers & Cancer Research Technology & UK & Unspecified \\
\hline TAPET vectors & Vion Pharmaceuticals & USA & Unspecified \\
\hline \multicolumn{4}{|l|}{ Phasel } \\
\hline hu3\$193 & Recepta biopharma & Brazil & Cancer, colorectal \\
\hline SM3 & Cancer Research Technology & UK & Diagnosis, cancer \\
\hline \multicolumn{4}{|l|}{ Phase II } \\
\hline depelestat & Dyax & USA & Cystic fibrosis \\
\hline
\end{tabular}

Source: Authors, based on Informa (2007a).

Note: Some of the diagnostics listed have therapeutics uses as well.

Genetic tests can identify specific genes and determine the presence or absence of mutations or other changes in an individual's genetic material. Genetic testing can yield information in a wide variety of circumstances from pre-implantation screening of embryos during in vitro fertilization (IVF), screening of foetuses, or of children or adults to diagnose genetic conditions, to identify a person's risk profile for developing or passing on certain medical conditions, or even to detect infectious agents such as the Human Papilloma Virus. Genetic tests are increasingly being developed to detect variations in several genes at once. For example, a diagnostic test for seven genes has recently been developed to assess the risk of common forms of breast cancer (deCODE, 2008). 
Table 18 lists some examples of genetic and immunological diagnostic technologies using modern biotechnology.

Unlike in-vivo diagnostics which are closely regulated, IVD regulation is considerably less demanding because they are not traditionally seen as damaging to health. Without such stringent registration guidelines, it is difficult to know the exact number of IVD products using biotechnology, but estimates do exist.

Table 18. Examples of diagnostic techniques using modern biotechnology

\begin{tabular}{|c|c|c|}
\hline Type of Technology & Technique & $\begin{array}{l}\text { Example(s) of diagnosis/ } \\
\text { risk factor }\end{array}$ \\
\hline Genentigtasts & 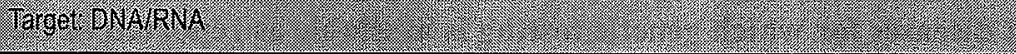 & \\
\hline Blotting methods 2,4 & $\begin{array}{l}\text { Identifies similar macromolecules, e.g. sets of DNA or RNA fragments, that are separable } \\
\text { by gel electrophoresis. }\end{array}$ & $\begin{array}{l}\text { Anaemia } \\
\text { Huntington's disease }\end{array}$ \\
\hline DNA methylation ${ }^{4}$ & $\begin{array}{l}\text { Measures the amounts of } 5 \text {-methylcytosine which arises from the methylation of cytosine } \\
\text { bases. The methylation status of DNA corresponds to its functional status. }\end{array}$ & Cancer \\
\hline DNA microarray ${ }^{4}$ & $\begin{array}{l}\text { A glass slide or bead containing microscopic DNA samples in an orderly pattern are treated } \\
\text { with complimentary-DNA and used to detect the relative expression level of each gene. }\end{array}$ & Cancer \\
\hline $\begin{array}{l}\text { Fluorescent } \ln \text { Situ } \\
\text { Hybridization } 4\end{array}$ & $\begin{array}{l}\text { A procedure involving the use of fluorescent DNA probes to locate in a tissue section } \\
\text { specific regions of DNA in the chromosomes. }\end{array}$ & $\begin{array}{l}\text { Williams-Beuren } \\
\text { syndrome }\end{array}$ \\
\hline Nuclear probes ${ }^{4}$ & $\begin{array}{l}\text { A procedure involving the use of radioisotope labelled oligo- or polynucleotide to detect } \\
\text { complementary sequences. }\end{array}$ & $\begin{array}{l}\text { Cancer } \\
\text { Lymphoma of Burkitt }\end{array}$ \\
\hline $\begin{array}{l}\text { Polymerase Chain } \\
\text { Reaction }(\mathrm{PCR})^{4}\end{array}$ & $\begin{array}{l}\text { A specific sequence of nucleotides within a double-stranded DNA is amplified to test for } \\
\text { disease and detect rare mutations. }\end{array}$ & $\begin{array}{l}\text { Anaemia } \\
\text { Infectious diseases } \\
\text { Huntington's disease } \\
\text { AIDS/HIV }\end{array}$ \\
\hline Mnuno-diagnostics & Target froens anibody. anligens. & \\
\hline Blotting methods 3,4 & $\begin{array}{l}\text { Identifies similar macromolecules, e.g. mixtures of intact proteins, that are separable by gel } \\
\text { electrophoresis. }\end{array}$ & $\begin{array}{l}\text { Hepatitis } \\
\text { Infectious diseases } \\
\text { AIDS/HIV }\end{array}$ \\
\hline $\begin{array}{l}\text { Enzyme-Linked } \\
\text { ImmunoSorbent } \\
\text { Assay }\end{array}$ & $\begin{array}{l}\text { The measurement of specific biochemical substances that depends upon the specificity } \\
\text { and high affinity shown by suitable antibodies for their complimentary antigens, which are } \\
\text { labelled with an enzyme as an indicator. }\end{array}$ & $\begin{array}{l}\text { Prostate cancer Infertility } \\
\text { Infectious diseases } \\
\text { AIDS/HIV }\end{array}$ \\
\hline Imaging agents 5 & $\begin{array}{l}\text { The production of an image of all or part of the body to examine gene expression or } \\
\text { proteomic data. }\end{array}$ & Cancer \\
\hline $\begin{array}{l}\text { Indirect Immuno- } \\
\text { Fluorescence Assay }{ }^{4}\end{array}$ & $\begin{array}{l}\text { An antigen or antibody is made fluorescent by conjugation to a fluorescent dye and then } \\
\text { allowed to react with its complimentary antibody or antigen in a sample. }\end{array}$ & Lyme disease \\
\hline $\begin{array}{l}\text { Monoclonal } \\
\text { antibodies }^{6}\end{array}$ & $\begin{array}{l}\text { Detect particular antigens by analyzing the immunoglobulin secreted by a single clone of } \\
\text { antibody producing cells which are only able to react with a single specified antigen. }\end{array}$ & $\begin{array}{l}\text { Rheumatoid } \\
\text { Arthritis } \\
\text { Cancer } \\
\text { Hepatitis } \\
\text { Diabetes type I }\end{array}$ \\
\hline $\begin{array}{l}\text { Radioimmuno- } \\
\text { precipitation }\end{array}$ & $\begin{array}{l}\text { Precipitates a protein out of a mixture by reaction with a specific radioisotope labelled } \\
\text { antibody or antigen. }\end{array}$ & AIDS/HIV \\
\hline
\end{tabular}

Source: Authors, with definitions adapted from the Oxford (2007).

Notes: 1. The list of "example(s) of diagnosis/risk factor" is not exhaustive.

2. Blotting methods in genetic testing are southern blot and northern blot.

3. Blotting methods in immunodiagnostics are western blot, south-western blot and far western blot.

4. In-vitro diagnostic technique.

5. In-vivo diagnostic technique.

6. Can be both an in-vivo and an in-vitro diagnostic technique. 
As shown in Figure 7, genetic tests are available for over 1600 diseases according to GeneTests (2008). Submissions to GeneTests are voluntary. This means that the catalogue might not include all genetic tests available worldwide, although it does provide a lower limit of the number of diseases for which genetic testing is available. Many of these tests target single genes that are linked to rare diseases. Other tests identify genetic risk factors for several diseases with a high frequency, such as cancer, AIDS/HIV or anaemia.

The use of genetic tests is also increasing rapidly. An OECD survey of 1306 genetic testing laboratories found that the number of genetic tests performed increased by $60.2 \%$, from 874608 in 2000 to 1401536 in 2002 (OECD, 2007c).

Figure 7. Number of diseases for which genetic testing is available as reported to GeneTests, by year

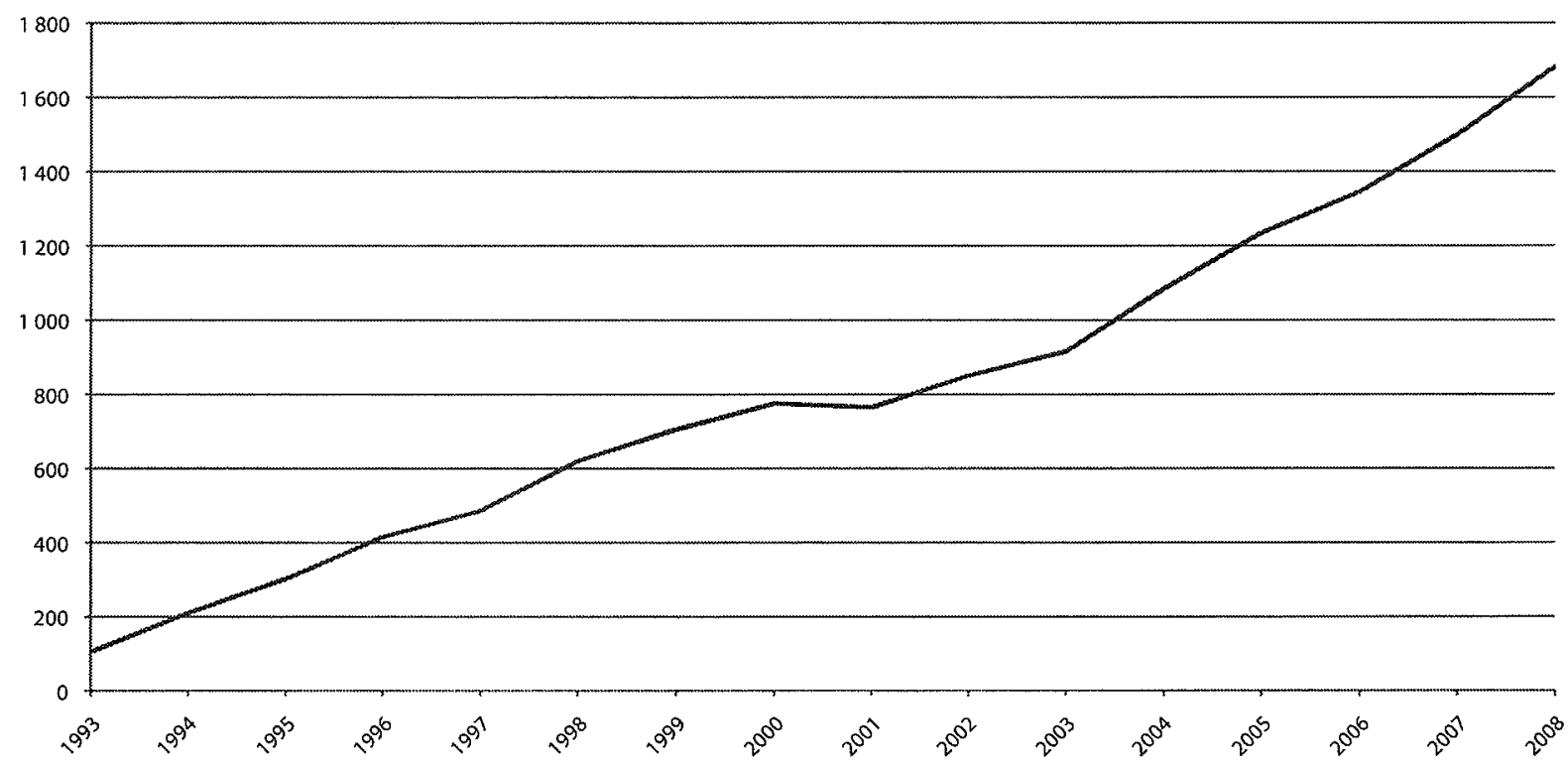

Source: Authors, based on GENETests (2008).

The 2007 report "Consequences, opportunities and challenges of modern biotechnology for Europe" estimated revenues from biotechnology-based diagnostics and IVDs for 2004 , by region of the world (see Table 19). The total IVD market was estimated at USD 27.6 billion of which:

- molecular diagnostics accounts for 5\% (USD 1.4 billion),

- immunochemical diagnostics accounts for 24\% (USD 6.6 billion),

- other (non-biotech) diagnostics account for 71\% (USD 19.6 billion) (ETEPS NET, 2006). ${ }^{33}$

As shown in Table 19, biotech-based IVDs represent an important share of the entire IVD market, ranging from $37 \%$ in the United States, to $29 \%$ in the EU-5, and $21 \%$ in all other countries. The United States spent slightly more on biotechnology based IVDs than all other countries combined, representing $51 \%$ of all biotech IVD revenues, while the EU-5 accounted for $26 \%$ of global revenues and other countries for $23 \%$. 
Table 19. Estimate of biotechnology-based diagnostics and in-vitro diagnostics revenues $-2004$

\begin{tabular}{lccc}
\hline & A & B & B/A \\
\hline & $\begin{array}{c}\text { NDs } \\
\text { (USD billions }{ }^{2}\end{array}$ & $\begin{array}{c}\text { Biotechnology-based IVDs } \\
\left.\text { (USD billions }{ }^{2}\right)\end{array}$ & Share of biotech in IVDs \\
\hline EU-51 & 7.2 & 2.1 & $29 \%$ \\
USA & 11.6 & 4.3 & $37 \%$ \\
Others & 8.8 & 1.8 & $21 \%$ \\
\hline Total & 27.6 & 8.2 & $30 \%$ \\
\hline
\end{tabular}

Source: JRC (2007).

Notes: 1. Includes France, Germany, Italy, Spain, and the United Kingdom.

2. Converted from original using 1 Euro $=1.24333$ USD in 2004, www.industrie.gouv.fr, accessed 13 August 2007.

Medical Product Outsourcing (2006) profiled the 15 leading IVD manufacturers for 2005. These 15 firms represent an estimated $77.8 \%$ (USD 24.6 billion) of sales of the USD 31.5 billion global IVD market in 2005 (see Table 20). ${ }^{34}$ Unfortunately, the data do not differentiate between biotech diagnostics and other types of diagnostics. Although the leading firm, Roche Diagnostics, is Swiss, nine of the top 15 firms are based in the UnitedStates. American firms account for $41.2 \%$ of global IVD sales. Of the other firms, three are based in Japan, one in Germany, and one in France.

Table 20. Leading in-vitro diagnostic companies - 2005

\begin{tabular}{lcccc}
\hline Company/Origin country & $\begin{array}{c}\text { 2005 IVD Sales } \\
\text { (USD billions) }\end{array}$ & $\begin{array}{c}\text { IVD Sales 2002-2005 } \\
\text { (\% change) }\end{array}$ & $\begin{array}{c}\text { Total 2005 Company } \\
\text { Sales (USD billions) }\end{array}$ & $\begin{array}{r}\text { ND as \% of Total } \\
\text { Business (2005) }\end{array}$ \\
\hline Roche Diagnostics - Switzerland & 6.3 & $21 \%$ & 27 & $23 \%$ \\
Abbott Laboratories - USA & 3.8 & $41 \%$ & 22.3 & $17 \%$ \\
Bayer Diagnostics - Germany & 2.5 & $19 \%$ & 32 & $8 \%$ \\
Becton, Dickinson and Co. - USA & 2.5 & $32 \%$ & 5.4 & $46 \%$ \\
Beckman Coulter - USA & 1.9 & $27 \%$ & 2.4 & $79 \%$ \\
Dade-Behring - USA & 1.7 & $31 \%$ & 1.7 & $100 \%$ \\
Ortho-Clinical Diagnostics - USA & 1.4 & $40 \%$ & 1.4 & $100 \%$ \\
bioMérieux - France & 1.2 & $29 \%$ & 1.2 & $100 \%$ \\
Sysmex - Japan & 0.7 & $102 \%$ & 0.7 & $100 \%$ \\
Bio-Rad Labs - USA & 0.6 & $36 \%$ & 1.2 & $52 \%$ \\
Arkray - Japan & 0.5 & N/A1 & 0.5 & $100 \%$ \\
Diagnostic Products - USA & 0.4 & N/A1 & 0.4 & $100 \%$ \\
Olympus America - Japan & 0.4 & N/A1 & 8.3 & $5 \%$ \\
Cytyc-USA & 0.4 & N/A1 & 0.5 & $71 \%$ \\
Gen-Probe - USA & 0.3 & N/A1 & 0.3 & $100 \%$ \\
\hline TOTAL & 24.6 & N/A1 & 105.3 & $23 \%$ \\
\hline
\end{tabular}

Source: Authors, based on Medical Product Outsourcing $(2003,2006)$.

Note: 2002 data not available. 
Nearly half of the leading 15 IVD companies are specialized only in IVD. These dedicated firms tend to be small however, accounting for only $19.7 \%$ of global sales. In contrast, the top three firms account for $40 \%$ of global IVD sales. All of the top 10 firms remained in the top 10 from 2002 to 2005, and all of them increased their sales over the time period.

\section{Current status of bioinformatics}

Bioinformatics facilitates the practical use of information from complex biological data. According to the OECD, this involves the "creation of extensive electronic databases on genomes, protein sequences, etc. Secondarily, it involves techniques such as the threedimensional modelling of biomolecules [including systems biology ${ }^{35}$ ] (OECD, 2005a)."

The worldwide bioinformatics market was estimated at USD 1.02 billion in 2002 (BBC Research, 2005b), though this may be highly influenced by definitional issues. In 2004, it was estimated that USD 775 million was spent on informatics for drug development and that figure would increase to over USD 1 billion in 2008 (Lawrence, 2005).

Bioinformatics are increasingly powerful, allowing researchers to garner more knowledge about more complex organisms and systems. From its foundations in the $1980 \mathrm{~s}$ through the 1990 s, bioinformatics involved the creation and management of databases containing experimental genomic and proteomic data, along with the full genome of some cellular

Figure 8. Billions of DNA base pairs included in INSDC, 1998 to 2008

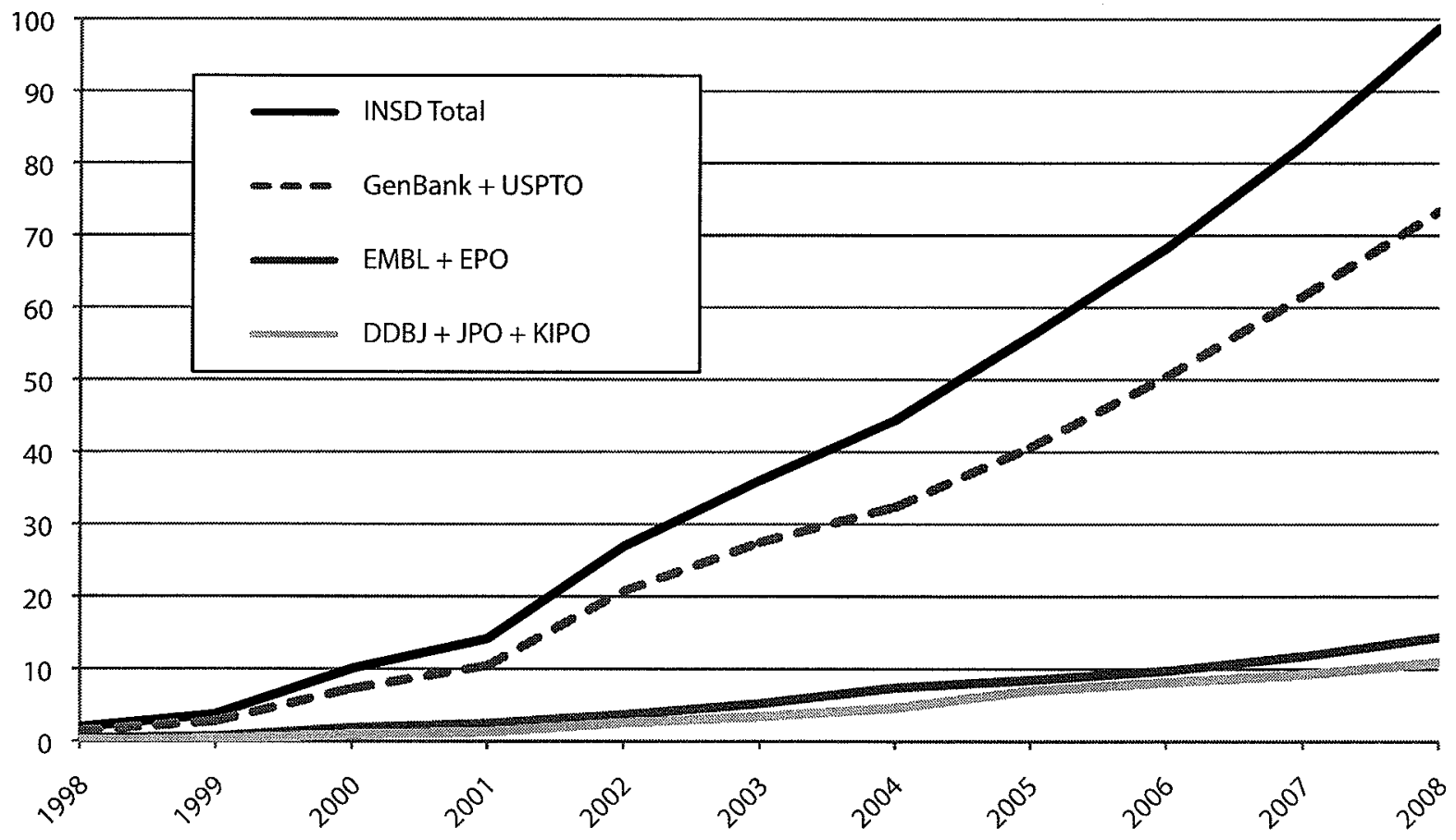

Source: Authors, based on DDBJ (2009).

Notes: 1. USPTO = United States Patent and Trademark Office; EMBL = European Molecular Biology Laboratory; $E P O=$ European Patent Office $; \mathrm{DDBJ}=\mathrm{DNA}$ Data Bank of Japan; JPO = Japan Patent Office $; \mathrm{KIPO}=$ Korean Intellectual Property Office

2. KIPO entries only began in 2008 . 
organisms (today more than 100 are available). Researchers use these databases coupled with bioinformatics tools (e.g. ThermonucleotideBLAST) to compare their research results with known DNA, RNA, and protein sequences and to identify the function of some individual genes and proteins. Today, there are hundreds of databases available 36 many of which contain knowledge created from the analysis of earlier databases in areas such as protein function sites, protein interactions, and ortholog (ancestor) groups (Kanehisa and Bork, 2003).

In addition to numerous privately established databases in universities and the private sector, in the mid-1980s the International Nucleotide Sequence Database Collaboration (INSDC) was created, allowing free and unrestricted access to data (both human and nonhuman) from GenBank in the United States, the European Molecular Biology Laboratory (EMBL), and the DNA Data Bank of Japan (DDBJ). In August 2005, the INSDC reached 100 gigabases of RNA and DNA data (NCBI, 2007; USNLM, 2005). Since then, the number of DNA base pairs has grown from over 45 million entries to nearly 100 million by the end of 2008 (see Figure 8). Large scale biobanks ${ }^{37}$ have also been established in a number of countries including, Australia, Canada, Estonia, Iceland, Japan, Latvia, Sweden, and the United Kingdom..$^{38}$ It is hoped that analyses of these datasets will improve the prevention, diagnosis, and treatment of a wide range of illnesses.

In addition, a number of public and private entities provide bioinformatics design tools. For example, companies provide design programs which facilitate the design of large and small DNA fragments, the optimization of expression in desired hosts, the construction of DNA from building blocks or the analysis of peptide sequences (DNA 2.0, 2007; Innovagen, 2007). A number of online bioinformatics tools are also available for designing PCR primers, which are required to identify the DNA sequence to be amplified during PCR. ${ }^{39}$ While some of these tools are subject to fees, some are offered for free by companies that propose complementary, for-fee, services, and many are provided online free of charge by noncommercial entities.

Many of these tools underpin the rapidly growing genome synthesis industry. At present, there are commercial companies in over 18 countries that offer synthesised DNA sequences, and there are many more with universities and private and public laboratories that have the same capability.

The continued development of bioinformatics simultaneously helps advance and depends on two other technologies: genome sequencing and pharmacogenetics and genomics.

\section{DNA sequencing}

DNA sequencing "is the determination of the order of the nucleotides (the base sequence) in a DNA molecule (NCBI, 2004)." It is one of the key technologies necessary to populate bioinformatics databases with genetic information. Advances in technology have significantly reduced the cost and time of sequencing. The Human Genome Project, begun in 1990, was completed in 2003 two years ahead of schedule and USD 300 million dollars below budget. Many experts have attributed this success with the development of faster and cheaper sequencing machines and methods, such as shotgun sequencing.

Over the past decade these technologies have led to a 500 -fold increase in productivity, measured in the number of base pairs sequenced per person per day, and a cost reduction over three orders of magnitude, from USD 1 to USD .001 per base pair. This corresponds to a doubling of productivity every 2 years (Carlson, 2007). Although full genome sequencing remains time-consuming and expensive, it is now possible to sequence all known human genes for around USD 1000 (Herper and Langreth, 2007). The race is on however for full 
genomes. The Archon X Prize for genomics is offering a USD 10 million prize to the first team to sequence 100 human genomes at a cost of less than USD 10000 per genome in less than 10 days. The hope is that this will catalyze the development of sequencing technologies that reduce time and cost (Archon X-Prize, 2007).

\section{Current status of pharmacogenetics}

Pharmacogenetics is "the study of the effects of variations in DNA sequence (genetic differences) on drug response, in terms of both metabolism (pharmacokinetics) and action (pharmacodynamics) of the drug delivered (OECD, 2007d)."40 Pharmacogenetics, which relies heavily on the identification of biomarkers, can affect every phase of drug research and development (target identification, selection of clinical trial subject, etc.) and prescription practices.

The OECD has identified three ways in which pharmacogenetics is applied in clinical practice:

- "To help identify responders and non-responders to a treatment."

- "To aid in establishing appropriate dosages for responders."

- "To identify susceptibility to [adverse drug reactions (ADR)] and possibly exclude some patients from treatment (OECD, 2007d)."

The global pharmacogenetics market was estimated at USD 1.24 billion in 2004 (39.2\% of which was for diagnostics) and expected to grow at 24.5\% per year to 2009 (BBC Research, 2005c). However despite this activity, less than a dozen pharmacogenetic testing products were on the market in 2007 (OECD, 2007d) (see Table 21 for some examples).

The widespread use of pharmacogenomics and pharmacogenetics could lead to personalized medicines, where the chemical and biological composition, as well as the dosage of drugs, is tailored to an individual's genome. There are a number of potential benefits to the application of these technologies development and delivery:

- Decrease drug development time and cost

- Encourage drug failure earlier in the development process

- Smaller, targeted clinical trials

- Decreased drug approval times

- Personalized (i.e. more effective) dosages

- Fewer adverse drug reactions (ADRs)

- Potential to decrease overall healthcare expenditures

There are numerous challenges in several domains that are influencing the large-scale development of pharmacogenetics:

- Scientific - The validation of biomarkers, which is one of the most important aspects of pharmacogenetics, is proving a daunting task. Roche CEO Franz Humer has stated, "It is as complex to find a biomarker as it is to find a new drug" (Hirschler, 2007). In addition, most drug responses are polygenetic, further increasing scientific complexity. 
Table 21. Examples of pharmacogenetic tests

\begin{tabular}{lll}
\hline Disease & \multicolumn{1}{c}{ Test } & \multicolumn{1}{c}{ Positive Result Recommendation } \\
\hline Breast cancer & High levels HER2 RNA or protein & If present, prescribe trastuzumab (Herceptin) \\
Chronic myeloid lukemia & Mutated bcr/abl gene & If present, prescribe imatinib (Glivec, Gleevec) \\
Maturity-onset diabetes of the young & Altered KATP gene & If present, prescribe sulphonylurea \\
Venous thrombosis & Mutated factor V Leiden gene & $\begin{array}{l}\text { Avoid prescribing oral contraceptives; as they may } \\
\text { trigger venous thrombosis }\end{array}$ \\
HIV & Variations in HLA-B*5701 \& Hsp70-Hom genes & $\begin{array}{l}\text { Avoid treatment with abacavir as it may cause fever, } \\
\text { rashes, digestive difficulties \& breathing problems }\end{array}$ \\
\hline
\end{tabular}

Source: The Royal Society (2005).

- Regulatory - Historically, diagnostics and drugs have been regulated independently (Phillips, 2006) and until recently, no regulation was in place for the use of pharmacogenetic information in the approval process for drugs. ${ }^{41}$ Furthermore, although the majority of clinical trials now collect genetic data, this is a recent trend and the information is not yet uniformly used to evaluate differences in drug response. Positive steps are being taken however, for instance through the work of The International Conference on Harmonisation (ICH). The ICH, which comprises the regulatory authorities of Europe, Japan and the United States and aims to harmonise regulations for pharmaceuticals across jurisdictions, endorsed a concept paper laying out guidelines for the validation of biomarkers (ICH, 2008).

- Economic - By identifying subgroups of patients that do not respond to a drug, pharmacogenetic research could reduce the market for approved drugs and consequently the revenue earned per drug by pharmaceutical firms. Alternatively, pharmacogenetics could decrease the cost of drug development or allow firms to charge higher prices for more effective drugs. ${ }^{42}$ Pharmacogenetics also has wider benefits. It could reduce the massive human and economic costs associated with adverse drug reactions (ADR), which are estimated to cost USD 136 billion and 100000 deaths per year in the United States alone (CDER, 2002). This is a powerful economic argument for pharmacogenetics.

- Human resources - Pharmacogenetic research is very labour-intensive and requires the integration of numerous disciplines. The widespread application of pharmacogenetics will entail changes to the way in which some healthcare providers, such as doctors, work. For instance, the "off-label prescribing" of drugs for unapproved indications accounts for about $20 \%$ of all prescriptions in the United States (Radley, Finkelstein and Stafford, 2006). This practice could become obsolete as prescribing practices are increasingly determined by the patient's genetic status.

- Public acceptance and access - Drugs designed for small groups of genetically similar people could exacerbate adverse drug reactions in people with a different genetic code unless prescribing practices are strictly controlled. A small number of high-profile errors could reduce public confidence in the development and consumption of pharmacogenetic products. In addition, genetic variations associated with ethnicity can affect responses to drugs. Ensuring safe and effective access to drugs could therefore require different ethnic groups to be included in clinical trials. At present, non-Caucasian ethnic groups and women are under-represented in clinical trials (Murthy et al., 2004; OECD, forthcoming). 
- Lifestyle choices - Not enough is known about the interaction between genetics and lifestyles (e.g. exercise, diet, alcohol consumption and smoking) as a factor in how individuals respond to medicines.

The PharmGKB database (https://www.pharmgkb.org/) aims to push forward pharmacogenomic research by collecting information that can be used to establish the link between drugs, diseases, and genes. As of December 19, 2007, the database had compiled information on 529 drugs whose effect was influenced by a specific gene variant. Of the numerous genes identified, 26 have been identified as "very important" or "of particular relevance to Pharmacogenetics and Pharmacogenomics" (PharmGKB, 2007). Some reviews have pointed out the difficulty in replicating evidence for gene association. A study of more than 600 positive associations between gene variants and diseases, of which 166 have been studied three or more times, showed that only six were consistently replicated (Hirschhorn et al., 2002).

A detailed analysis of the PharmGKB database, performed by the authors, identified 6532 gene-drug links. As shown in figure 9, 12\% were for clinical outcomes (e.g. efficacy and toxicity), $20 \%$ for pharmacodynamics and drug response (e.g. target, mechanism of drug reaction, and response), 16\% for pharmacokinetics (e.g. absorption, distribution, metabolism, and excretion), $26 \%$ for molecular and cellular functional assays (i.e. altering molecular test results), and $26 \%$ for genotype (i.e. inherited genetic information).

The analysis also identifies the year of identification of each of the drug-gene links, by using the first relevant publication in the database. Despite several years in which the number of identifications declined, ${ }^{43}$ since the early 1990 s the number of identified genedrug links has soared (see Figure 10).

\section{Figure 9. Types of drug-gene relationships identified in the PharmGKB database}

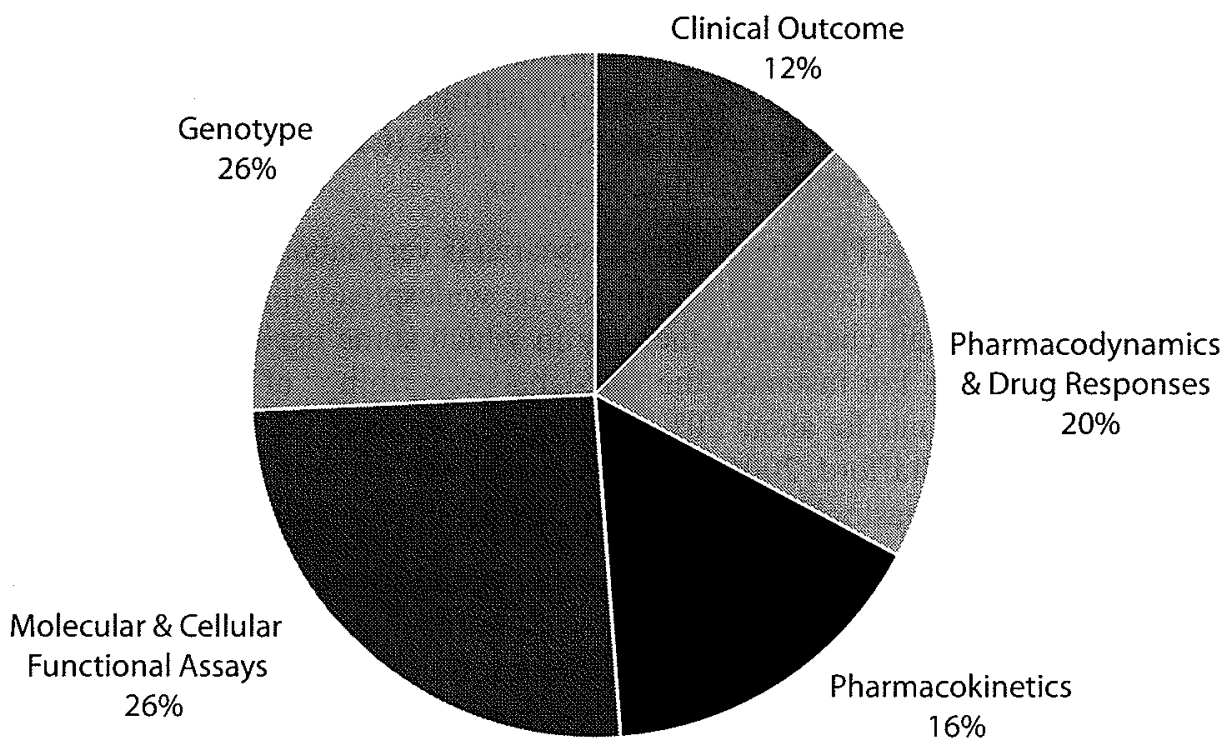

Source: Authors, based on PharmGKB (2007).

Note: As of December 10, 2007. 
Figure 10. Number of identified drug-gene relationship, 3-year running average, by year of first publication

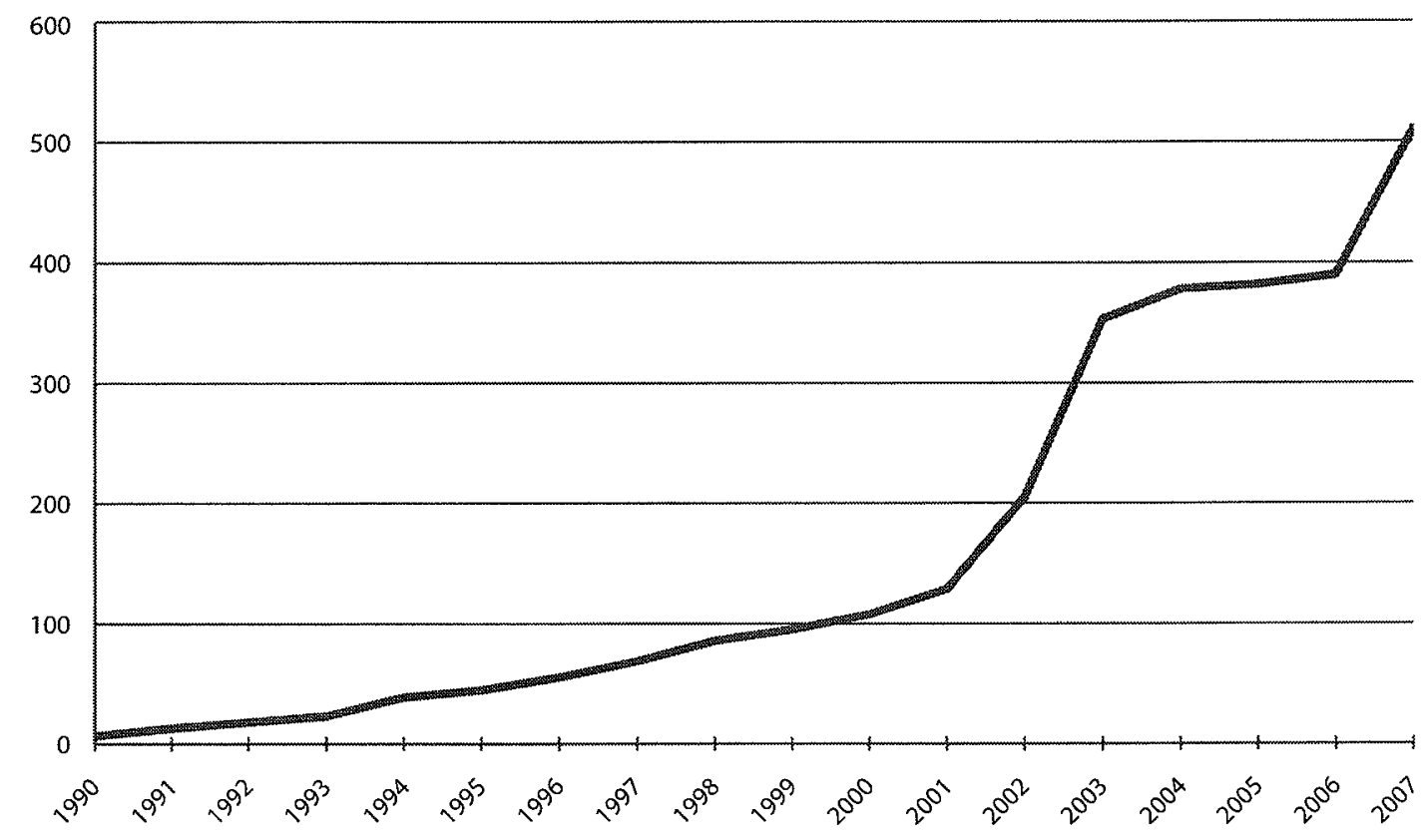

Source: Authors, based on PharmGKB (2007).

Note: As of December 10, 2007.

This trend is similar to the trend for publication references to "pharmacogenetics" and "pharmacogenomics" (see Figure 11). An analysis of the archives of PubMed, which contains 16 million biomedical journal abstracts and articles from over 300 research journals, shows a rapid increase in the mention of "pharmacogenetics" and "pharmacogenomics" from 2000 to 2007. These results mirrored very closely the same analysis performed on the archives of the Journal of the American Medical Association (JAMA). JAMA is a broad medical journal that is widely read by general medical practitioners, indicating that interest in this research is a part of a general trend.

\section{Biomarkers}

The FDA defines a biomarker as valid if, "(l) it is measured in an analytical test system with well-established performance characteristics and (2) there is an established scientific framework or body of evidence that elucidates the physiologic, pharmacologic, toxicologic, or clinical significance of the test results (FDA, 2005)." As shown in Table 22, as of April 2008, the FDA had identified 27 valid biomarkers: four are required, nine are recommended, and 14 are identified as for "information only". This was a $50 \%$ increase in the number of validated biomarkers over October 2006 levels. In addition, the proportion of those biomarkers for "information only" decreased from $72 \%$ to $52 \%$.

The share of FDA approved drugs containing pharmacogenetic information on their labels has increased significantly over the past 25 years. While only $10 \%$ of all FDA approved drugs contain such information, the percentage has increased more than 7 times from only $5 \%$ of drugs approved in 1990 to $37 \%$ of drugs approved in 2005 (see Figure 12). 
Table 22. Valid FDA genomic biomarkers and genetic testing requirements - October 2006 and April 2008

\begin{tabular}{lcc}
\hline FDA Category & $\begin{array}{c}\text { Number of Drugs } \\
\text { as of October 2006 }\end{array}$ & $\begin{array}{c}\text { Number of Drugs } \\
\text { as of April 2008 }\end{array}$ \\
\hline Test Required & 2 & 4 \\
Test recommended & 3 & 92,3 \\
Information only & 13 & 14 \\
\hline Total & 181 & $27^{4}$ \\
\hline
\end{tabular}

Source: Authors, based on FDA (2008)

Notes: 1 . One drug (Cetuximab) is counted twice because testing is required for colorectal cancer and recommended for head and neck cancer.

2. One drug (Warafin) has three associated genomic biomarkers for which testing is recommended.

3. Testing for one drug (Carbamazepine) is only recommended for at risk persons

4. In addition to those drugs cited in notes $2 \& 3$, one drug (Cetuximab) is counted twice because testing is required for colorectal cancer and recommended for head and neck cancer.

Figure 11. Number of publications with "pharmacogenetics" and "pharmacogenomics" as keywords Journal of the American Medical Association

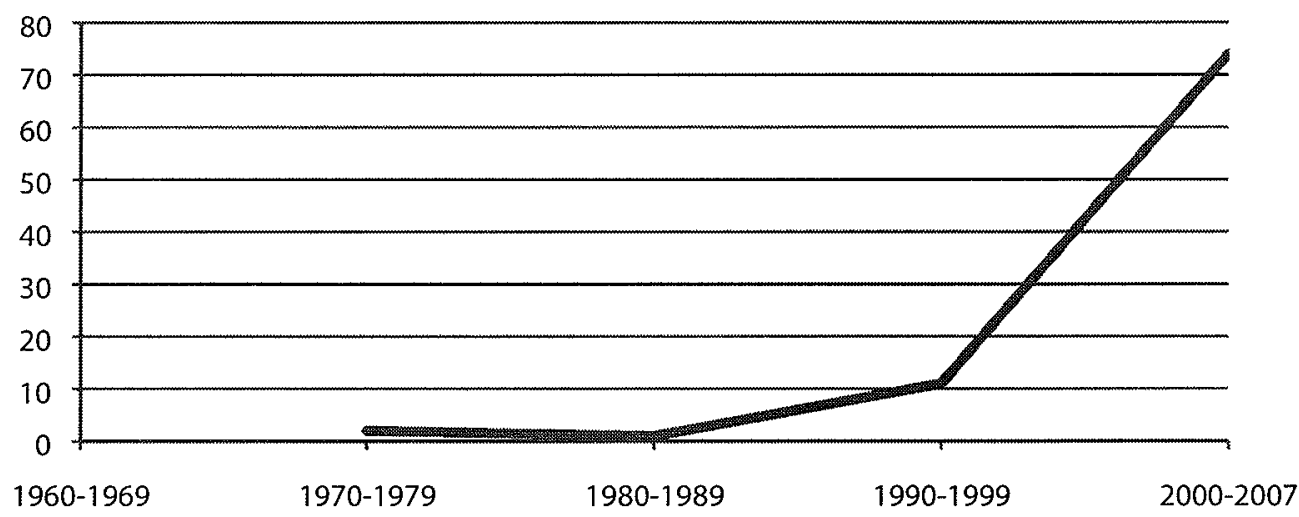

PubMed

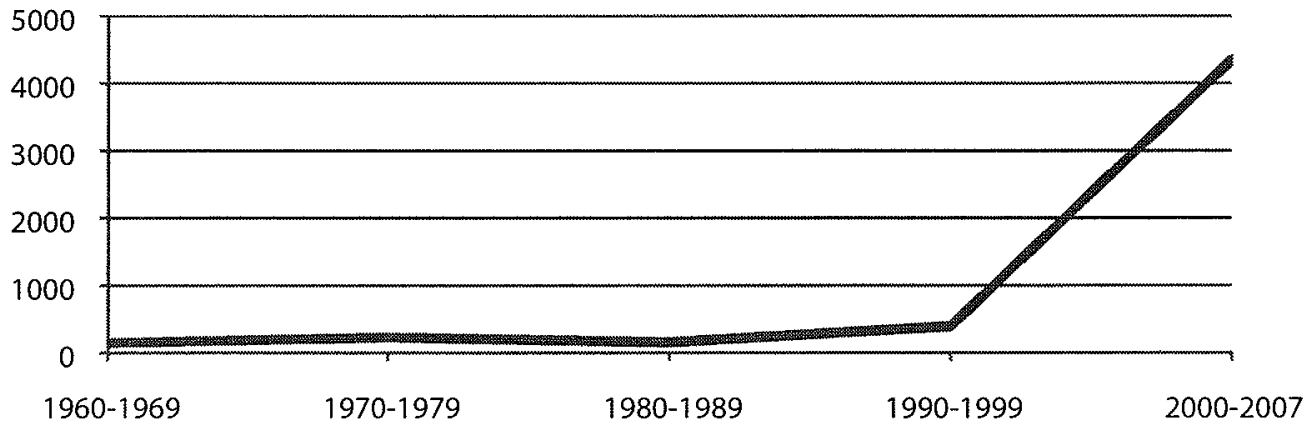

Source: Authors, based on PubMed (2007).

Notes: 1. Chart scales are different.

2. Searches performed December 6, 2007. 
Figure 12. Labels of FDA approved drugs with pharmacogenomic information

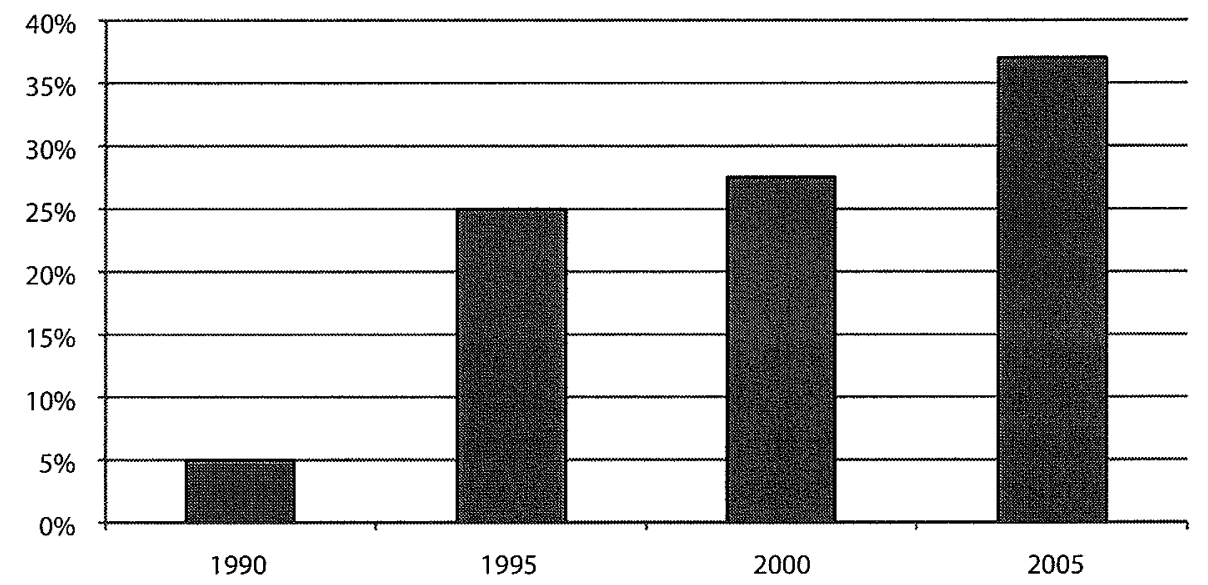

Source: Frueh (2006).

\section{Forecasting for diagnostics}

The importance of diagnostic tests, and hence biotechnology based diagnostics, are likely to continue to increase to 2015 . This will be particularly apparent if trends towards the increased use of pharmacogenetics (see the section on "forecasting for pharmacogenetics") and preventative medicine continue in unison.

\section{In-vivo diagnostics}

As shown in Table 17, the pipeline for biotechnology in-vivo diagnostics is relatively small. With only a few products in clinical trials, it is very difficult to ascertain with any certainty the number of products likely to enter the market by 2015 . However some general conclusions can be drawn by examining the success rate from the Pharmapredict database for all diagnostics and imagining agents, which includes biotechnology in-vivo diagnostics. This category has a short average product development time (93 months from phase I to launch), the highest historical success rate from preclinical trials to market, and an above average success rate across all development phases. It is therefore likely that several of the products currently in development will reach the market before 2015. Also, since some products will go from the end of preclinical trials to launch in less than 93 months, there may also be some products that arrive on the market in 2015 which are not yet even in preclinical trials.

\section{In-vitro diagnostics}

In-vitro diagnostics are likely to see much stronger growth to 2015 than in-vivo diagnostics. Many experts see double digit annual growth in diagnostics sales through 2015, in part driven by the increased use of pharmacogenetics (see the section on "forecasting for pharmacogenetics").

As noted in the section on diagnostics, the availability and use of in vitro diagnostics, and in particular genetic tests, has increased substantially since the mid-1990s. There are no data available that can be used to predict the number of genetic tests that will reach the market in the future. There are about 6000 known genetic disorders (Human Genome Project Information, 2008), but many of the disorders which currently lack a diagnostic test are very rare. The very small diagnostic market for these disorders will limit commercial 
and academic interest in developing a genetic test for them. This could reduce the discovery rate for new genetic tests in the future.

Genetic testing is likely to shift from identifying single genetic mutations to tests for multiple genes that increase the risk of diseases caused by a large number of different factors. These tests could use microarray technology to identify multiple gene variations.

\section{Forecasting for bioinformatics}

The creation, population, and maintenance of databases will continue to be a very important function of bioinformatics to 2015. These databases are likely to become increasingly complex, integrating information from disciplines beyond biology and computer science, such as physics and chemistry (Kanehisa and Bork, 2003). This information is required in order to model cells as systems, a necessary step to predicting function (Tsoka and Ouzounis, 2000).

Databases will continue very rapid growth to 2015. Not only will more base pairs and sequences be available, but so will the full genome of an increasing number of organisms. The rapid rate of increase in data compilation shown in Figure 8, will continue, particularly if the cost of sequencing continues to fall as projected. Indeed the cost of genome sequencing will probably continue to decline rapidly. If the cost per base pair continues to decline at historical rates, "Thousand Dollar Genome" could become a reality around 2020 (Carlson, 2007). There are however indications that this could occur much sooner. The gene sequencing firm Complete Genomics, for instance, has announced that it will soon start offering sequencing of 8 or more full human genomes for USD 20000 each and 1000 or more full human genomes for USD 5000 each (Duncan, 2009).

BCC Research estimates that the worldwide bioinformatics market will reach USD 3.0 billion in 2010 , corresponding to a $15.8 \%$ average annual growth rate over 2002 levels. The report concludes the use of bioinformatics will reduce the time for drug discovery and the annual cost of development by $30 \%$ and $33 \%$, respectively by 2010 (BBC Research, 2005b).

\section{Forecasting for pharmacogenetics}

Similar claims regarding reducing drug discovery time and cost have been made about the closely related field of pharmacogenetics. PWC (2005) states that "using pharmacogenomics in clinical trial design is expected to reduce the clinical development time from 10 to 12 years in traditional commercialization to just 3 to 5 years." Jean-Pierre Garnier, CEO of GlaxoSmithKline, is less optimistic. He recently commented that "pharmacogenetics is not going to transform this market any time soon ... it's going to take 20 years plus" (Hirschler, 2007).

Indeed, due to the highly varied nature of the challenges facing pharmacogenetics, it is very difficult to perform a quantitative analysis leading to projections of the number of pharmacogenetic products arriving on the market by 2015. In the end, a complicated convergence of regulatory policies, business plans, and scientific developments are going to determine the final trajectory of these technologies, but we can draw out a few general observations regarding likely near term developments.

An increasing number of drugs that are tailored for groups of people who share specific genetic characteristics are likely to reach the market by 2015 . This is shown by the increase in the number of gene-drug links identified, publications examining "pharmacogenetics" and "pharmacogenomics", and drug labels containing pharmacogenomic information (see 
the section on the "current status of pharmacogenetics"). Also, there are encouraging signs such as the work of ICH on guidelines for the validation of biomarkers (ICH, 2008) and FDA - EMEA collaboration on harmonizing rules for pharmacogenetic data submissions. There is also the possibility that pharmacogenomic data submissions for new drug applications will become mandatory (PWC, 2005). This sort of increased collection of standardized pharmacogenetic data could have a major impact on pharmacogenetic drug development.

The use of pharmacogenetics up to 2015 is likely to focus on improving safety and reducing ADRs. Concern over high-profile drug withdrawals (such as Vioxx) should also encourage firms to use pharmacogenetics during drug development to minimize severe adverse drug reactions. Another application is to use pharmacogenetics to identify subgroups of responders. This could "rescue" drugs that fail in clinical testing by identifying sub-groups of patients for which the drug is safe and effective (DePalma, 2006). However, this is more difficult and expensive than identifying subgroups that develop ADRs. Astra Zeneca adopted this approach to rescue its lung cancer drug candidate Iressa, but failed.

BCC Research (2005c) estimates that the global market for pharmacogenomics is likely to grow by $24.5 \%$ per year, from USD 1.24 billion in 2004 to USD 3.7 billion by 2009. Diagnostics formed $39.2 \%$ of this market in 2004 and should account for $45.3 \%$ of the market in 2009 .

\section{Potential}

The Human Genome Project and other related initiatives have led to the identification of several genes that increase the risk of an inherited disease. This allows the development of new kinds of molecular diagnostic tests that can diagnose diseases caused by more than one gene and determine a patient's genetic predisposition to a given disease. Yet it is very unlikely that biotechnology-based diagnostics will dominate the IVD market by 2015. Most molecular diagnostics do not replace existing tests, but add new market segments, such as for diagnostics to identify multi gene diseases or for use in personalized medicine in combination with pharmacogenetics.

\section{Diagnostics, bioinformatics, and pharmacogenetics summary}

Table 23 summarizes the main developments in biotechnology-based diagnostics, bioinformatics, and pharmacogenetics that are expected by 2015.

Table 23. Main short-term trends in biotechnology-based diagnostics, bioinformatics and pharmacogenetics to 2015

\begin{tabular}{ll}
\hline Diagnostics & $\begin{array}{l}\text { Forecast outcomes } \\
\text { larly the case for in-vitro diagnostics which are likely to see much stronger product development to } 2015 \\
\text { than in-vivo diagnostics. While the number of diagnostic tests produced could slow somewhat due to a } \\
\text { saturation of gene targets, the increased use of pharmacogenetics and personalised medicine could spur } \\
\text { development, particularly of multi-gene tests based on micro-arrays. }\end{array}$ \\
The continued creation, population, and maintenance of databases will continue to be a very important, \\
perhaps even primary, function of bioinformatics to 2015 , but this data will often be more complex. The \\
amount of information stored in large genetic databases will continue to grow, in part due to a fall in the \\
price of genome sequencing. \\
The number of drugs where prescribing practice depends on a genetic test should continue to grow to 2015. \\
The primary purpose is likely to be to reduce ADRs (i.e. warfarin) but the number of responder linked drugs \\
should also increase (i.e. HER2 test for Herceptin). The widespread use of pharmacogenetics to identify \\
respondent and non respondent subgroups in clinical trials, however, is unlikely to occur before 2015.
\end{tabular}




\section{Miscellaneous: functional foods, nutraceuticals and medical devices}

This miscellaneous category includes areas where biotechnology has possible applications to health, but to date the effect of biotechnology has been fairly minor.

\section{Functional foods and nutraceuticals}

Health Canada defines functional foods and nutraceuticals as follows:

- "A functional food is similar in appearance to, or may be, a conventional food that is consumed as part of a usual diet, and is demonstrated to have physiological benefits and/or reduce the risk of chronic disease beyond basic nutritional functions, i.e. they contain bioactive compounds."

- "A nutraceutical is a product isolated or purified from foods that is generally sold in medicinal forms not usually associated with foods. A nutraceutical is demonstrated to have a physiological benefit or provide protection against chronic disease (Health Canada, 1998)."

It is not possible to determine what percentage of the overall food products and beverage sector is involved in functional food and nutraceuticals (FFN). However, the FFN sector is estimated in Canada to account for approximately $5.3 \%$ of the total food and beverage sector (see Table 24). This roughly corresponds to the estimate of 5.4\% provided by comparing total food and beverage sales in the United States (USD 592 billion) (EU KLEMS, 2007) with estimates of functional foods sales in the United States (USD 32 billion) for 2005 (Nutrition Business Journal as cited by US GAO, 2000).

Other research provides large variations in the estimated size of the FFN sector. For example, the Nutrition Business Journal as cited by Sloan (2005) indicates that the global functional food market was USD 47.6 billion in 2001, with the United States accounting for USD 18.25 billion. The US market was expected to grow at $7.5 \%$ through 2005 bringing the overall United States functional foods market to USD 24.4 billion in 2005. Another study estimated that the FFN sector in the United States was much smaller, only USD 1.26 billion in 2001 (Food \& Drink Weekly, 2001). Although estimates of the overall market size tend to vary significantly, analyst seem to agree that the industry is growing at a rapid pace (double digit per annum) when compared to the conventional food sector which is growing by just $2 \%$ to $3 \%$ per year (Van Dusen, 2007).

Table 24. Employment in the functional food and nutraceutical (FFN) sector in Canada

\begin{tabular}{ccc}
\hline $\begin{array}{c}\text { Total Canadian FFN employment } \\
(2004)\end{array}$ & $\begin{array}{c}\text { Total Canadian food products and beverage } \\
\text { employment (2003) }\end{array}$ & $\begin{array}{c}\text { \% of all Canadian food product and } \\
\text { beverage employees working in FFN }\end{array}$ \\
\hline 12872 & 241.000 & $5.3 \%$ \\
\hline
\end{tabular}

Source: Authors, based on FFN employment data from Palinic (2007) and Canadian employment data from OECD (2007a). 
While most analysts do not appear to differentiate between functional foods and nutraceuticals, a rough estimate of the overall FFN share can be gleaned from the Canadian employment data cited in Table 24. Of the 12872 Canadian employees active in FFN, 4024 are involved in functional foods, 6471 are active in nutraceuticals, and 2377 are working in both fields (Palinic, 2007). This implies, as a very rough estimate, that functional foods and nutraceuticals account for roughly $40 \%$ and $60 \%$, respectively, of the overall FFN market.

Of note, many functional foods (e.g. foods with added nutrients) and nutraceuticals, such as fish oils, have been available for decades and are not produced using modern biotechnology. Biotechnology can however be applied to plants and animals to engineer or select specimens with increased levels of certain nutrients or functional components that can then be consumed or extracted for use. There is no data available to determine the exact percentage of the overall FFN sector which currently uses biotechnology. The authors assume that the biotechnology share is relatively small, not exceeding $10 \%$ and probably far less.

Increased knowledge in the "omics" (e.g. genomics, proteomics, metabolomics, etc.) may lead to an era of nutragenomics, where dietary regimes are tailored to a person's specific genome to prevent disease or improve health. This form of personalized medicine would likely make use of both functional foods and nutraceuticals, but appears to be far in the future.

\section{Current status of functional foods}

Table 25 provides some examples of functional food components. While many of these benefits are unverified, some have received approval from the United States" FDA as "qualified health claims." These are general claims that indicate a specific substance may be effective in reducing a health risk such as heart disease, high blood pressure, osteoporosis, etc. Some of these functional components (zeaxanthin, beta-carotene, omega-3 fatty acids, stanol) are currently or have been the subject of genetically modified (GM) field trials. ${ }^{44}$

Some examples of functional foods using biotechnology which are available or currently under development are:

- In the United States, researchers are using biotechnology to increase the amount of ellagic acid, a cancer protective agent, in strawberries (Smith, 2007).

- Soybeans have been developed through conventional breeding (e.g. Vistive 1 from Monsanto) which produce no trans fats when cooked due to their low levels of linolenic acids. Soybeans with both low levels of linolenic acids and increased levels of oleic acid and low saturated fats are under development using biotechnology (Powell, 2007).

- An English-German-Japanese consortium has developed a GM tomato containing 3.5 times the level of b-carotene of a normal tomato (BBC News, 2000).

In addition, some biotechnology functional foods have been or are being developed to address the needs of the developing world:

- Golden rice and iron-enriched rice are genetically engineered to provide enhanced levels of iron and b-carotene. This could have an impact on common health problems caused by nutrient deficiencies such as blindness and anaemia (Hasler, 2002). 


\section{Table 25. Examples of functional food components ${ }^{1}$}

\begin{tabular}{|c|c|c|}
\hline Functional components ${ }^{2}$ & Current Source 1 & Potential benefits \\
\hline \multicolumn{3}{|l|}{ Strotenoids } \\
\hline Beta-carotene 4 & $\begin{array}{l}\text { carrots, pumpkin, sweet potato, } \\
\text { cantaloupe }\end{array}$ & $\begin{array}{l}\text { neutralizes free radicals, which may damage cells; bolsters cellular antioxidant } \\
\text { defences; can be made into vitamin A in the body }\end{array}$ \\
\hline Lutein, Zeaxanthin 4 & $\begin{array}{l}\text { kale, collards, spinach, corn, eggs, } \\
\text { citrus }\end{array}$ & may contribute to maintenance of healthy vision \\
\hline Lycopene & $\begin{array}{l}\text { tomatoes and processed tomato } \\
\text { products, watermelon, } \\
\text { red/pink grapefruit }\end{array}$ & may contribute to maintenance of prostate health \\
\hline \multicolumn{3}{|l|}{ 201 } \\
\hline $\begin{array}{l}\text { Monounsaturated fatty } \\
\text { acids (MUFAs) }\end{array}$ & tree nuts, olive oil, canola oil & may reduce risk of coronary heart disease (CHD) \\
\hline $\begin{array}{l}\text { Polyunsaturated fatty } \\
\text { acids (PUFAs) } \\
\text { - Omega-3 fatty acids } \\
\text { - Alpha-linolenic acid } \\
(A L A)^{4}\end{array}$ & walnuts, flax & $\begin{array}{l}\text { may contribute to maintenance of heart health; may contribute to maintenance of } \\
\text { mental - Omega-3 fatty acids - ALA and visual function }\end{array}$ \\
\hline $\begin{array}{l}\text { PUFAs - Omega-3 fatty } \\
\text { acids - Docosahexaenoic } \\
\text { acid (DHA)/ } \\
\text { Eicosapentaenoic acid } \\
\text { (EPA) } 3,4\end{array}$ & $\begin{array}{l}\text { salmon, tuna, marine, and other } \\
\text { fish oils }\end{array}$ & $\begin{array}{l}\text { may reduce risk of } \mathrm{CHD} \text {; may contribute to maintenance of mental and visual } \\
\text { function }\end{array}$ \\
\hline $\begin{array}{l}\text { Conjugated linoleic acid } \\
\text { (CLA) }\end{array}$ & beef and lamb; some cheese & $\begin{array}{l}\text { may contribute to maintenance of desirable body composition and healthy } \\
\text { immune function }\end{array}$ \\
\hline \multicolumn{3}{|l|}{ Merate Asies } \\
\hline Caffeic acid, Ferulic acid & $\begin{array}{l}\text { apples, pears, citrus fruits, some } \\
\text { vegetables, coffee }\end{array}$ & $\begin{array}{l}\text { may bolster cellular antioxidant defences; may contribute to maintenance of } \\
\text { healthy vision and heart health }\end{array}$ \\
\hline \multicolumn{3}{|l|}{ 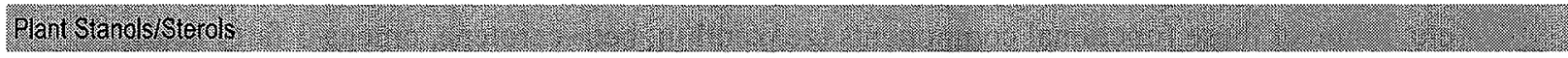 } \\
\hline Free Stanols/Sterols 3,4 & $\begin{array}{l}\text { corn, soy, wheat, wood oils, fortified } \\
\text { foods and beverages }\end{array}$ & may reduce risk of $\mathrm{CHD}$ \\
\hline Stanol/Sterol esters ${ }^{3}$ & $\begin{array}{l}\text { fortified table spreads, stanol ester } \\
\text { dietary supplements }\end{array}$ & may reduce risk of $\mathrm{CHD}$ \\
\hline $\begin{array}{l}\text { Inulin, Fructo- } \\
\text { oligosaccharides (FOS), } \\
\text { Polydextrose }\end{array}$ & $\begin{array}{l}\text { whole grains, onions, some fruits, } \\
\text { garlic, honey, leeks, fortified foods } \\
\text { and beverages }\end{array}$ & may improve gastrointestinal health; may improve calcium absorption \\
\hline $\begin{array}{l}\text { Yeast, Lactobacilli, } \\
\text { Bifidobacteria, and } \\
\text { other specific strains of } \\
\text { beneficial bacteria }\end{array}$ & $\begin{array}{l}\text { certain yogurts and other cultured } \\
\text { dairy and non-dairy applications }\end{array}$ & $\begin{array}{l}\text { may improve gastrointestinal health and systemic immunity; benefits are } \\
\text { strain-specific }\end{array}$ \\
\hline \multicolumn{3}{|l|}{ Ply taestrogens? } \\
\hline $\begin{array}{l}\text { Isoflavones - Daidzein, } \\
\text { Genistein }\end{array}$ & soybeans and soy-based foods & $\begin{array}{l}\text { may contribute to maintenance of bone health, healthy brain and immune } \\
\text { function; and for women, menopausal health }\end{array}$ \\
\hline Lignans & flax, rye, some vegetables & may contribute to maintenance of heart health and healthy immune function \\
\hline
\end{tabular}

Source: Authors, adapted from IFIC (2007)

Notes: 1. Examples are not an all inclusive list.

2. Functional food components also exist in dietary fiber, flavonoids, isothiocyanates, minerals, soy protein, sulfides/thiols, \& vitamins.

3. US FDA approved health claim.

4. GM field trials undertaken or underway on this functional component. 
- The BioCassava Plus programme aims to improve the nutrition of the more that 250 million sub-Saharan Africans who rely on cassava as a staple. The goal is to create cassava which deliver "enhanced bioavailable levels of zinc, iron, protein, vitamin A, vitamin E, and reduced quantities of toxic cyanogenic glycosides, improved post-harvest durability, and improved resistance against viral diseases (BioCassava PLUS, 2007)."

\section{Current status of nutraceuticals}

At present, almost all nutraceuticals are dietary supplements from basic plants. None appear to use biotechnology, but biotechnology (e.g. marker assisted selection or GM) could be used to change plant composition, thereby increasing extraction yield. Many vitamins are produced through fermentation and Vitamin B12 is produced exclusively through synthesis by micro-organisms. However, these are not "isolated or purified from foods" and are therefore not considered to be nutraceuticals.

\section{Other biotech health benefits}

Biotechnology can also be used to modify the composition of foods. While these are neither functional foods, due to the lack of bioactive compounds, nor nutraceuticals because they are consumed as normal foods (i.e. not in medicinal form), they can have an impact on human health. For example:

- Animal scientists are using biotechnology to create meat products, such as beef with lower fat content and pigs with a higher meat-to-fat ratio (BIO, 2007).

- Potatoes, produced through biotechnology, with altered starch content leads to less oil absorption during frying and therefore the consumption of fewer fat calories (Curtis, McClusky, and Wahl, 2002).

\section{Forecasting for functional foods and nutraceuticals}

As previously stated, estimates of the current FFN market are highly variable indicating that any projections will be unreliable. In 2000, one source predicts the United States' FFN market to reach USD 49 billion by 2010 (Nutrition Business Journal as cited by US GAO, 2000). Two years later, the estimate was revised downwards to USD 34.3 billion (see Table 26). Another source estimated the European FFN market in 2012 at USD 300 billion. This would amount to, "nearly two orders of magnitude larger than that of the United

Table 26. United States functional food sales

\begin{tabular}{lcc}
\hline & $\begin{array}{c}\text { Estimated 2001 } \\
\text { (USD billions) }\end{array}$ & $\begin{array}{c}\text { Projected 2010 } \\
\text { (USD billions) }\end{array}$ \\
\hline Beverages & 8.9 & 13.4 \\
Breads \& grains & 4.9 & 7.2 \\
Packaged/prepared & 1.6 & 4.8 \\
Dairy & 1.1 & 4.0 \\
Snack foods & 1.6 & 4.8 \\
Condiments & 0.15 & 0.1 \\
\hline TOTAL & 18.25 & 34.3 \\
\hline
\end{tabular}

Source: Nutrition Business Journal (2002) as cited by Sloan (2005). 
States (Hodgson, 2002)." The report points out however that this large discrepancy is highly dependent upon the definition of FFN.

Definitional issues aside, most analysts see strong growth for the FFN sector in the near to medium term. The United States GAO has identified three factors contributing to this growth: "(l) the aging of the baby-boom generation, (2) an increased interest in selfsufficiency and prevention in health care, and (3) advances in science that are identifying new relationships between diet and disease (US GAO, 2000)."

Even by 2015 , biotechnology is unlikely to play a large role in the FFN sector, but there are indications that active research applying biotechnology to FFN is occurring and that biotechnology's share of the FFN market may increase. Arundel and Sawaya (2009) provide estimates of the types of agricultural biotechnologies likely on the market by 2012-2015. The article demonstrates that GM trials for the product quality traits oils and fatty acids, and proteins and amino acids have increased since 2003, and that some of these product quality traits are likely to enter the market between 2010 and 2012 with a large increase in the number of product quality traits by 2015 .

\section{Medical devices}

Medical devices include a wide range of technologies including surgical instruments and equipment (bandages, surgical gloves, bedpans etc), diagnostics, tissue engineering, medical imaging equipment, and products that effect the structure of a person but which do not achieve their effects through being metabolized in vivo (implants, prostheses, pacemakers, infusion pumps, dialysis machines etc). The regulation of medical devices depends on their potential for harm. Non-invasive devices such as imaging equipment can have mandatory performance standards but they are not regulated as stringently as invasive devices such as implants or heart valves.

\section{Current status of medical devices}

The medical device industry (or biomedical device industry) is commonly linked to biotechnology, particularly in the United States, but the link is due more to the structure of the sector, with a large number of venture-capital funded start-ups, than with shared technologies. An exception is diagnostics, including medical imaging, and tissue engineering (discussed above).

The medical device sector in the US had sales of 123 billion USD in 2006, but very little of this is in areas where biotechnology has possible applications (Lewin Group, 2007).

Many of the applications of biotechnology to medical devices are still in the lab. An example is biosensors that use changes in protein folding to determine activity of a substrate. Exposure triggers a movement in the protein which triggers an electrical device. Protein based sensors do not depend on a chemical reaction and consequently have a long lifetime, with a range of potential applications, such as in glucose monitoring for diabetics. Another example is regenerative medicine, in which stem cells are combined with mechanical devices or substrates.

Medical devices also include several new forms of drug delivery. Medgenics is developing a biopump, in which autologous cells from a patient are modified to produce biopharmaceuticals. The cells are reimplanted into the patient. This is essentially a drug delivery technology that avoids the need for injections (In Pharma Technologist, 2007). Other potential drug delivery devices include a nanodevice that releases drugs in response 
to overexpression of undesirable proteins. According to experts, such a device would not be available by 2015 , but could reach the market by $2030 . .^{45}$ An alternative drug delivery device for insulin is to deliver it in tiny plastic particles of less than 2 microns.

\section{Forecasting for medical devices}

Due to a lack of data, it is not possible to forecast developments in medical devices, based on biotechnology, to 2015. A few new developments in drug delivery are likely to reach the market by 2015 , but other devices such as biosensors are unlikely to reach the market until after 2015 . 


\section{Conclusions}

Based on an analysis of past success rates and the number of clinical trials for bioNMEs in each phase of development, this article estimates that approximately 13 bioNMEs will receive market approval each year to 2015, compared to an annual average of eight bio-NME market approvals between 2000 and 2007 inclusive. The increase is due to a large number of drug candidates in late stage clinical trials in biotherapeutic drug classes with high past success rates.

Biotechnological knowledge will also be used at some point in the development or use of almost all new small and large molecule pharmaceuticals by 2015 . For example, biotechnology could be used to identify new drug targets, assess safety, or guide prescribing practices. Industrial biotechnology will be increasingly used to reduce the cost of manufacturing pharmaceutical precursors. Consequently, soon it will no longer be useful to separate the pharmaceutical sector from the health biotechnology sector.

New biopharmaceuticals will continue to improve health outcomes and some will reach "blockbuster" status. However, theses advances are unlikely to have a major impact on the way in which healthcare is delivered and received, and they will almost certainly - without substantial changes to regulatory and market frameworks - increase healthcare costs (OECD, 2009b).

However, the promise of biotechnology in health is much greater than simply adding new drugs to a doctor's existing arsenal. Experimental therapies of the kind described in this article have the potential to cure rather than treat numerous debilitating illnesses. While it is difficult to predict the short-term future of these therapies, a few successful treatments highlight the potential. For example, in 2008, a woman had her damaged trachea replaced by using donated scaffold cartilage covered with new tissue produced from her own bone marrow stem cells.

Substantial improvements to healthcare delivery could also come through the development of predictive and preventive medicine, which aim to predict the development of disease before symptoms are visible and to prevent or delay the onset of disease through treatment. This would partly involve the use of diagnostics, bioinformatics, and pharmacogenetics to identify and prescribe personalised treatments that account for interactions between the patient's genotype and response to drugs.

The key technology components for a personalised medicine system have been developing rapidly. Bioinformatic tools are increasingly powerful; tremendous amounts of information are being stored and processed, including in public databases accessible over the internet. DNA sequencing costs have decreased dramatically, while at the same time sequencing efficiencies - measured in the number of base pairs a machine can sequence per day - are increasing at a nearly ultra-exponential pace. Both trends are expected to continue in the future. There has also been a rapid increase in the number of identified 
gene-drug relationships, genetic tests available, publications on pharmacogenetics and pharmacogenomics, and drug labels containing pharmacogenetic information.

A transition from current healthcare models to a predictive and preventive health system has already begun. Healthcare reforms under consideration around the world are likely to continue this trend. In addition to solving a number of technological challenges, the success of predictive and preventive healthcare will require changes to how health products are developed, regulated, marketed, and delivered. These issues are extensively discussed in the OECD (2009b) book The Bioeconomy to 2030: Designing a Policy Agenda.

The contribution of biotechnology to health research will continue to grow, but it is too early to tell if it results in a radical improvement in health outcomes or it if the future lies in incremental improvements. The former is the preferable option, but achieving it will not only rely on solving technological and scientific problems. It will also depend upon changes in the private and public spheres to implement appropriate policies and business plans. 


\section{Notes}

1. Humulin received FDA approval in 1982. Developed by Genentech and Eli Lilly, it is a human insulin produced by genetically modified bacteria.

2. The FDA categorizes all new drugs by their therapeutic potential. The highest to lowest categories are as follows: Priority NME, Standard NME, Priority non-NME, Standard nonNME. Of note, the classification is made before the completion of all clinical trials that are required for the drug approval process. This means that some drugs assigned to the highest priority could offer only minimal therapeutic advances over drugs that are already on the market.

3. Bioinformatics and diagnostics are often separated into two distinct fields. In this article diagnostics are viewed as a sub-category of bioinformatics because many biotechnological diagnostics depend on bioinformatics. For example, diagnostic genetic tests require extensive bioinformatics research to identify the genes that are responsible for a specific disease or the risk of developing a chronic condition such as heart disease.

4. For examples of the benefits of using large public databases, see Hall and Lucke (2007) and Graham et al. (2005).

5. A small share of the economic effects from medical devices will be assigned to the medical and surgical instruments sector (NACE 33.1).

6. R\&D intensive biotechnology firms that have no sales of manufactured products are assigned to International Standard Industrial Classification (ISIC) or NACE (revision 1) sector 73.1 (Research and experimental development on natural sciences and engineering). Many firms can remain in this sector for a decade or longer. Once they produce manufactured products, they are reassigned to manufacturing if their manufacturing sales force exceeds that of their services force. In most European countries, the R\&D expenditures of these firms are assigned to the sector of the potential product (for instance pharmaceuticals), but in the United States the R\&D is assigned to the service sector. This acts to depress estimates of R\&D expenditures in pharmaceuticals in the United States and to reduce comparability between US and European R\&D data.

7. In both countries, the value added output of the pharmaceutical sector has grown in absolute terms - it is only the pharmaceutical share of total value-added (similar to GDP) that has declined in the United States, due to faster growth rates in other economic sectors.

8. Gross value-added is approximately equal to GDP. Value added equals the sales revenues at current prices minus all material and capital input costs. Of note total value added can differ substantially from total sales. Global sales of pharmaceutical products are over twice as large as total value added in the pharmaceutical sector.

9. This list refers to newly registered medicines or those who obtained an extension of indication.

10. In medicine, indication refers to the condition that is treated by a specific drug or treatment.

11. The therapeutic advance of all other drugs is also falling, from $16.0 \%$ before 2001 to $10.6 \%$ afterwards, but the decline was not as steep. 
12. This contrasts with the results given by Pisano (2006, pp 125-126) which show that the mid to large size firms are more active in developing novel drugs than small firms. The difference in results is largely due to the types of data used. First, Pisano uses market capitalisation rather than employment as a measure of size, which means that some highly capitalised biotechnology firms would be included with much larger firms in terms of employment. Second, Pisano's measure of novelty is for drugs in clinical trials, whereas the HAS and Prescrire results are for drugs that have received marketing approval. Third, the analyses in this report are based on the firm that developed the drug, instead of the firm that applied for market approval.

13. HAS gave ratings of between an "important improvement" and a "minor improvement" for seven of the biopharmaceuticals considered by Prescrire to be "not acceptable" ( 6 drugs) or "judgement reserved" (1 drug).

14. Twenty years after establishment allows sufficient time for the firm to develop a revenue stream from the sale of biopharmaceuticals. Development work on biopharmaceuticals that were marketed 20 years after establishment would have begun approximately a decade earlier.

15. Autologous cells are taken from an individual, cultured (or stored), and, possibly, genetically manipulated before being infused back into the original donor (FAO, 1999).

16. In October 2003, a gene therapy (p53, trademarked as Gendicine) developed by Shenzhen SiBiono GeneTech Co., Ltd. (www.sibiono.com/), obtained the marketing approval from the China State Food \& Drug Administration (SFDA). In 2005, SFDA approved H101, developed by Shanghai Sunway Biotech.

17. Of these 66 projects, there are 4 on the market, 2 in pre-registration, 4 in phase III clinical trials, 12 in phase II clinical trials, 4 in phase I clinical trials, and 40 in preclinical trials. In contrast to other clinical trial analyses undertaken in this report, this data does include formulations as this is one of the primary areas of nanobiotechnology research.

18. See Cockburn (2006) and Hopkins, et al. (2007).

19. Cockburn (2006) provides data estimating that approximately $30 \%$ of drug candidates are withdrawn by pharmaceutical firms because of "prohibitively high manufacturing costs" or other unspecified reasons, and that this has increased from 5\% in 1991. This suggests that there could be a substantial market for producing small molecule drugs in plants, animals or micro-organisms using rDNA technology.

20. An example is Carbamazepine, used to treat epilepsy. Patients with the allele HLA-B* 1502 can suffer serious adverse skin reactions.

21. Large protein molecule drugs need to be injected, frequently in a hospital or clinic setting, whereas most small molecules can be taken orally at home. Patients have a strong preference for the latter.

22. Before it was bought out by UCB, Celltech's strategy was to develop a mAb, then follow up with a small molecule drug (Personal communication, Michael Hopkins, December 2007).

23. These are defined by Pharmapredicts as "originator firms". They differ from the "developer" firms used in Figures 1 and 2 and Tables 6 and 7, which are defined as the firms that developed the NME. For most Phase I and II clinical trials, the developer firm is likely to be the same as the originator firm.

24. The US share is $55.1 \%$ of phase I trials, $52.3 \%$ of phase II trials, and $55.3 \%$ of phase III trials.

25. Majors are defined here as companies with 5 or more bio-NMEs or compounds in any clinical trial phase or pre-registration. They include Amgen, Astra Zeneca, AVI BioPharma, Bayer, Biogen Idec, Cancer Research Technolgy, Crucell, Cytos Biotechnology, Dynavax Technologies, Eli Lilly, Emergent BioSolutions, Genentech, Genmab, GSK, Green Cross, ImClone Systems, Immunomedics, Introgen Therapeutics, Isis Pharmaceuticals, Johnson \& 
Johnson, Medarex, Merck KGaA, Northwest Biotherapeutics, Novartis, Oxford BioMedica, PDL BioPharma, Pfizer, Sanofi-Aventis, Shanghai CP Guojian, Targeted Genetics, Transgene, Vical and Wyeth.

26. The analyses use OECD data on venture capital investments in the life sciences for 2001 to 2003 inclusive (van Beuzekom and Arundel, 2006) and for 2007 (van Beuzekom and Arundel, 2009). All R2 coefficients were under 0.04 .

27. Pharmapredict (Informa, 2007b) is a quarterly publication. The version used for this analysis (Qtr4 2007) is based on data extracted in March 2008 from Pharmaprojects (Informa, 2007a), and on financial data supplied annually by EvaluatePharma.

28. Success rates and estimated launch dates are calculated with average time spent, for similar drugs, in each of the phases of development. Pharmapredict has been collating this data since 1989 and over 5500 development phase timings are included.

29. Without success rate data for the experimental bio-NMEs, it is very difficult to estimate the expected market approval date, as this requires an estimate of the probability of each biopharmaceutical moving from Phase I to Phase II, from Phase II to Phase III, and from Phase III to market approval. However, if we assume that 1) all products reach the market or fail between 2010 and 2015,2 ) that the success rate for the $38 \%$ of bio-NMEs with no data equals that of the bio-NMEs with data, and 3) that the success rate for the $15 \%$ of nonbio-NMEs equals that of the nonbio-NMEs with data, then the average biopharmaceutical share of all approved pharmaceuticals between 2010 and 2015 increases from approximately $15 \%$ to approximately $21 \%$.

30. Pharmapredict shows that biotechnology drugs spend a mean average of 36 months in phase 2,30 months in phase 3,17 months in pre-registration, and 8 months prior to market entry following registration.

31. Unpublished results from Boris Mannhardt, biotechnologie.de.

32. Diagnostics are classified as medical devices, but they are covered here because of their importance and link with bioinformatics.

33. Other diagnostics include, inter alia, assays for urea, glucose, cholesterol, sodium, potassium, hepatic and cardiac enzymes or faecal occult blood.

34. Though Medical Product Outsourcing does not provide a figure for the global IVD market in 2005, TriMark Publications (2007) gave the value of the global IVD market in as USD 31.5 billion in 2005.

35. Systems biology is a, "field that seeks to study the relationships and interactions between various parts of a biological system (metabolic pathways, organs, cells, and organisms) and to integrate this information to understand how biological systems function (National Institute of General Medical Sciences, 2006)."

36. For examples see http://au.expasy.org/links.html (ExPASy, 2007).

37. The OECD defines a biobank as a, "collection of biological material and the associated data and information stored in an organised system, for a population or a large subset of a population (OECD, 2005b)."

38. For detailed information on these, and other biobanks, see OECD (2006c) or, "The Victorian Cancer Biobank," www.viccancerbiobank.org.au (Australia); "CARTaGENE,", www.cartagene.qc.calen (Canada); "The Estonian Genome Project," www.geenivaramu.ee/index.php (Estonia); "DeCode," www.decode.com/ (Iceland); "The Biobank Japan Project," http:// biobankjp.org (Japan); "Latvian Genome Project," http://bmc.biomed.lu.lv/gene/ (Latvia); "The Swedish National Biobank Program," www.biobanks.se (Sweden); and "The UK biobank," www.ıkbiobank.ac.uk (United Kingdom).

For examples see, Abd-Elsalam (2003). 
40. Pharmacogenomics differs from pharmacogenetics in that it studies the effect of the entire genome (or systems of genes) on drug response.

41. In 2005, the FDA released guidelines on what types of genomic information it will require (FDA, 2005) and in 2006 the FDA and EMEA agreed on a procedure to be jointly briefed following voluntary submission of genomic data (EMEA, 2006). Also, in February 2007 Health Canada produced a guidance document on the submission of pharmacogenomic information (Health Canada, 2007).

42. One study argues that pharmacogenetics will not reduce revenues, estimating that the net present value of a pharmacogenetics drug is approximately USD 85 million higher than that of a conventional drug (Research and Markets, 2006).

43. The number of identifications decreased from 72 in 1994 to 36 and 58 in 1995 and 1996 respectively before returning to 112 in 1997. Likewise, after 595 identifications in 2003, there were only 225 and 325 in 2004 and 2005 respectively. The number increased to to 619 in 2006.

44. The UNU-MERIT GM Field Trial database indicates that there has been one trial for the increase of zeaxanthin (potato), three trials for increased beta-carotene (Potato \& Tomato), seven trials involving omega-3 fatty acids (soybean), and six trials for increased stanol content (soybean).

45. The examples in this section are from an interview on October 8, 2007 with Steve Dahms, Thomas Lobl, and Joseph Schulman. 


\section{References}

Abd-Elsalam, K. (2003), "Bioinformatic tools and guideline for PCR primer design", African Journal of Biotechnology, Vol. 2, No. 5, Academic Journals, pp. 91-95.

Archon X-Prize (2007), "A \$10 million Prize for the First Team to Successfully Sequence 100 Human Genomes in 10 Days", Archon X Prize for Genomics, http://genomics.xprize.org/genomics/archon-x-prize-for-genomics/prize-overview, accessed 14 December 2007.

Arundel, A. and D. Sawaya (2009), "Trends in the Application of Biotechnology to Agriculture and Related Natural Resources to 2015", OECD Journal: General Papers, Volume 2009/3, OECD, Paris.

Beuzekom van, B. and A. Arundel (2006), OECD Biotechnology Statistics - 2006. OECD, Paris.

Beuzekom van, B. and A. Arundel (2009), OECD Biotechnology Statistics - 2009. OECD, Paris.

Ashton, G. (2001), "Growing pains for biopharmaceuticals", Nature Biotechnology, Vol. 19, No. 4, Nature, pp. 307-311.

BBC News (2000), "GM tomatoes 'fight cancer", 30 May 2000, http://news.bbc.co.uk/1/ hi/health/769507.stm, accessed 14 December 2007.

BCC Research (2005a), "Nanotechnology in Life Science Applications", October 2005, www.bccresearch.com/RepTemplate.cfm?reportID $=419 \&$ RepDet $=H L T \&$ cat $=$ nan\&tar get $=$ repdetail.cfm, accessed 14 December 2007.

BCC Research (2005b), "Bioinformatics: Technical Status and Market Prospects", August 2005, www.bccresearch.com/RepTemplate.cfm?reportID =100\&RepDet $=H L T \&$ cat $=$ bio \&target=repdetail.c.fm, accessed 14 December 2007.

BCC Research (2005c), "Pharmacogenomics: New Technologies in the Development of Personalized Medicine", August 2005, www.bccresearch.com/RepTemplate.cfm?report $I D=468 \&$ RepDet $=H L T \& c a t=p h m \&$ target $=$ repdetail.cfm, accessed 14 December 2007 .

The Biobank Japan Project (2007), http://biobankjp.org, accessed 14 December 2007.

BioCassava PLUS (2007), "Grand Challenges in global Health: Mission \& Objectives", http://biocassavaplus.org/program_description.htm, accessed 14 December 2007.

BIO (Biotechnology Industry Organization) (2007), "Food Biotechnology", www.bio.org/ speeches/pubs/er/food.asp, accessed 14 December 2007.

BMJ Clinical Evidence (2007), "A full list of Clinical Evidence sections and systematic reviews", http://clinicalevidence.bmj.com/ceweb/conditions/conditions.jsp, accessed 30 May 2007. 
Bogdanovic, S. and B. Langlands (2006), "Drug Discovery: Focus on Small Molecule Kinease Inhibitors", Business Wire, 29 September 2007, Business Wire, www.thefreelibrary.com/Drug+Discovery $\% 3 a+$ Focus + on + Small + Molecule + Kinase + Inhibitor s.-a0154274171, accessed 19 December 2007.

Carlson, R. (2007), Genome Synthesis and Design Futures: Implications for the US Economy, Bio-Era.

CARTaGENE (2007), www.cartagene.qc.calaccueil/index.asp, accessed 14 December 2007.

CDER (2002), "Preventable Adverse Drug Reactions: A Focus on Drug Interactions", 31 July 2002, FDA, www.fda.gov/CDER/drug/drugreactions/default.htm, accessed 14 December 2007.

Cheng, A., et al. (2007), "Structure-based maximal affinity model predicts small-molecule druggability", Nature Biotechnology, Vol. 25, No. 1, Nature, pp. 71-75.

Cockburn, I. (2006), "Is the Pharmaceutical Industry in a Productivity Crisis?", Innovation Policy and the Economy, Vol. 7, MIT Press for the National Bureau of Economic Research, Cambridge MA, pp. 1-32.

Curtis, K., J. McCluskey and T. Wahl (2002), "Is China the market for genetically modified potatoes?", AgBioForum, Vol. 5, No. 4, AgBioForum, pp. 175-178, www.agbioforum. org/v5n4/v5n4a06-curtis.htm, accessed 14 December 2007.

De Palma, A. (2006), "Pharmacogenomics and the Brave New World of Personalized Medicine", PharmaManufacturing.com, www.pharmamanufacturing.com/articles/2006/047.html, accessed 14 December 2007.

deCODE genetics (2007), www.decode.com/, accessed 14 December 2007.

deCODE (2008), deCODE Launches deCODE BreastCancer ${ }^{\mathrm{TM}}$, a Genetic Test to Screen for Risk of the Most Common Forms of Breast Cancer, www.decode.com/ News/2008_10_08.php, accessed 3 February 2009.

DNA 2.0 (2007), "Gene Designer: Gene Design Automation Tool", www.dna20.com/ genedesigner/GD_v1_help_v1.pdf, accessed 14 December 2007.

DDBJ (DNA Data Bank of Japan) (2009), "Proportion of Contribution to the DDBJ/EMBL/ GenBank International Nucleotide Sequence Database (entry)", www.ddbj.nig.ac.jp/ breakdown_stats/prop_ent.html, accessed 27 August 2009.

Duncan, D. (2009), Complete Genomics Sequences 14 Genomes, MIT Technology Review.

Edelstein, M., M. Abedi and J. Wixon (2007), "Gene therapy clinical trials worldwide to 2007: an update", The Journal of Gene Medicine, Vol. 9, No. 10, Wiley InterScience, pp. 833-842.

eJournalUSA (2005), "Glossary of Biotechnology Terms", The Promise of Biotechnology, US Department of State, Bureau of International Information Programs, http://hisinfo. state.gov/journals/ites/1005/ijee/glossary.htm, accessed 12 December 2007.

EMEA (2006), "PUBLIC STATEMENT: EU (European Commission and EMEA) and FDA agree on guiding principles for joint FDA EMEA voluntary genomic data submission briefing meetings", 31 May 2006, www.emea.europa.eu/pdfs/general/direct/ pr/19136706en.pdf, accessed 14 December 2007. 
Emedicine (2007), "Deep Venous Thrombosis and Thrombophlebitis", www.emedicine. com/emerg/topic122. htm, accessed 30 May 2007.

Emerton, D. and M. Belsey (2006), "Increased uptake of biologics in historically small molecule blockbuster-dominated therapeutics", Journal of Commercial Biotechnology, Vol. 13, No. 1, Palgrave Macmillan, pp. 48-51.

Endy, D. (2005), "Foundations of Engineering Biology", Nature, Vol. 438, Nature, pp. 449-453.

The Estonian Genome Project (2007), www.geenivaramu.ee/index.php, accessed 14 December 2007.

ETC Group (2007), Extreme Genetic Enginering: An Introduction to Synthetic Biology, January 2007.

ETEPS NET (2006), "Case Studies Report: the Impact of Human Health Applications, Annex to Report 3", Consequences, Opportunities and Challenges of Modern Biotechnology for Europe (BIO4EU): Task 2, European Commission.

EU KLEMS (2007), EU KLEMS Project Database, 2007 Edition, European Commission.

EC (European Commission) (2005), Synthetic Biology Applying Engineering to Biology, NEST High-Level Expert Group.

European Organisation for Rare Diseases (2007), "Rare diseases in numbers", www. ec.europa.eu/health/ph_threats/non_com/docs/rdnumbers.pdf, accessed 30 May 2007.

ExPASy (2007), "ExPASy Life Science Directory", http:/lau.expasy.org/links.html, accessed 14 December 2007.

FAO (1999), "Glossary of Biotechnology and Genetic Engineering, FAO Research and Technology Paper", www.fao.org/DOCREP/003/X3910E/X3910E04.htm, accessed 12December 2007.

FDA (1999), "FDA approves First Home Test for Hepatitis C Virus", 29 April 1999, www. fda.gov/bbs/topics/ANSWERS/ANS00952.html, accessed 14 December 2007.

FDA (2001), "Testing Yourself for HIV-1, the Virus that Causes AIDS: Home Test System Is Available", January 2001,www.fda.gov/cber/infosheets/hiv-home.htm, accessed 14 December 2007.

FDA (2004), "Innovation Stagnation: Challenge and Opportunity on the Critical Path to New Medical Products", March 2004, www:fda.gov/oc/initiatives/criticalpath/whitepaper.html, accessed 14 December 2007.

FDA (2005), "Guidance for Industry: Pharmacogenomic Data Submissions", March 2005, www.fda.gov/cder/guidance/6400fnl.pdf, accessed 14 December 2007.

FDA (2006), "Table of Valid Genomic Biomarkers in the Context of Approved Drug Labels", October 2006, www.fda.gov/cder/genomics/genomic_biomarkers_table.htm, accessed 14 December 2007.

FDA (2007), "FDA Approves Tykerb for Advanced Breast Cancer Patients", 13 March 2007, www:fda.gov/bbs/topics/NEWS/2007/NEW01586.html, accessed 19 December 2007. 
FDA (2008), "Table of Valid Genomic Biomarkers in the Context of Approved Drug Labels", April 2008, www.fda.gov/cder/genomics/genomic_biomarkers_table.htm, accessed 1 April 2008.

Food \& Drink Weekly (2001), "New Study Sees Bright Future For Functional Foods: US Functional Food Market study, Brief Article, Statistical Data Included", 12 November 2001, http://findarticles.com/p/articles/mi_mOEUY/is_45_7/ai_80088490, accessed 14 December 2007.

Frueh, F. (2006), "Personalized Medicine: Today!", 22 May 2006, FDA, Clinical Ligand Assay Society, 32nd International Meeting, Louisville, www.fda.gov/cder/genomics/ presentations/CLAS.pdf, accessed 14 December 2007.

GENETests (2008), www.genetests.org/, accessed 27 August 2009.

GEBN (Genetic Engineering \& biotechnology News) (2006), "Small Molecule Drugs: Avoiding Roadblocks in Development", Genetic Engineering \& biotechnology News, 1 November 2006, www.genengnews.com/articles/chitem.aspx?aid=1934, accessed 19 December 2007.

Global Information (2007), "US Demand for Nanotechnology Medical OProducts to Approach \$53 billion in 2011", 27 March 2007, www.giikorea.co.kr/press/FD49304 kr.html, accessed 14 December 2007.

Graham, D., et al. (2005), "Risk of acute myocardial infarction and sudden cardiac death in patients treated with cyclo-oxygenase 2 selective and non-selective non-steroidal anti-inflammatory drugs: nested case-control study", The Lancet, Vol. 365, No. 9503, The Lancet, pp. 475-481.

The Guardian (2007), "I am creating artificial life, declares US gene pioneer", 6 October 2007, www.guardian.co.uk/science/2007/oct/06/genetics.climatechange, accessed 13 December 2007.

Hall, W. and J. Lucke (2007), "Assessing the impact of prescribed medicines on health outcomes", Australia and New Zealand Health Policy, Vol. 4, BioMed Central, pp. 1-9.

Hasler, C. (2002), "Functional Foods: Benefits, Concerns and Challenges, A Position Paper from the American Council on Science and Health", The Journal of Nutrition, Vol. 132, American Society for Nutraceutical Sciences, pp. 3772-3781, http://jn.nutrition.org/cgi/ content/full/132/12/3772, accessed 14 December 2007.

HAS (Haute Autorité de Santé) (2008), Database of therapeutic evaulations, Haute Autorité de Santé, Paris.

Health Canada (1998), "Nutraceuticals/Functional Foods and Health Claims on Foods", Policy Paper, www.hc-sc.gc.calfn-an/alt_formats/hpfb-dgpsa/pdf/label-etiquet/nutrafunct_foods-nutra-fonct_aliment_e.pdf, accessed 14 December 2007.

Health Canada (2007), "Release of Guidance Document: Submission of Pharmacogenomic Information", 14 February 2007, www.hc-sc.gc.caldhp-mps/brgtheraplapplic-demande/ guides/pharmaco/pharmaco_guid_ld_2007-02_e.html, accessed 14 December 2007.

Hedgecoe, A. and P. Martin (2003), "The Drugs Don't Work", Social Studies of Science, Vol. 33, No. 3, Sage Journals, pp. 327-364.

Herper, M. and R. Langreth (2007), "Will You Get Cancer?", 18 June 2007, Forbes, www. forbes.com/business/forbes/2007/0618/052_2.html, accessed 14 December 2007. 
Hirschhorn, J., et al. (2002), "A comprehensive review of genetic association studies", March-April 2002, Genetics in Medicine, www.nslij-genetics.org/ld/hirschhorn02-gm. $p d f$, accessed 14 December 2007.

Hirschler, B. (2007), "Personalized Medicine slowly taking shape", 15 November 2007, Reuters, www.reuters.com/article/idUSDIS55581820071115, accessed 14 December 2007.

Hodgson, J. (2002), "Nutraceuticals tread business tightrope in Europe", Nature Biotechnology, Vol. 20, No. 4, Nature, pp.322-333.

Hopkins, M., et al. (2007), "The myth of the biotech revolution: An assessment of technological, clinical and organisational change", Research Policy, Vol. 36, No. 4, Elsevier, pp. 566-589.

IMF (2006), World Economic Outlook Database, September 2006 Edition, World Economic and Financial Surveys.

IMS Health (2007), "IMS Health Reports Global Pharmaceutical Market Grew 7.0 Percent in 2006, to $\$ 643$ billion", 20 March 2007, www.imshealth.com/ims/portal/front/articleC/0,2777,6599_3665_80560241,00.html, accessed 12 December 2007.

INFORMA Healthcare (2007a), PHARMAPROJECTS database, 2007, UK, accessed May 2007.

INFORMA Healthcare (2007b), PHARMAPREDICT database, 2007, UK, accessed March 2007.

Innovagen (2007), "How to design peptides suitable for antibody production", www.innovagen.se/custom-peptide-polyclonal-antisera/peptide-design-info-pa.asp, accessed 14 December 2007.

In-Pharma Technologist.com (2007), "Medgenics gets (bio)pumping. Http://in-pharmatechnologist.com/news/printNewsBis.asp?id=81822, last accessed 8 December 2007.

Institute for OneWorld Health (2004), "\$42.6 million Five-Year Grant from Gates Foundation for Antimalarial Drug Brings Together Unique Collaboration of Biotech, Academia, and Nonprofit Pharma", 13 December 2004, www.oneworldhealth.org/ media/details.php?prID=103, accessed 13 December 2007.

ICH (International Conference on Harmonisation) (2008), Genomic Biomarkers Related to Drug Response: Context, Structure and Format of Qualification Submissions, www.ich. org/LOB/media/MEDIA4745.pdf, accessed 23 January 2009.

IFOPA (International Fibrodysplasia Ossificans Progressiva Association) (2007), "Glossary of Medical and Research Terms", www.ifopa.org/glossary.html, accessed 12 December 2007.

IFIC (International Food Information Council) (2007), "Functional Foods", www.ific.org/ nutrition/functional/upload/functionalfoodsbackgrounder.pdf, accessed 14 December 2007.

iGEM (International Genetically Engineered Machine Competition) (2006a), "iGEM 2006: The international Genetically Engineered Machine competition", http://parts.mit.edu/ wiki/index.php/Main_Page, accessed 13 December 2007.

iGEM (2006b), "The iGEM history", www.igem2006.com/history.htm, accessed 13 December 2007. 
iGEM (2007a), "Registry of Standard Biological Parts", http://parts.mit.edu/, accessed 13 December 2007.

iGEM (2007b), "Teams Registered for iGEM 2007", http://parts.mit.edu/r/parts/igem/ team_list.cgi, accessed 13 December 2007.

IHT (International Herald Tribune) (2007), "Gene-silencing therapy at heart of potential $\$ 1$ billion licensing pact", 9 July 2007, www.iht.com/articles/ap/2007/07/09/business/ NA-FIN-COM-US-Roche-Alnylam.php, accessed 13 December 2007.

ITPS (2006), Pharmacogenetics and Pharmacogenomics: State-of-the-art and potential socio-economic impacts in the EU, April 2006, European Commission, http://ftp.jrc.es/ eur22214en.pdf, accessed 14 December 2007.

Jain, K. (2000), "Antisense Therapy: Technical Aspects and Commercial Opportunities", Business Insights, www.globalbusinessinsights.com/content/rbhc0027t.pdf, accessed 13 December 2007.

Jarvis, L. (2007), "Biotechs Target Smal Molecules: Amgen, Genentech snatch early-stage drugs", Chemical \& Engineering News, Vol. 85, No. 2, American Medical Society, p. 10.

Jia, H. (2006), "Gene therapy finds welcoming environment in China", Nature Medicine, Vol. 12, No. 3, Nature, pp. 263-264.

JRC (European Commission Joint Research Centre) (2007), Consequences, Opportunities and Challenges of Modern Biotechnology for Europe, April 2007, European Commission.

Kanehisa, M. and P. Bork (2003), "Bioinformatics in the post-sequence era", Nature Genetics Supplement, Vol. 33, Nature, pp. 305-310.

Latavian Genome Project (2007), http://bmc.biomed.lu.lv/genel, accessed 14 December 2007.

Lawrence, S. (2005), "IT Use for Drug Discovery to Rise", 29 June 2005, CIO Insight, www.cioinsight.com/article2/0,1540,1832630,00.asp, accessed 14 December 2007.

Lewin Group. "State impacts of the Medical Technology Industry", Falls Church, VA, July 2007.

Paul Martin, Michael Hopkins and Paul Nightingale (2008), 'Living with 'Dinosaurs': Genomics, and the industrial dynamics of the pharmaceutical industry", 25th DRUID Conference, Copenhagen Business School.

Medical Product Outsourcing (2003), "Top Companies Report", June 2003, www.mpo-mag. com/articles/2003/06/top-companies-report, accessed 14 December 2007.

Medical Product Outsourcing (2006), "The Top 15 IVD Companies Report", June 2006, www.mpo-mag.com/articles/2006/06/top-ivd-companies-report, accessed 14 December 2007.

MedicineNet (2001), "Definition of Cell Therapy", July 2001, www.medterms.com/script/ main/art.asp?articlekey=17905, accessed 12 December 2007.

Murthy, V., H.M. Krumholz, and C. P. Gross (2004), Participation in Cancer Clinical Trials, Journal of the American Medical Association, Vol 291, pp 2720-2726. 
National Institute of General Medical Sciences (2006), "Glossary", The New Genetics Publication No. 07-662, National Institutes of Health, October 2006, http://publications. nigms.nih.gov/thenewgenetics/glossary. html, accessed 13 December 2007.

NISTEP (National Institute of Science and Technology Policy) (2005), Health, medical care, and welfare field, The 8th Science and Technology Foresight Survey: Delphi Analysis, www.nistep.go.jp/achiev/ftx/eng/rep097e/pdf/rep097e08.pdf, accessed 13 December 2007.

National Organisation for Rare Disorders (2007), "The Physicians's Guide to Pompe Disease", www.rarediseases.org/programs/pompe_brochure.html, accessed 30 May 2007.

NSF (National Science Foundation) (2007), "Tissue Engineering", November 2007, www.nsf.gov/od/lpa/nsf50/nsfoutreach/htm/n50_z2/pages_z3/45_pg.htm, accessed 12 December 2007.

NCBI (2004), "One Size Does Not Fit All: The Promise of Pharmacogenomics", 31 March 2004, www.ncbi.nlm.nih.gov/About/primer/pharm.html, accessed 14 December 2007.

NCBI (2007), "GenBank Overview: International databases exceed 100 gigabases", www. ncbi.nlm.nih.gov/Genbank/index.html, accessed 14 December 2007.

NZ MoRST (New Zealand Ministry of Research, Science and Technology) (2005), Biotechnologies to 2025, Futurewatch, www.morst.govt.nz/business/biotech-to-2025/.

OECD (2005a), "Bioinformatics", OECD Glossary of Statistical Terms, http://stats.oecd. org/glossary/detail.asp?ID=6307, accessed 14 December 2007.

OECD (2005b), "Biobank", OECD Glossary of Statistical Terms, http://stats.oecd.org/glossary/detail.asp?ID=7220, accessed 14 December 2007.

OECD (2006a), Projecting OECD Health and Long-term Care Expenditures: What are the Main Drivers?, internal working document, Economics Department, OECD, Paris.

OECD (2006b), Creation and Governance of Human Genetic Research Databases, Directorate for Science, Technology and Industry, OECD, Paris.

OECD (2007a), STAN Structural Analysis Databases, 2007 Edition, OECD, Paris.

OECD (2007b), Patent Database, June 2007 Edition, OECD, Paris.

OECD (2007c), Genetic Testing: A survey of quality assurance and proficiency standards, Working Party on Biotechnology, Directorate for Science, Technology and Industry, Committee for Scientific and Technological Policy, OECD, Paris.

OECD (2007d), Pharmacogenetics Policy Report: Opportunities and Challenges for Health Systems, Working Party on Biotechnology, Directorate for Science, Technology and Industry, Committee for Scientific and Technological Policy, OECD, Paris.

OECD (2008), National Accounts of OECD Countries, OECD, Paris.

OECD (2009a), Health Database, June 2009 Edition, OECD, Paris.

OECD (2009b). The Bioeconomy to 2030: Designing a Policy Agenda, OECD, Paris.

OECD (forthcoming), Pharmacogenetics: Opportunities and Challenges for Health Innovation, OECD, Paris. 
Orphanet (2007), "The Portal for Rare and Orphan Diseases", www.orpha.net/consor/cgibin/Disease.php?lng=EN, accessed 30 May 2007.

Oxford (2007), "Oxford Dictionary of Biochemistry and Molecular Biology", 2nd Edition, Oxford University Press.

Palinic, R. (2007), Results from the Functional Foods and Nutraceuticals Survey 2005, Working Paper, Statistics Canada, Science, Innovation and Electronic Information Division, www.statcan.calenglish/freepub/88F0006XIE/88F0006XIE2007003.pdf, accessed 14 December 2007.

PharmGKB (2007), "Annotated PGx Gene Information", www.pharmgkb.org/search/annotatedGene/index.jsp, accessed 14 December 2007.

Phillips, K. (2006), "The Intersection of Biotechnology and Pharmacogenomics: Health Policy Implications", Health Affairs, Vol. 25, No. 5, Health Affairs, pp. 1271-1280.

Pisano, G. (2006), Science Business, Harvard Business School Press, Boston.

Powell, K. (2007), "Functional foods from biotech: an unappetizing prospect?", Nature Biotechnology, Vol. 25, No. 5, Nature, pp. 525-531.

Prescrire (1989-2008), various issues, Prescrire, Paris.

PWC (Price Waterhouse Coopers) (2005), Personalized Medicine: The Emerging Pharmacogenomics Revolution, February 2005, www.pwc.com/techforecast/pdfs/ pharmaco-wb-x.pdf, accessed 14 December 2007.

PubMed (2007), www.ncbi.nlm.nih.gov/sites/entrez, accessed 14 December 2007.

Radley, D., S. Finkelstein and R. Stafford (2006), "Off-label Prescribing Among OfficeBased Physicians", Archive of Internal Medicine, Vol. 166, pp. 1021-1026.

Research and Markets (2006), "How to Succeed in Personalized Medicine by Using Tools and Techniques", January 2006, Drug amd Market Development, http://researchandmarkets.com/reportinfo.asp?report_id $=344555$, accessed 14 December 2007.

Ro, D-K., et al. (2006), "Production of the antimalarial drug precursor artemisinic acid in engineered yeast", Nature, Vol. 440, No. 7086, Nature, pp. 940-943.

The Royal Society (2005), Pharmacogenetics: the hopes and realities of personalised medicines, a guide for health professionals, October 2005, The Royal Society, http:// royalsociety.org/downloaddoc.asp?id=2484, accessed 14 December 2007.

Scheu, M. et al. (2006), "Mapping nanotechnology patents: the EPO approach", World Patent Information, Vol. 28, No. 3, Elsevier, pp. 204-211.

ScienceDaily (2006), "Gene Machine: Cells Engineered To Prevent Sepsis Win Synthetic Biology Competition", 15 November 2006, www.sciencedaily.com/ releases/2006/11/061114193826. htm, accessed 13 December 2007.

Sloan, E. (2005), “Top 10 Global Food Trends", Food Technology, Vol. 59, No. 4, Institute of food Technologists, pp. 20-32.

Smith, B. (2007), "Boosting Ellagic Acid Strawberries", United States Department Of Agriculture, Agricultural Research Service, www.ars.usda.gov/is/AR/archive/aug97/ ellagic0897.htm, accessed 14 December 2007.

The Swedish National Biobank Program, www.biobanks.se, accessed 14 December 2007. 
Tamm, I., B. Dörken, G. Hartmann (2001), "Antisense Therapy in Oncology: New Hope for an Old Idea?", The Lancet, Vol. 358, No. 9280, The Lancet, pp. 489-497.

TriMark Publications (2007), Clinical Chemistry Analyzers, TriMark Publications.

Tsoka, S. and C. Ouzounis (2000), "Recent developments and future directions in computational genomics", FEBS Letters, Vol. 480, No. 1, Elsevier, pp. 42-48.

US DOE (United States Department of Energy) (2007), "Human Genome Project Information: Gene Therapy", www.ornl.gov/sci/techresources/Human_Genome/medicine/genetherapy.shtml, accessed 13 December 2007.

US GAO (2000), Food Safety: Improvements Needed in Overseeing the Safety of Dietary Supplements and "Functional Foods", US GAO, Washington D.C.

US GAO (2006), New Drug Development-Science, Business, Regulatory, and Intellectual Property Issues Cited as Hampering Drug Development Efforts, US GAO, Washington, D.C.

USNLM (United States National Library of Medicine) (2005), "Public Collections of DNA and RNA Sequence Reach 100 Gigabases", 22 August 2005, www.nlm.nih.gov/news/ press_releases/dna_rna_100_gig.html, accessed 14 December 2007.

Universidad de Grenada (2001), "Invasive-Diagnostic Test", www.ugr.es/ oncoterm/ csdata/INVASIVE-DIAGNOSTIC-TEST.html, accessed 14 December 2007.

UNU-MERIT (2007), Database of biopharmaceuticals, 2007, Netherlands.

The UK biobank, www.ukbiobank.ac.uk, accessed 14 December 2007.

Van Dusen, A. (2007), "Top Allergy-Friendly Food Finds", Forbes, 12 Sept 2007, www. forbes.com/health/2007/09/11/allergy-food-health-forbeslife-cx_avd_0912health.html, accessed 14 December 2007.

Victorian Cancer Biobank (2007), www.viccancerbiobank.org.au, accessed 14 December 2007.

Wrongdiagnosis (2007), "Disease Center", www.wrongdiagnosis.com/diseasecenter.htm, accessed 30 May 2007.

Zimmer, C. (2006), "Scientist of the Year: Jay Keasling, Which scientist had the greatest impact in the past year?", Discover Magazine, 22 November 2006, http://discovermagazine.com/2006/dec/cover, accessed 13 December 2007. 


\section{Annex $A$}

\section{Supporting tables on biopharmaceuticals and clinical trials}

Table 27. List of $\mathbf{1 5 5}$ biopharmaceuticals that received market approval between January 1989 and January 2009

\begin{tabular}{|c|c|c|c|}
\hline Scientific name & Registration year & Developer company & Head office country \\
\hline 1311-tositumomab & 2003 & Corixa & US \\
\hline abatacept & 2006 & BMS & US \\
\hline abciximab & 1995 & Centocor & US \\
\hline adalimumab. & 2002 & Cambridge Antibody Technology & UK \\
\hline agalsidase alfa & 2001 & Transkaryotic Therapies & US \\
\hline agalsidase beta & 2001 & Genzyme & US \\
\hline aldesleukin & 1989 & Cetus & US \\
\hline alefacept & 2003 & Biogen ldec & US \\
\hline alemtuzumab & 2001 & Millenium & US \\
\hline alfa-1 antritrypsin & 2003 & Mitsubishi Pharma & Japan \\
\hline alglucosidase alfa & 2006 & Genzyme & US \\
\hline alteplase & 1996 & Genentech & US \\
\hline anakinra & 2001 & Amgen & US \\
\hline antithrombin alfa & 2006 & Aventis & France \\
\hline arctiumomab & 1996 & Immunomedics & US \\
\hline ART-123 (thrombomodulin) & 2008 & Asahi Kasei Pharma & Japan \\
\hline asparaginase (L-) & 1994 & Enzon & US \\
\hline basiliximab & 1998 & Novartis & Switzerland \\
\hline becaplermin & 1998 & Chiron & US \\
\hline bevacizumab & 2004 & Genentech & US \\
\hline capromab pendetide & 1997 & Cytogen & US \\
\hline carperitide & 1995 & Suntory & Japan \\
\hline Celmoleukin & 1992 & Ajinomoto & Japan \\
\hline certolizumab pegol & 2008 & Celltech & UK \\
\hline cetuximab & 2003 & ImClone & US \\
\hline choriogonadotropin alfa & 2000 & Serono & Switzerland \\
\hline Clotinab & 2006 & ISUABXIS & South Korea \\
\hline Coagulation factor VIla & 1996 & Novo Nordisk & Denmark \\
\hline Coagulation factor VIII & 1993 & Genentech & US \\
\hline Coagulation factor VIII & 1993 & Genetics institute & US \\
\hline Coagulation factor VIII & 2008 & Wyeth & US \\
\hline
\end{tabular}


Table 27. List of 155 biopharmaceuticals that received market approval between January 1989 and January 2009 (continued)

\begin{tabular}{|c|c|c|c|}
\hline Scientific name & Registration year & Developer company & Head office country \\
\hline Coagulation factor VIII-2 & 1999 & Bayer & Germany \\
\hline daclizumab & 1998 & Protein Design Labs & US \\
\hline darbepoetin alfa & 2001 & Amgen & US \\
\hline denileukin diftitox & 1999 & Seragen & US \\
\hline desirudin & 1997 & Novartis & Switzerland \\
\hline dibotermin alfa & 2002 & Genetics institute & US \\
\hline dornase alfa & 1993 & Genentech & US \\
\hline drotrecogin alfa & 2001 & Eli Lilly & US \\
\hline duteplase (tPA) & 1993 & Genetics institute & US \\
\hline DWP-401 & 2001 & Daewoong & South Korea \\
\hline eculizumab & 2007 & Alexion & US \\
\hline edrecolomab & 1995 & Centocor & US \\
\hline efalizumab & 2003 & Genentech & US \\
\hline endostatin & 2005 & Yantai Medgenn & China \\
\hline Epoetin alfa (erythropoietin) & $1990^{\circ}$ & Genetics institute & US \\
\hline Epoetin beta & 1989 & Amgen & US \\
\hline epoetin beta (pegylated) & 2007 & Roche & Switzerland \\
\hline epoetin delta & 2002 & Transkaryotic Therapies & US \\
\hline eptotermin alfa & 2001 & Stryker-Curis & US \\
\hline etanercept & 1998 & Immunex & US \\
\hline FGF (fibroblast growth factor) & 2007 & Sinobiomed & China \\
\hline filgrastim & 1991 & Amgen & US \\
\hline Filgrastim (pegylated) & 2002 & Amgen & US \\
\hline follitropin alfa & 1995 & Serono & Switzerland \\
\hline follitropin beta & 1996 & Organon & Netherlands \\
\hline fomivirsen sodium & 1998 & Isis Pharmaceuticals & US \\
\hline FSH (follicle stimulating hormone) & 2006 & LG Life Sciences & South Korea \\
\hline galsulfase & 2005 & Biomarin & US \\
\hline GEM-21S & 2005 & Biomimetic & US \\
\hline gemtuzumab ozogamicin & 2000 & Wyeth & US \\
\hline glucagon & 1999 & Eli Lilly & US \\
\hline$H-101$ & 2005 & Shanghai Sunway Biotech & China \\
\hline hep-B vaccine & 2000 & Bio-Technology General & Israel \\
\hline hep-B vaccine & 2000 & Evans Vaccines & UK \\
\hline hep-B vaccine & 1991 & Biogen & US \\
\hline hep-B vaccine & 1991 & Genentech & US \\
\hline hep- $B$ vaccine & 2003 & Rhein Biotech & Germany \\
\hline hep-B vaccine & 2005 & Corixa & US \\
\hline HPV vaccine & 2006 & CSL & Australia \\
\hline HPV vaccine & 2007 & Medimmune & US \\
\hline hyaluronidase & 2005 & Halozyme Therapeutics & US \\
\hline ibritumomab tiuxetan & 2002 & IDEC & US \\
\hline
\end{tabular}


Table 27. List of 155 biopharmaceuticals that received market approval between January 1989 and January 2009 (continued)

\begin{tabular}{|c|c|c|c|}
\hline Scientific name & Registration year & Developer company & Head office country \\
\hline idursulfase & 2006 & Transkaryotic Therapies & US \\
\hline imciromab & 1991 & Centocor & US \\
\hline Imiglucerase & 1994 & Genzyme & US \\
\hline infliximab (TNF) & 1998 & Centocor & US \\
\hline influenza vaccine & 2003 & Medimmune & US \\
\hline influenza vaccine & 2007 & Medimmune & US \\
\hline insulin aspart & 1999 & Novo Nordisk & Denmark \\
\hline insulin detemir & 2004 & Novo Nordisk & Denmark \\
\hline Insulin glargine & 2000 & Aventis & France \\
\hline insulin glulisine & 2004 & Aventis & France \\
\hline insulin lispro & 1995 & Eli Lilly & US \\
\hline insulin recombinant human & 1991 & Novo Nordisk & Denmark \\
\hline interferon alfa & 1997 & Amgen & US \\
\hline interferon alfa $2 a$ (peg) & 2002 & Roche & Switzerland \\
\hline interferon alfa $2 b$ & 2002 & Biogen & US \\
\hline interferon alfacon 1 & 2002 & Amgen & US \\
\hline interferon beta1a & 1996 & Biogen & US \\
\hline Interferon beta1a & 1998 & Serono & Switzerland \\
\hline Interferon beta1b & 1993 & Chiron & US \\
\hline Interferon gamma1b & 1991 & Genentech & US \\
\hline ior-cea1 & 1995 & Center of Molecular Immunology & Cuba \\
\hline ior-egftr3 & 1995 & Center of Molecular Immunology & Cuba \\
\hline laronidase & 2003 & Biomarin & US \\
\hline lenograstim & 1992 & Chugai & Japan \\
\hline lepirudin & 1997 & Hoechst & Germany \\
\hline Lutropin alfa (FSH) & 2000 & Serono & Switzerland \\
\hline Lyme vaccine & 1998 & GSK & UK \\
\hline mecasermin & 1994 & Fujisawa & Japan \\
\hline mecasermin rinfabate & 2005 & Celtrix pharmaceuticals & US \\
\hline monteplase (tPA) & 1998 & Eisai & Japan \\
\hline moroctocog alfa & 1999 & Genetics institute & US \\
\hline muromonab OKT3 & 1992 & Ortho Biotech & US \\
\hline nartograstim & 1994 & Kyowa Hakko & Japan \\
\hline natalizumab & 2004 & Elan & Ireland \\
\hline nateplase (tPA) & 1996 & Mitsui & Japan \\
\hline nesiritide citrate & 2001 & Scios & US \\
\hline nimotuzumab & 2005 & Center of Molecular Immunology & Cuba \\
\hline nonacog alfa & 1997 & Genetics institute & US \\
\hline octocog alfa & 2003 & Baxter & US \\
\hline omalizumab & 2002 & Genentech & US \\
\hline oprelvekin & 1998 & Genefics institute & US \\
\hline OspA lyme disease vaccine & 1998 & GSK & UK \\
\hline
\end{tabular}


Table 27. List of 155 biopharmaceuticals that received market approval between January 1989 and January 2009 (continued)

\begin{tabular}{|c|c|c|c|}
\hline Scientific name & Registration year & Developer company & Head office country \\
\hline palifermin & 2004 & Amgen & US \\
\hline palivizumab & 1998 & Medimmune & US \\
\hline panitumumab & 2006 & Amgen & US \\
\hline Parathyroid hormone (human) & 2006 & Allelix & Canada \\
\hline pediatric vaccine & 2006 & Chiron & US \\
\hline pegaptanib octasodium & 2004 & Gilead Sciences & US \\
\hline pegaspargase & 1994 & Enzon & US \\
\hline pegvisomant & 2002 & Sensus & US \\
\hline Pertussis vaccine & 1993 & Chiron & US \\
\hline ranibizumab & 2006 & Genentech & US \\
\hline rasburicase & 2001 & Sanofi-Aventis & France \\
\hline reteplase (tPA) & 1996 & Roche & Switzerland \\
\hline Rexin-G & 2006 & Epeius Biotechnologies & US \\
\hline rhCG & 2000 & Serono & Switzerland \\
\hline rhLH & 2000 & Serono & Switzerland \\
\hline rilonacept & 2008 & Regeneron & US \\
\hline rituximab & 1997 & IDEC & US \\
\hline romiplostim & 2008 & Amgen & US \\
\hline Sargramostim & 1991 & Berlex labs & US \\
\hline Satumomab pendetide & 1993 & Cytogen & US \\
\hline Sinteplase & 1991 & Integrated Genetics & US \\
\hline somatomedin-1 & 1994 & Biogen & US \\
\hline somatomedin-1 & 2005 & Tercica & US \\
\hline somatropin & 1994 & Genentech & US \\
\hline somatropin & 2008 & Cangene & Canada \\
\hline sulesomab & 1997 & Immunomedics & US \\
\hline tasonerim (TNF) & 1999 & Genentech & US \\
\hline Tc $99 \mathrm{~m}$ nofetumomab merpentan & 1997 & NeoRX & US \\
\hline Tc 99m votumumab (HumaSPECT) & 1998 & Intracel & US \\
\hline technetium Tc $99 \mathrm{~m}$ fanolesomab & 2004 & Palatin & US \\
\hline tenecteplase (tPA) & 2000 & Genentech & US \\
\hline teriparatide & 2002 & Eli Lilly & US \\
\hline thrombin alfa & 2008 & ZymoGenetics & US \\
\hline thyrotropin alfa & 1998 & Genzyme & US \\
\hline tocilizumab & 2005 & Chugai & Japan \\
\hline tositumomab & 2003 & Corixa & US \\
\hline trafermin & 2001 & Scios & US \\
\hline trastuzumab & 1998 & Genentech & US \\
\hline Tumour Necrosis Therapy & 2003 & Peregrine & US \\
\hline ustekinumab & 2009 & Centocor & US \\
\hline
\end{tabular}

Source: Authors, based on Informa (2007a), FDA, EMEA. 
Table 28 . Number of biotechnology clinical trials and pre-registrations by country

\begin{tabular}{|c|c|c|c|c|c|}
\hline & Phase I & Phase II & Phase III & Pre-registration & Total \\
\hline Australia & 7 & 7 & 0 & 0 & 14 \\
\hline Austria & 4 & 4 & 1 & 0 & 9 \\
\hline Belgium & 4 & 1 & 0 & 1 & 6 \\
\hline Bermuda & 0 & 3 & 1 & 0 & 4 \\
\hline Brazil & 1 & 1 & 0 & 0 & 2 \\
\hline Canada & 6 & 13 & 2 & 1 & 22 \\
\hline China & 3 & 8 & 0 & 0 & 11 \\
\hline Denmark & 10 & 12 & 3 & 0 & 25 \\
\hline Finland & 1 & 1 & 0 & 0 & 2 \\
\hline France & 11 & 11 & 2 & 0 & 24 \\
\hline Germany & 9 & 21 & 6 & 2 & 38 \\
\hline India & 2 & 0 & 0 & 0 & 2 \\
\hline Ireland & 0 & 3 & 0 & 0 & 3 \\
\hline Israel & 1 & 7 & 2 & 0 & 10 \\
\hline Italy & 4 & 8 & 2 & 0 & 14 \\
\hline Japan & 5 & 12 & 3 & 1 & 21 \\
\hline Malta & 1 & 0 & 0 & 0 & 1 \\
\hline Netherlands & 7 & 5 & 0 & 1 & 13 \\
\hline Russian Federation & 0 & 2 & 0 & 2 & 4 \\
\hline South Korea & 6 & 5 & 3 & 1 & 15 \\
\hline Spain & 0 & 1 & 0 & 0 & 1 \\
\hline Sweden & 1 & 3 & 2 & 0 & 6 \\
\hline Switzerland & 12 & 12 & 3 & 0 & 27 \\
\hline United Kingdom & 19 & 37 & 12 & 2 & 70 \\
\hline United States & 140 & 194 & 52 & 7 & 393 \\
\hline Total & 2581 & $372^{2}$ & 94 & 18 & $742^{3}$ \\
\hline
\end{tabular}

Source: Authors, based on data from Informa (2007a).

Notes: 1. The originator country was not specified for 4 biotechnology drugs clinical trials in phase I.

2. The originator country was not specified for I biotechnology drugs clinical trials in phase II.

3. The column does not sum do to the 5 biotechnology drugs clinical trials for which the originator country was not specified (see notes 1 and 2). 
Table 29. Number of experimental biotechnology therapies in clinical trials and pre-registrations by country

\begin{tabular}{|c|c|c|c|c|c|c|c|c|c|c|c|}
\hline \multirow[b]{2}{*}{ Therapy Type } & \multicolumn{11}{|c|}{ Phase I (experimental therapies) } \\
\hline & 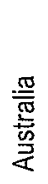 & 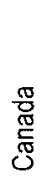 & 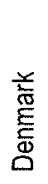 & 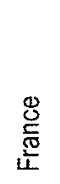 & $\begin{array}{l}\bar{\Phi} \\
\overline{\mathbb{W}} \\
\underline{\underline{\omega}}\end{array}$ & 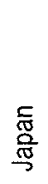 & 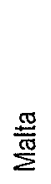 & 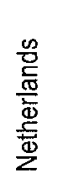 & 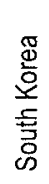 & 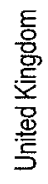 & 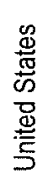 \\
\hline Antisense & 1 & 1 & 1 & 0 & 0 & 0 & 0 & 1 & 0 & 1 & 5 \\
\hline Cell \& tissue, non-stem cell & 0 & 0 & 1 & 1 & 0 & 1 & 0 & 0 & 1 & 1 & 6 \\
\hline Stem cell & 1 & 0 & 0 & 0 & 1 & 0 & 0 & 0 & 1 & 0 & 9 \\
\hline Gene therapy & 0 & 1 & 0 & 1 & 0 & 0 & 1 & 0 & 1 & 0 & 16 \\
\hline RNA-interference & 0 & 0 & 0 & 0 & 0 & 0 & 0 & 0 & 0 & 1 & 1 \\
\hline TOTAL & 2 & 2 & 2 & 2 & 1 & 1 & 1 & 1 & 3 & 3 & 37 \\
\hline
\end{tabular}

Source: Authors, based on data from Informa (2007a).

\begin{tabular}{|c|c|c|c|c|c|c|c|c|c|c|c|c|c|c|c|c|}
\hline \multirow[b]{2}{*}{ Therapy Type } & \multicolumn{16}{|c|}{ Phase II (experimental therapies) } \\
\hline & 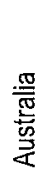 & 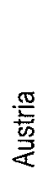 & $\begin{array}{l}\overline{\overline{\mathbb{N}}} \\
\stackrel{\tilde{\omega}}{\oplus}\end{array}$ & $\begin{array}{l}\stackrel{\mathbb{D}}{\mathbb{D}} \\
\text { 胥 } \\
0\end{array}$ & 䄈 & 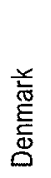 & $\begin{array}{l}\stackrel{\Xi}{\mathrm{U}} \\
\stackrel{\mathbb{W}}{\mathbb{4}}\end{array}$ & 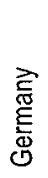 & $\begin{array}{l}\overline{\mathbb{W}} \\
\text { 霑 } \\
\end{array}$ & $\stackrel{\text { ल्ञ }}{\underline{\underline{\Phi}}}$ & 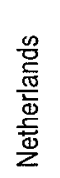 & 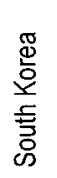 & $\begin{array}{l}\frac{5}{\mathbb{0}} \\
\frac{0}{n}\end{array}$ & $\begin{array}{l}\text { क्ष } \\
\text { क्ष } \\
\text { on }\end{array}$ & 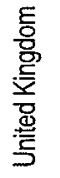 & 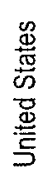 \\
\hline Antisense & 1 & 0 & 0 & 5 & 0 & 1 & 0 & 1 & 0 & 0 & 0 & 0 & 0 & 1 & 1 & 11 \\
\hline Cell \& tissue, non-stem cell & 2 & 0 & 1 & 1 & 0 & 1 & 2 & 1 & 0 & 1 & 2 & 0 & 1 & 0 & 4 & 21 \\
\hline Stem cell & 0 & 0 & 0 & 0 & 0 & 0 & 0 & 2 & 0 & 0 & 0 & 1 & 0 & 0 & 0 & 4 \\
\hline Gene therapy & 0 & 1 & 0 & 0 & 1 & 1 & 3 & 0 & 2 & 2 & 1 & 3 & 0 & 0 & 3 & 27 \\
\hline RNA-interference & 0 & 0 & 0 & 0 & 0 & 0 & 0 & 0 & 0 & 0 & 0 & 0 & 0 & 0 & 1 & 2 \\
\hline TOTAL & 3 & 1 & 1 & 6 & 1 & 3 & 5 & 4 & 2 & 3 & 3 & 4 & 1 & 1 & 9 & 65 \\
\hline
\end{tabular}

Source: Authors, based on data from Informa (2007a).

\begin{tabular}{|c|c|c|c|c|c|c|c|c|c|c|c|}
\hline \multirow[b]{2}{*}{ Therapy Type } & \multicolumn{8}{|c|}{ Phase III (experimental therapies) } & \multicolumn{3}{|c|}{$\begin{array}{c}\text { Pre-registration } \\
\text { (experimental } \\
\text { therapies) }\end{array}$} \\
\hline & 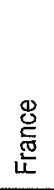 & 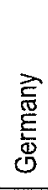 & $\begin{array}{l}\bar{\Phi} \\
\underline{\mathbb{J}} \\
\underline{\omega 0}\end{array}$ & 彥 & 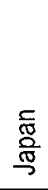 & 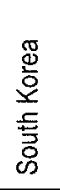 & 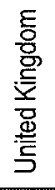 & 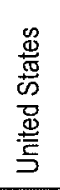 & $\begin{array}{l}\frac{E}{5} \\
\frac{5}{\Phi} \\
\infty\end{array}$ & 忘 & 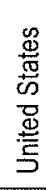 \\
\hline Antisense & 0 & 0 & 0 & 0 & 0 & 0 & 0 & 2 & 0 & 0 & 1 \\
\hline Cell \& tissue, non-stem cell & 0 & 1 & 0 & 0 & 0 & 0 & 1 & 4 & 1 & 0 & 1 \\
\hline Stem cell & 0 & 1 & 1 & 0 & 0 & 0 & 0 & 2 & 0 & 0 & 0 \\
\hline Gene therapy & 1 & 0 & 0 & 1 & 1 & 1 & 3 & 5 & 0 & 1 & 1 \\
\hline RNA-interference & 0 & 0 & 0 & 0 & 0 & 0 & 0 & 1 & 0 & 0 & 0 \\
\hline TOTAL & 1 & 2 & 1 & 1 & 1 & 1 & 4 & 14 & 1 & 1 & 3 \\
\hline
\end{tabular}

Source: Authors, based on data from Informa (2007a).

Note: Experimental therapies include cell and tissue engineering (including sten cells) and gene related therapies (including gene therapy, antisense and RNA-interference). 
Table 30. Number of NMEs and bio-NMEs expected to reach registration, by year

\begin{tabular}{cccc}
\hline Year & $\begin{array}{c}\text { Non-bio NMEs } \\
\text { expected to reach registration }\end{array}$ & $\begin{array}{c}\text { Bio-NMEs } \\
\text { expected to reach registration }\end{array}$ & Bio share of registrations \\
\hline 2008 & 71.3 & 8.4 & $11.8 \%$ \\
2009 & 66.1 & 13.7 & $20.7 \%$ \\
2010 & 81.8 & 17.6 & $21.5 \%$ \\
2011 & 82.8 & 13.4 & $16.2 \%$ \\
2012 & 110.1 & 11.7 & $10.6 \%$ \\
2013 & 94.7 & 14.2 & $15.0 \%$ \\
2014 & 92.6 & 15.6 & $16.8 \%$ \\
2015 & 55.7 & 11.0 & $19.8 \%$ \\
2016 & 36.3 & 5.3 & $14.5 \%$ \\
2017 & 24.1 & 3.2 & $13.1 \%$ \\
2018 & 13.7 & 0.4 & $2.7 \%$ \\
\hline Total & 729.1 & 114.4 & $15.7 \%$ \\
\hline
\end{tabular}

Source: Authors, based on Informa (2007b).

Note: Results exclude formulations. See the text for details and methodology. 


\section{Ammex $B$}

\section{Therapeutic value tables}

Table 31. Highest HAS evaluation and indication for selected biopharmaceuticals

\begin{tabular}{|c|c|c|c|}
\hline & Generic name & Indication with highest evaluation & Highest Evaluation \\
\hline 1 & Abatacept & Rheumatoid polyarthritis & 2 \\
\hline 2 & Adalimumab & Rheumatoid polyarthritis & 2 \\
\hline 3 & Agalsidase alfa & Fabry's syndrome & 2 \\
\hline 4 & Agalsidase beta & Fabry's syndrome & 2 \\
\hline 5 & Alemtuzumab & Leukemia & 2 \\
\hline 6 & Alglucosidase alfa & Pompe disease & 2 \\
\hline 7 & Anakinra & Rheumatoid polyarthritis & 3 \\
\hline 8 & Basiliximab & Kidney rejection & 4 \\
\hline 9 & Bevacizumab & Colorectal cancer & 2 \\
\hline 10 & Cetuximab & Head and neck cancer & 3 \\
\hline 11 & Choriogonadotropine alfa & Infertility & 4 \\
\hline 12 & Daclizumab & Kidney transplant rejection & 5 \\
\hline 13 & Darbepoetin alfa & Anaemia & 1 \\
\hline 14 & Desirudin & Venous thrombosis & 5 \\
\hline 15 & Dibotermin alfa & Bone regeneration & 3 \\
\hline 16 & Dornase alfa & Cystic fibrosis & 3 \\
\hline 17 & Drotrecogin alfa & Severe sepsis & 6 \\
\hline 18 & Eculizumab & Anaemia & 2 \\
\hline 19 & Efalizumab & Psoriasis & 4 \\
\hline 20 & Epoetin beła & Anaemia after chemotherapy & 1 \\
\hline 21 & Epoetin delta & Anaemia & 5 \\
\hline 22 & Etanercept & Rheumatoid arthritis juvenile & 2 \\
\hline 23 & Filgrastim & Neutropenia & 3 \\
\hline 24 & Follitropin alfa & Infertility & 4 \\
\hline 25 & Fomivirsen sodium & Cytomegalovirus & 6 \\
\hline 26 & Gaisulfase & Mucopolysaccharidosis, type VI & 3 \\
\hline 27 & Idursulfase & Mucopolysaccharidosis, type II & 2 \\
\hline 28 & Imiglucerase & Gaucher's syndrome & 1 \\
\hline 29 & Infliximab & Crohn's disease & 2 \\
\hline 30 & Insulin Aspart & Diabetes & 5 \\
\hline 31 & Insulin glargine & Diabetes & 3 \\
\hline 32 & Insulin lispro & Diabetes & 5 \\
\hline
\end{tabular}


Table 31. Highest HAS evaluation and indication for selected biopharmaceuticals (continued)

\begin{tabular}{lllc}
\hline & Generic name & Indication with highest evaluation & Highest Evaluation \\
\hline 33 & Interferon beta 1a & Multiple sclerosis & 1 \\
34 & Interferon beta 1b & Multiple sclerosis & 5 \\
35 & Interferon gamma1b & Chronic granulomatous disease & 4 \\
36 & Laronidase & Mucopolysaccharidosis, type 1 & 2 \\
37 & Lutropin alfa & Stimulating ovulation & 4 \\
38 & Moroctocog alfa & Haemophilia A & 6 \\
39 & Natalizumab & Multiple sclerosis & 3 \\
40 & Nonacog alfa & Haemophilia B & 5 \\
41 & Octocog alfa & Haemophilia A & 5 \\
42 & Omalizumab & Severe asthma & 4 \\
43 & Palifermin & Severe oral mucositis & 3 \\
44 & Palivizumab & Respiratory tract syncytial virus & 3 \\
45 & Parathyroid hormone & Osteoporosis & 5 \\
46 & Pegaptanib octasodium & Macular degeneration & 3 \\
47 & Ranibizumab & Macular degeneration & 2 \\
48 & Rasburicase & Lymphoma & 5 \\
49 & Somatropin & Growth hormone & 5 \\
50 & Tasonermin & Sarcoma cancer & 6 \\
51 & Tenecteplase & Myocard infarction & 4 \\
52 & Teriparatide & Osteoporosis & 3 \\
53 & Trastuzumab & Breast cancer & 1 \\
\hline
\end{tabular}

Source: Authors, based on HAS (2008).

Note: Evaluation categories: $\quad \mathbf{1}=$ Major therapeutic progress

$4=$ Minor improvement

$2=$ Important improvement

$5=$ No improvement ("me too")

$3=$ Moderate improvement

$6=$ Judgement reserved 
Table 32. Highest Prescrire evaluation and indication for selected biopharmaceuticals

\begin{tabular}{|c|c|c|c|c|}
\hline & Generic name & & Indication with highest evaluation & Highest Evaluation \\
\hline 1 & Abciximab & & Coronary & 3 \\
\hline 2 & Adalimumab & & Rheumatoid polyarthritis & 4 \\
\hline 3 & Agalsidase alfa & & Fabry's syndrome & 2 \\
\hline 4 & Agalsidase beta & & Fabry's syndrome & 5 \\
\hline 5 & Aldesleukin & & Kidney cancer & 6 \\
\hline 6 & Alemtuzumab & & Leukemia & 4. \\
\hline 7 & Alfa-1 antitrypsin human & & Alpha-1 antitrypsin deficit & 5 \\
\hline 8 & Alglucosidase alfa & & Pompe disease & 3 \\
\hline 9 & Alteplase rDNA & & Myocardial infarction & 4 \\
\hline 10 & Anakinra & & Rheumatoid polyarthritis & 5 \\
\hline 11 & Basiliximab & & Kidney rejection & 4 \\
\hline 12 & Becaplermin (gel) & & Diabetic ulcers & 4 \\
\hline 13 & Bevacizumab & & Colorectal cancer & 6 \\
\hline 14 & Blood Factor VIII hemophilia & & Haemophiliacs factor VIII & 2 \\
\hline 15 & Cetuximab & & Head and neck cancer & 4 \\
\hline 16 & Choriogonadotropin alfa & & Infertility & 4 \\
\hline 17 & Daclizumab & & Kidney transplant rejection & 5 \\
\hline 18 & Darbepoetin alfa & & Anaemia & 5 \\
\hline 19 & Dornase, alfa recombinant & & Cystic fibrosis & 4 \\
\hline 20 & Drotrecogin alfa & & Severe sepsis & 5 \\
\hline 21 & Efalizumab & & Psoriasis & 6 \\
\hline 22 & Epoetin alfa & & Anaemia after chemotherapy & 3 \\
\hline 23 & Epoetin beta & & Anaemia after chemotherapy & 4 \\
\hline 24 & Epoetine delta & & Anaemia & 5 \\
\hline 25 & Etanercept & & Rheumatoid arthritis juvenile & 3 \\
\hline 26 & Filgrastim & & Neutropenia & 4 \\
\hline 27 & Follitropin alfa & & Infertility & 5 \\
\hline 28 & Follitropin beta & & Male sterility & 3 \\
\hline 29 & Fomivirsen sodium & & Cytomegalovirus & 7 \\
\hline 30 & Galsufase & & Mucopolysaccharidosis, type VI & 7 \\
\hline 31 & Glucagon (rDNA origin) & & Diabetes & 5 \\
\hline 32 & Human parathyroid hormone & & Osteoporosis & 5 \\
\hline 33 & Ibritumomab tiuxetan & & Lymphoma & 6 \\
\hline 34 & Idursulfase & & Mucopolysaccharidosis, type II & 6 \\
\hline 35 & Imiglucerase & & Gaucher's syndrome & 2 \\
\hline 36 & Infliximab & & Crohn's disease & 3 \\
\hline 37 & Insulin asparte & & Diabetes & 5 \\
\hline 38 & Insulin determir recombinant & - & Diabetes & 5 \\
\hline 39 & Insulin glargine & & Diabetes & 4 \\
\hline 40 & insulin glulisine recombiant & & Diabetes & 5 \\
\hline
\end{tabular}




\section{Table 32. Highest Prescrire evaluation and indication for selected biopharmaceuticals} (continued)

\begin{tabular}{|c|c|c|c|}
\hline & Generic name & Indication with highest evaluation & Highest Evaluation \\
\hline 41 & Insulin lispro recombinant & Diabetes & 4 \\
\hline 42 & Insulin recombinant human & Diabetes & 2 \\
\hline 43 & Interferon alfa 2a (peg) & Chronic hepatitis C & 4 \\
\hline 44 & Interferon alfacon 1 & Chronic hepatitis $\mathrm{C}$ & 5 \\
\hline 45 & Interferon alpha $2 b$ & Karposi's sarcoma & 2 \\
\hline 46 & Interferon beta 1alpha & Multiple sclerosis & 3 \\
\hline 47 & Interferon beta $1 \mathrm{~b}$ & Multiple sclerosis & 3 \\
\hline 48 & Interferon gamma 1b & Chronic granulomatous disease & 3 \\
\hline 49 & Laronidase & Mucopolysaccharidosis, type I & 3 \\
\hline 50 & Lepirudin (rDNA) for injection & Anticoagulant & 4 \\
\hline 51 & Lutropine alfa recombinant & Stimulating ovulation & 5 \\
\hline 52 & Methoxy Polyethylene Glycol-Epoetin Beta & Anaemia associated with chronic renal failure & 5 \\
\hline 53 & Muromonab-CD3 & Kidney transplant rejection & 3 \\
\hline 54 & Natalizumab & Multiple sclerosis & 6 \\
\hline 55 & Omalizumab & Severe asthma & 6 \\
\hline 56 & Palifermin & Severe oral mucositis & 6 \\
\hline 57 & Palivizumab & Respiratory tract syncytial virus & 4 \\
\hline 58 & Pegfilgrastim & Neutropenia after chemotherapy & 4 \\
\hline 59 & Pegvisomant & Acromegaly & 4 \\
\hline 60 & Ranibizumab & Macular Degeneration & 3 \\
\hline 61 & Rasburicase & Lymphoma & 5 \\
\hline 62 & Reteplase plasminogen activator & Myocardial infarction & 5 \\
\hline 63 & Rituximab & Lymphoma & 3 \\
\hline 64 & Somatropin rDNA & Growth hormone & 4 \\
\hline 65 & Tenecteplase & Myocardial infarction & 4 \\
\hline 66 & Teriparatide & Osteoporosis & 5 \\
\hline 67 & Thyrotropin alfa & Thyroid cancer & 4 \\
\hline 68 & Trastuzumab & Breast cancer & 3 \\
\hline
\end{tabular}

Source: Authors, based on Prescrire (various). 


\section{Annex $C$ \\ Prescrire evaluations category definitions}

Based on the results of its expert drug evaluations, Prescrire assigns each drug to one out of six categories, ranging from a "major" advance to "not acceptable" (the drug offers no benefits over existing alternatives but has potential or real disadvantages). In addition, a seventh category is used when the available data are insufficient for assessing the therapeutic value of the drug. A full definition of each evaluation category is given in Table 33.

Table 33. Prescrire definitions

\begin{tabular}{|c|c|c|c|}
\hline & English & French & Definition \\
\hline 1 & Major advance & Bravo & $\begin{array}{l}\text { The drug is a major therapeutic innovation in an area where previously no treatment } \\
\text { was available. }\end{array}$ \\
\hline 2 & $\begin{array}{l}\text { Important } \\
\text { advance }\end{array}$ & Intéressant & The product is an important therapeutic innovation but has certain limitations. \\
\hline 3 & Some advance & $\begin{array}{l}\text { Apporte quelque } \\
\text { chose }\end{array}$ & $\begin{array}{l}\text { The product has some value but does not fundamentally change the present } \\
\text { therapeutic practice. }\end{array}$ \\
\hline 4 & $\begin{array}{l}\text { Minimal } \\
\text { advance }\end{array}$ & $\begin{array}{l}\text { Eventuellement } \\
\text { utile }\end{array}$ & $\begin{array}{l}\text { The product has minimal additional value and should not change prescription } \\
\text { practices except in rare circumstances. }\end{array}$ \\
\hline 5 & $\begin{array}{l}\text { No advance } \\
\text { ("me too") }\end{array}$ & $\begin{array}{l}\text { N'apporte rien } \\
\text { de nouveau }\end{array}$ & $\begin{array}{l}\text { The product may be a new molecule but is superfluous because it does not add to } \\
\text { the clinical possibilities offered by previously available products. In most cases it } \\
\text { concerns a me-too product. }\end{array}$ \\
\hline 6 & Not acceptable & Pas d'accord & Product without evident benefit but with potential or real disadvantages. \\
\hline 7 & $\begin{array}{l}\text { Judgment } \\
\text { reserved }\end{array}$ & $\begin{array}{l}\text { Ne peut se } \\
\text { prononcer }\end{array}$ & $\begin{array}{l}\text { The editors postpone their judgment until better data and a more thorough evaluation } \\
\text { of the drug are available. }\end{array}$ \\
\hline
\end{tabular}

Source: English definitions are from Prescrire International. 


\section{Annex D \\ Pharmaprojects biotechnology classifications}

T2A1 RECOMBINANT INTERFERON - Interferons which have been produced using recombinant DNA technology (genetic engineering).

T2A2 RECOMBINANT INTERLEUKIN - Interleukins which have been produced using recombinant DNA technology (genetic engineering).

T2A3 RECOMBINANT GROWTH FACTOR - Growth factors which have been produced using recombinant DNA technology (genetic engineering) including colony stimulating factors, transforming growth factor, epidermal growth factor, fibroblast growth factor, platelet-derived growth factor, nerve growth factor and ciliary neurotrophic factor.

T2B RECOMBINANT VACCINE - Vaccines, including cancer vaccines and contraceptive vaccines, which have been produced using recombinant DNA technology (genetic engineering). This includes prophylactic nucleic acid vaccines ("naked DNA" vaccines).

T2C RECOMBINANT HORMONE - Animal hormones which have been produced using recombinant DNA technology (genetic engineering) including calcitonin and somatomedin.

T2D LYTIC VIRUS - Replication-competent viruses, which lyse pathogenic cells directly, particularly oncolytic viruses which specifically attack cancer cells. These are normally GM to render them harmless to normal tissues.

T2Z RECOMBINANT, OTHER - Proteins and their derivatives which have been produced using recombinant DNA technology (genetic engineering), except interferons, interleukins, growth factors, vaccines and hormones, which have there own sections as shown above. Recombinant molecules in development include clotting factors, cell adhesion molecules, cytokine antagonists, enzyme replacement therapies and chimaeric molecules.

T3A1 MONOCLONAL ANTIBODY, MURINE - Monoclonal antibodies which are not conjugated to another agent and which are derived from immunization of mice and rats.

T3A2 MONOCLONAL ANTIBODY, HUMAN - Monoclonal antibodies which are not conjugated to another agent and which are completely derived from humans, or have fullyhuman sequences.

T3A4 MONOCLONAL ANTIBODY, CHIMAERIC - Monoclonal antibodies which are not conjugated to another agent and which are engineered to contain portions derived from both human and animal sources, but are less than $70 \%$ human. This section does not include humanized antibodies (see T3A5).

T3A5 MONOCLONAL ANTIBODY, HUMANIZED - Monoclonal antibodies which are not conjugated to another agent and which are engineered to contain $90-95 \%$ human sequences, with the remainder usually consisting of rodent sequences. Fully-human monoclonal antibodies are classified separately in T3A2. 
T3A9 MONOCLONAL ANTIBODY, OTHER - Monoclonal antibodies which are not conjugated to another agent and which are derived from an unknown source, or cannot be classified in other T3A categories.

T3B1 IMMUNOTOXIN - Immunotoxins are conjugates or fusion proteins of immunoglobulins (usually monoclonal antibodies) and toxins. The immunoglobulin will deliver the toxin to cells exhibiting the appropriate antigen, without the toxin coming into contact with normal cells.

T3B9 IMMUNOCONJUGATE, OTHER - Conjugates of immunoglobulins with other agents, excluding toxins, which are listed in Immunotoxin (T3B1). With all of these agents the antibody part of the molecule is used to direct it to its target, where the effector part of the molecule will perform its action.

T4A GENE THERAPY - Gene therapy is a term used to describe vector-mediated introduction of a therapeutic genetic sequence into target cells in vivo or ex vivo. Vectors may be viral or non-viral (e.g. plasmids). Strategies include replacement of defective or missing genes (e.g. for cystic fibrosis), or introduction of more broadly-acting (e.g. immunostimulant) sequences for the treatment of multifactorial diseases (e.g. cancer). Gene therapy vectors may also be used to deliver antisense and RNA interference sequences (see T4B and T4F). Lytic viruses which do not deliver therapeutic DNA are covered in T2D and nonrecombinant mammalian cells are covered in T5A (stem cells) and T5Z (other types). Direct administration of oligonucleotides without using vectors is covered separately in T4B (for antisense), T4F (for RNA interference) or T4E (for other oligonucleotide types). Platform technologies for gene delivery are covered separately in T4D.

T4B ANTISENSE THERAPY - Includes all entries for antisense compounds under development as potential therapeutics. Antisense compounds may be synthetic oligonucleotides, or antisense RNA may be expressed from a vector as a form of gene therapy (see T4A). They may prevent the expression of a specific protein in vivo by binding to and inhibiting the action of mRNA, since they have a specific oligonucleotide sequence which is complementary to the DNA or RNA sequence which codes for the protein.

T4D GENE DELIVERY VECTOR - Platform technologies for the delivery of therapeutic genes or nucleic acid vaccines. Viral and non-viral vectors (e.g. liposome systems) are included. Actual therapies and vaccines using these technologies are covered separately in T4A (for gene therapy) and T2B (for nucleic acid vaccines).

T4E OLIGONUCLEOTIDE, NON-ANTISENSE, NON-RNAI - Synthetic therapeutic oligonucleotides which operate by a mechanism other than antisense or RNA interference (RNAi). This includes ribozymes, aptamers, decoys, CpGs and mismatched and immunostimulant oligonucleotides. Sequences delivered using vectors (gene therapy) are covered separately in T4A. Antisense and RNAi oligonucleotides are covered separately in T4B and T4F, respectively.

T4F RNA INTERFERENCE - Includes all entries for products which act therapeutically via an RNA interference (RNAi) mechanism, including small interfering RNAs (siRNAs). These may be synthetic oligonucleotides, or RNAi sequences may be expressed from a vector as a form of gene therapy (see T4A). In vivo, these sequences block the expression of a specific protein by forming an RNA-induced silencing complex, which then specifically binds to and degrades a complementary mRNA encoding the target protein. The use of RNAi purely as a drug discovery tool (e.g. in transgenic animal model production or in target validation) is not covered in this section. 
T5A STEM CELL THERAPY - Non-recombinant cultured mammalian stem cells used as therapeutics. Recombinant stem cells are classified separately as ex vivo gene therapy (in T4A).

T5Z CELLULAR THERAPY, OTHER - Non-recombinant cultured mammalian therapeutic cells other than stem cells. Includes products such as dendritic cells, pancreatic islet implants, cultured wound healing products and cultured T-lymphocytes. 
